\title{
IDENTIFICATION DE LA MUTATION RESPONSABLE DE LA MUCOLIPIDOSE DE TYPE II DANS LA RÉGION DU SAGUENAY-LAC-ST-JEAN
}

\author{
Mémoire présenté \\ à la Faculté des études supérieures de l'Université Laval \\ comme exigence partielle du programme de maîtrise en médecine \\ expérimentale - génétique des populations humaines \\ offert à l'Université du Québec à Chicoutimi \\ en vertu d'un protocole d'entente avec l'Université Laval \\ pour l'obtention du grade de maître ès sciences (M.Sc.)
}

FACULTÉ DE MÉDECINE UNIVERSITÉ LAVAL QUÉBEC

et

DÉPARTEMENT DES SCIENCES HUMAINES UNIVERSITÉ DU QUÉBEC À CHICOUTIMI

SAGUENAY 


\section{Bibliothèque}

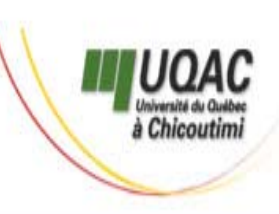

\section{Mise en garde/Advice}

Afin de rendre accessible au plus Motivated by a desire to make the grand nombre le résultat des results of its graduate students' travaux de recherche menés par ses research accessible to all, and in étudiants gradués et dans l'esprit des accordance with the rules règles qui régissent le dépôt et la governing the acceptation and diffusion des mémoires et thèses diffusion of dissertations and produits dans cette Institution, theses in this Institution, the l'Université du Québec à Université du Québec à Chicoutimi (UQAC) est fière de Chicoutimi (UQAC) is proud to rendre accessible une version make a complete version of this complète et gratuite de cette œuvre. work available at no cost to the reader.

L'auteur conserve néanmoins la The author retains ownership of the propriété du droit d'auteur qui copyright of this dissertation or protège ce mémoire ou cette thèse. thesis. Neither the dissertation or Ni le mémoire ou la thèse ni des thesis, nor substantial extracts from extraits substantiels de ceux-ci ne it, may be printed or otherwise peuvent être imprimés ou autrement reproduced without the author's reproduits sans son autorisation. permission. 


\section{RÉSUMÉ}

Afin d'identifier la mutation responsable de la mucolipidose de type II dans la région du Saguenay-Lac-St-Jean (Québec, Canada), un groupe de 27 porteurs obligatoires a été recruté. L'ADN de ces individus a été comparé à celui de 50 sujets provenant d'une autre population. Le gène de la $\mathrm{N}$-acétylglucosamine-1-phosphotransférase (GNPTAB) a été ciblé comme candidat suite à la revue de la littérature. Ensuite, pour vérifier la provenance de la mutation et savoir si l'effet fondateur pouvait expliquer son incidence auprès de cette même population, l'étude généalogique de tous les sujets a été effectuée. Ainsi, les ascendances des individus porteurs obligatoires et d'une cohorte témoin ont été reconstituées.

En conclusion, ce projet a permis d'identifier la mutation responsable de la MLII au SLSJ et les études généalogiques suggèrent que sa prévalence au SLSJ résulte d'un effet fondateur. Trois noyaux ancestraux originaires de la France sont plus susceptibles d'être à l'origine de cette mutation. 


\section{AVANT-PROPOS}

Je tiens à profiter de cette section du mémoire pour remercier profondément toutes les

personnes qui m'ont appuyée au cours de mes études. À commencer tout d'abord par ma directrice de maitrise, Catherine Laprise, qui m'a proposé un intéressant projet. Quoi demander de plus qu'un projet qui englobe toutes les étapes de la recherche scientifique, en plus d'avoir un impact direct et concret pour la population régionale?

Je désire exprimer ma gratitude envers les gens qui m'ont aidé. Je pense notamment à l'équipe du laboratoire du Centre de médecine génique communautaire (CMGC) situé au Centre de santé et de services sociaux de Chicoutimi (CSSSC), à commencer par Sébastien Claveau, avec qui j'ai débuté la recherche du gène d'intérêt. Merci à Denise et Nadia, vos conseils et vos dons de magicienne sont venus à bout de la mise au point cauchemardesque de certains PCR. Ce temps passé au laboratoire fût de courte durée, mais mémorable. Outre la génétique moléculaire, il y avait aussi la génétique des populations. Cette dernière qui est fondée sur l'analyse généalogique, a été possible grâce à Hélène Vézina et Ėve-Marie Lavoie, du Projet BALSAC, que je remercie sincèrement.

Sur une touche personnelle, je remercie ma famille, ma belle-famille, mes amies pour leur encouragement et plus particulièrement Bhaskor, mon compagnon de vie et complice de mes projets. Ton support moral (et informatique!) était indispensable. Merci.

Enfin, mes salutations distinguées aux parents qui ont participé à l'étude, sans qui je n'aurais pu mener cette recherche. Je sais que certains ne pensaient pas avoir de nouvelles, qu'il s'agissait d'un coup d'épée dans l'eau. Cela n'a pas été le cas. Grâce à vous, d'autres couples n'auront pas à traverser l'épreuve que vous avez vécue. Il s'agissait d'une lueur d'espoir pour atteindre la connaissance... 


\section{TABLE DES MATIÈRES}

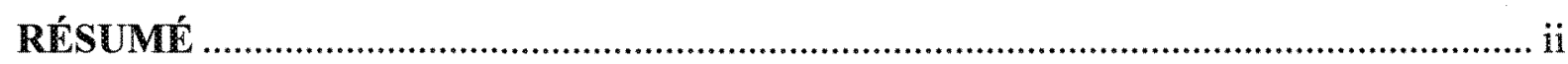

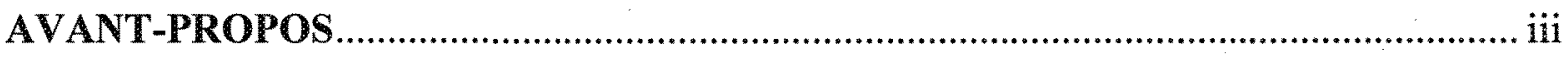

TABLE DES MATIÈRES..................................................................................... iv

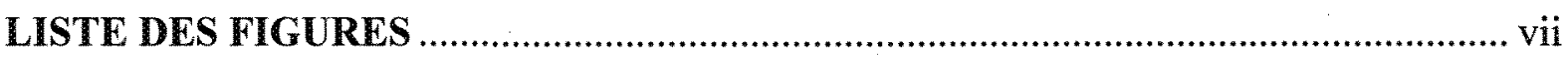

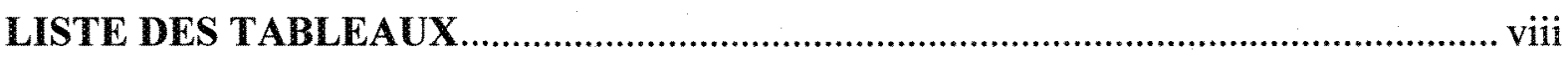

LISTE DES ABRÉVIATIONS .............................................................................. ix

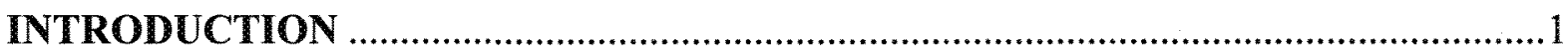

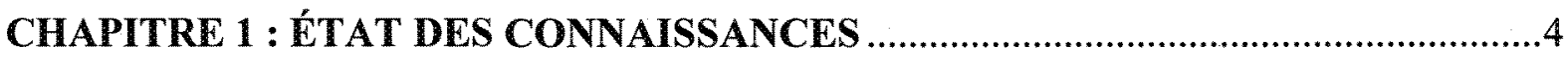

1.1 Épidémiologie et distribution de la mucolipidose de type II ..............................4

1.2 Phénotype de la mucolipidose de type II ..........................................................

1.2.1 La morphologie particulière ..................................................................6

1.2.2 Les études enzymologiques et cytologiques .............................................7

1.2.3 L'atteinte cardiaque ...............................................................................9

1.2.4 L'atteinte neurologique........................................................................9

1.2.5 L'atteinte respiratoire ...................................................................... 10

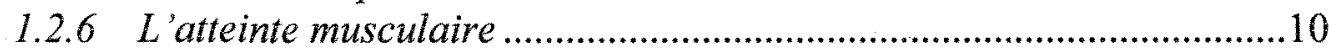

1.2.7 L'atteinte du système squelettique ..................................................10

1.2.8 Le pronostic .......................................................................................11

1.3 Les lysosomes - Activité normale ……………............................................12

1.3.1 La physiologie des lysosomes .........................................................12

1.3.2 La synthèse des hydrolases acides .....................................................13

1.3.3 L'adressage des hydrolases acides .....................................................13

1.4 Pathophysiologie des lysosomes en relation avec la MLII................................16

1.5 Diagnostic de la MLII ...................................................................................

1.5.1 Le diagnostic prénatal par les analyses enzymatiques .........................18

1.5.2 Le diagnostic prénatal par l'analyse microscopique ............................19

1.5.3 Le diagnostic des nouveaux-nés ........................................................20

1.5.4 Le dépistage des hétérozygotes ............................................................20 


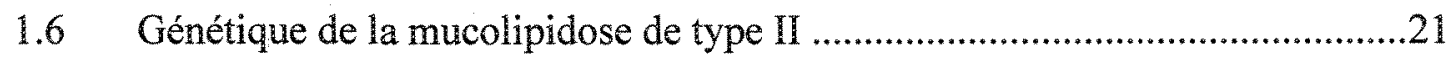

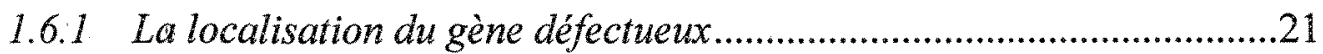

1.6.2 La structure et le produit du gène GNPTAB .......................................22

1.6.3 Les études fonctionnelles .....................................................................26

1.6.4 Le lien entre la MLII et les autres mucolipidoses..................................26

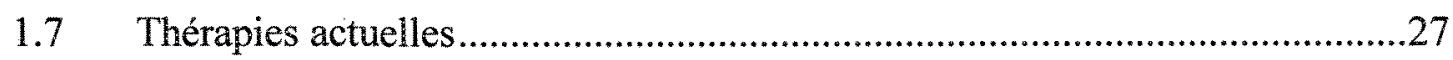

1.8 La structure de la population du SLSJ ........................................................28

CHAPITRE 2 : LA MUCOLIPIDOSE DE TYPE 2 : UNE SEULE MUTATION

DANS LE GÈNE DE LA N-ACÉTYLGLUCOSAMINE-1PHOSPHOTRANSFÉRASE (GNPTAB) EST IDENTIFIÉE AU SEIN D'UNE POPUlation CANAdIENNE FRANÇAISE À EFFET

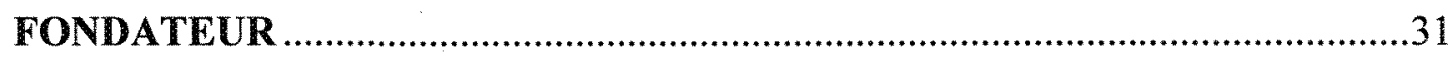

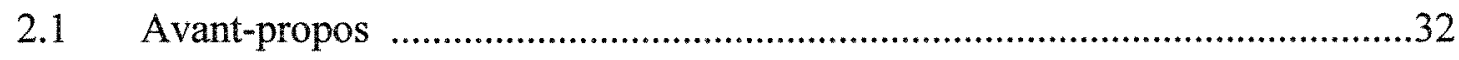

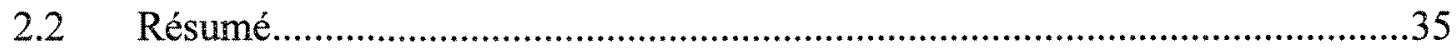

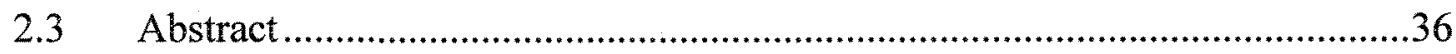

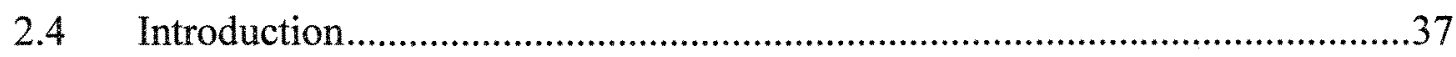

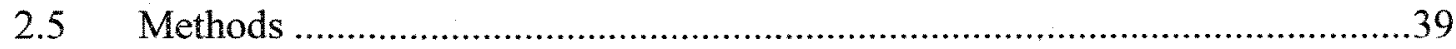

2.5.1 Mucolipidosis type II carriers ........................................................39

2.5.2 Isolation of genomic DNA and sequencing ..........................................39

2.5.3 Genealogical reconstruction ...............................................................40

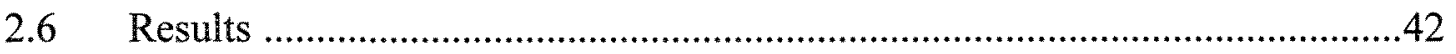

2.6.1 Mutation identification .................................................................42

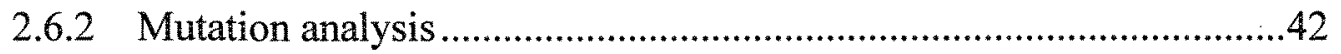

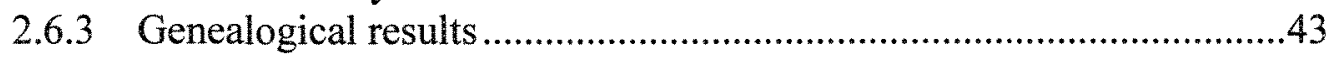

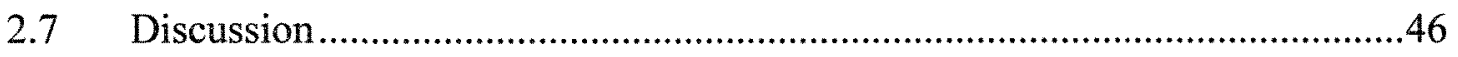

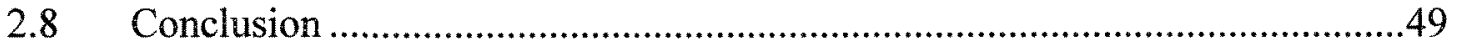

$2.9 \quad$ Acknowlegments ......................................................................................50

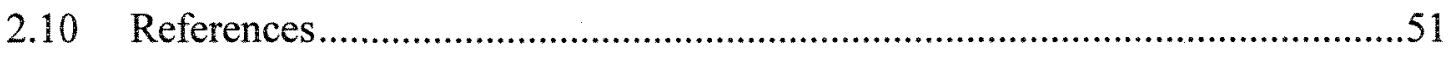

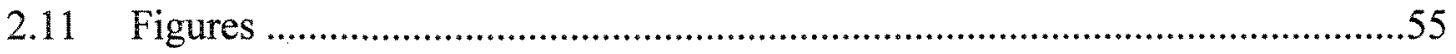

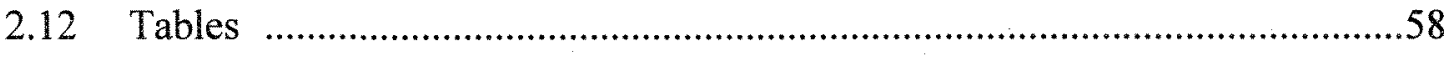

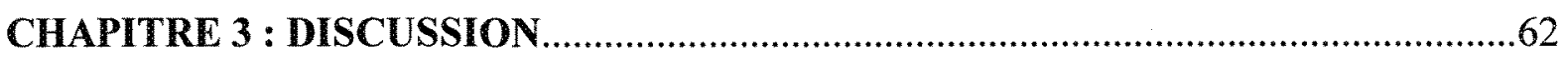

3.1 Analyse moléculaire …………………………......................................62

3.1.1 La mutation responsable de la MLII au SLSJ......................................62

3.1.2 Les études fonctionnelles......................................................................63 
3.2 Analyse généalogique ................................................................................64

3.2.1 Analyse généalogique descriptive ....................................................65

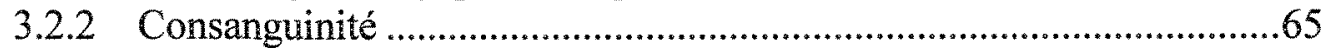

3.2.3 L'origine des individus ayant introduit la MLII ....................................67

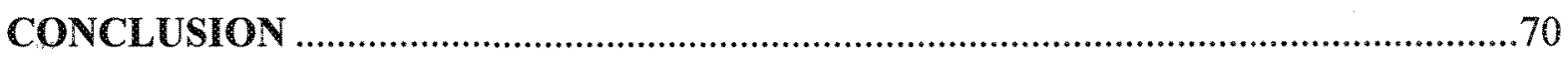

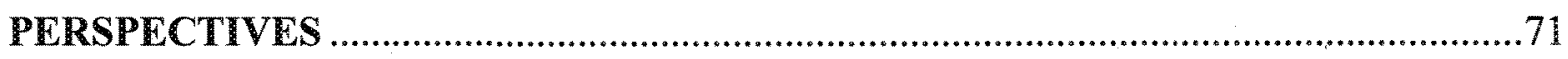

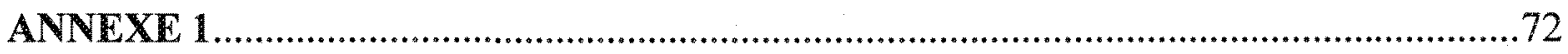

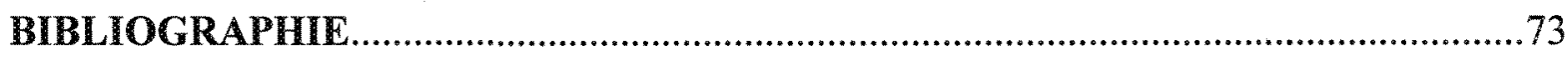




\section{LISTE DES FIGURES}

Figure 1: $\quad$ Mucolipidose de type II chez un sujet à l'âge de 7 ans et 12 ans ............6

Figure 2: Hypertrophie des gencives typique du nouveau-né atteint de la MLII....7

Figure 3: Fibroblaste de culture d'un sujet atteint de la mucolipidose de type II ....8

Figure 4: Radiographie du thorax d'un enfant de quatre mois ayant la mucolipidose de type II....................................................................11

Figure 5: Localisation intracellulaire des lysosomes et activité de phagocytose ...12

Figure 6: Phosphorylation des enzymes lysosomales .......................................14

Figure 7 : Trajet intracellulaire des enzymes lysosomales....................................15

Figure 8: Cellule d'un individu ayant la mucolipidose de type II.........................16

Figure 9: Localisation chromosomique du gène de la sous-unité $\alpha$ et $\beta$ de la $\mathrm{N}$-acétylglucosamine-1-phosphotransférase (GNPTAB) ....................22

Figure 10: Schéma de la structure de la $\mathrm{N}$-acétylglucosamine-1phosphotransférase.

Figure 11: Location of mutations identified in GNPTAB gene by sequencing of proband relatives $D N A$...................................................................55

Figure 12: Part of electrophoregram of GNPTAB exon 19..................................55

Figure 13 : Mean inbreeding coefficients for subjects with mucolipidosis type II

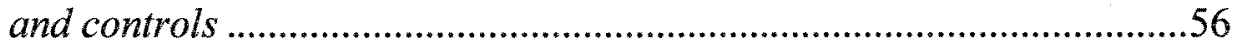

Figure 14 : Localization of Saguenay-Lac-Saint-Jean .........................................56

Figure 15: Genetic contribution of potential introducers of the mucolipidosis type II mutation to regional populations of Quebec. 


\section{LISTE DES TABLEAUX}

Tableau 1 : Distribution et incidence de la MLII dans le monde ..............................5

Tableau 2: Mutations répertoriées associées à la MLII .......................................25

Tableau 3 : Différenciation des mucolipidoses sur le plan génique et protéinique

Tableau 4 : Oligonucleotide primers sequences and annealing temperature used for PCR of the 21 exons of the GNPTA gene .........................................58

Tableau 5: SLSJ mutations identified in GNPTAB gene ..........................................59

Tableau 6: Descriptive parameters of the genealogies..........................................60

Tableau 7: Description of the three couples of ancestors with the highest probability of having introduced the mucolipidosis mutation in the French Canadian population..............................................................60

Tableau 8 : Location of documented GNPTAB mutations causing MLII .................61 


\section{LISTE DES ABREVIATIONS}

ADNc: $\quad$ Acide désoxyribonucléque complémentaire

CEPH : $\quad$ Centre d'étude du polymorphisme humain

CORAMH : Corporation de recherche et d'action sur les maladies héréditaires

GlcNAc: $\quad \mathrm{N}$-acétylglucosamine

GlcNAcPT : UDP-N-acétylglucosamine-1-phosphotransférase

GNPTAB : Gène codant les sous-unités $\alpha$ et $\beta$ de la GlcNAcPT

GNPTG : Gène codant la sous-unité $\gamma$ de la GlcNAcPT

OMIM : Online mendelian inheritance in man

PCR : Réaction de polymérisation en chaîne (polymerase chain-reaction)

M6P : $\quad$ Mannose-6-phosphate

MLII : $\quad$ Mucolipidose de type II

MLIII : $\quad$ Mucolipidose de type III

RER : Réticulum endoplasmique rugueux

RM6P: Récepteur du mannose-6-phosphate

SLSJ : $\quad$ Saguenay-Lac-Saint-Jean 


\section{INTRODUCTION}

Les maladies lysosomales forment un groupe de 41 maladies génétiques distinctes où chacune est le résultat d'une déficience en une protéine lysosomale ou parfois nonlysosomale, impliquée dans la biogénèse des lysosomes (Meikle et al, 1999). La mucolipidose de type II (MLII) est une maladie métabolique de surcharge lysosomale où une enzyme, la $\mathrm{N}$-acétylglucosamine-1-phosphotransferase, est défectueuse (Kornfeld et Sly, 2001). Cela entraîne un trouble quant au triage des enzymes lysosomales qui cause l'accumulation de métabolites non digérés au niveau cellulaire. Le décès de l'enfant atteint de la maladie est inéluctable (Kornfeld et Sly, 2001).

La transmission de la MLII suit un mode autosomal récessif. Cela signifie que l'enfant a hérité de deux allèles mutants associés à la MLII, l'un reçu de la mère, l'autre du père. Normalement, la probabilité de recevoir deux allèles causant une maladie récessive est négligeable, mais dans certaines populations, ce risque est accru. Ainsi, plusieurs

populations connaissent une incidence élevée pour certaines maladies génétiques, alors qu'elles sont rares ailleurs dans le monde. La consanguinité proche, par la dérive génétique et l'effet fondateur ou encore par une combinaison de ces facteurs représentent des causes possibles à ce phénomène (Hartl et Clark, 1997).

Cette dérive génétique conjuguée à l'effet fondateur explique la distribution particulière de certaines maladies autosomales récessives. Certains allèles se retrouvent concentrés en des régions particulières et ainsi, les parents d'enfants atteints de ces maladies n'ont pas nécessairement d'histoire familiale documentée. Il faut remonter dans le temps de la colonisation pour comprendre comment ces parents ont pu être tous les deux porteurs d'une seule et même mutation. Au Saguenay-Lac-Saint-Jean (SLSJ), par exemple, la littérature rapporte un triple effet fondateur qui expliquerait la structure génétique de la population actuelle. 
Jusqu'à présent, plusieurs études ont été faites dans le but de caractériser le bassin de population du SLSJ et d'identifier les mutations génétiques causant des maladies à haute prévalence. Cette structure génétique particulière a mené à la construction d'un fichierréseau de la population saguenéenne. Ce fichier se nomme BALSAC, acronyme composé des premières lettres des régions et des sous-régions de l'est du Québec touchées initialement par le projet du même nom (Bas-Saint-Laurent, Lac-Saint-Jean, Saguenay, Charlevoix, Chibougamau-Chapais, Côte-Nord), et permet l'étude des généalogies de familles originaires du SLSJ. C'est également la structure généalogique et génétique de la population du SLSJ qui a conduit à la création de la Corporation de recherche et d'action sur les maladies héréditaires (CORAMH). Cet organisme régional à caractère humanitaire sans but lucratif a pour mission la sensibilisation, l'information et la prévention auprès de la population à propos des maladies héréditaires au SLSJ.

L'objectif du présent travail est d'identifier la ou les mutations causales de la MLII et d'en déterminer l'origine probable et ce, afin de vérifier si la mutation a été introduite par un nombre restreint de fondateurs. Cette étude a été possible grâce à la présence de plusieurs familles touchées par la MLII au SLSJ (16 familles documentées au service de conseil génétique du Centre de santé et de services sociaux de Chicoutimi (CSSSC)) et en raison des ressources disponibles en génétique humaine au SLSJ (laboratoire du Centre de médecine génique communautaire de l'Université de Montréal au CSSSC, service de conseil génétique du CSSSC, fichier de population BALSAC). Puisque l'état de la recherche actuelle ne fait mention d'aucun test de dépistage moléculaire, seule l'étude enzymatique est actuellement utilisée quant à la planification des naissances chez un couple ayant déjà eu un enfant atteint de la MLII. L'objectif ultime de ce projet est l'identification de la mutation qui cause la MLII dans le but de développer un test de détection des porteurs qui permettra le dépistage en cascade dans les familles ayant une histoire de MLII.

Ce mémoire trace tous les travaux qui ont été réalisés afin de faire avancer les connaissances sur la MLII et rapporte la démarche méthodologique de même que les résultats relatifs à l'identification de la mutation responsable de la MLII dans l'échantillon étudié. Précisément, le premier chapitre est composé d'une revue de la littérature portant 
essentiellement sur l'épidémiologie, la description de la physiopathologie, les moyens de diagnostic utilisés ainsi que les connaissances génétiques actuelles relatives à la MLII.

Le deuxième chapitre est composé de l'article qui a été soumis en mars 2007 à la revue Clinical Genetics. Il relate brièvement le contexte qui explique la structure génétique de la population du SLSJ et les résultats concernant la recherche de la mutation responsable de la MLII dans l'échantillon étudié ainsi que l'étude généalogique recherchant l'identification d'un possible effet fondateur. Le chapitre se termine par une discussion qui compare les mutations documentées aux mutations identifiées dans ce projet de recherche et tente de faire un lien entre cette mutation et certains individus fondateurs de la population du SLSJ par l'étude généalogique et de la démogénétique.

Le troisième chapitre est une discussion plus approndie des éléments déjà abordés au chapitre précédent. Il discute des résultats obtenus sur le plan moléculaire et généalogique.

Ce mémoire se termine par une brève conclusion rappelant les principaux résultats, les applications possibles et les perspectives. 


\section{CHAPITRE 1}

\section{ÉTAT DES CONNAISSANCES}

C'est en 1967 que Leroy et De Mars ont décrit une maladie semblable aux mucopolysaccharidoses et confondue avec la lipomucopolysaccharidose de Spranger et Wiedemann, aussi appellée mucolipidose de type I (Maroteaux et al, 1970). Cette maladie fut nommée "I-cell disease 》 (inclusion-cell disease), en raison des nombreuses inclusions cytoplasmiques observées par microscopie en contraste de phase dans les fibroblastes de biopsie de peau (Leroy et DeMars, 1967). En 1970, le terme " mucolipidose de type II » (MLII, OMIM \#252500) apparaît dans la littérature, car la maladie avait à la fois les caractéristiques des mucopolysaccharidoses et des sphingolipidoses (Spranger et Wiedemann, 1970). Il s'agit d'une maladie ressemblant au syndrome de Hurler, mais dont les symptômes sont plus sévères. La MLII se distingue de ces classes de maladie par l'absence des mucopolysaccharides urinaires, ainsi que par les aspects enzymologique, cytologique, hématologique et radiologique (Kornfeld et Sly, 2001), qui seront abordés au cours du présent chapitre.

\section{1 Épidémiologie et distribution de la mucolipidose de type II}

Malgré la diversité de la provenance des différents cas de MLII rapportés dans la littérature, rares sont les pays où l'incidence a été documentée. Le tableau 1 dresse un résumé des cas répertoriés dans la littérature. Selon la région, on observe que certains chercheurs ont étudié et travaillé sur les statistiques de plusieurs maladies lysosomales, dont la MLII (Australie, Pays-Bas, Portugal), d'autres ont étudié l'incidence de la MLII précisément (Japon, SLSJ), tandis que dans les autres pays on ne présente que des histoires de cas, sans mention quant à la distribution de ceux-ci (Inde, Thaillande, Chili, Cuba, République tchèque, Grèce, 
Russie). En République tchèque, ce n'est qu'en 1997 qu'on y rapporte un premier cas de MLII (Elleder et Martin, 1997). Au Québec, les cas de MLII sont localisés majoritairement dans la région du SLSJ, une particularité qui n'est pas documenté pour les différents pays rapportés au tableau 1.

Tableau 1. Distribution et incidence de la MLII dans le monde

\begin{tabular}{|l|c|c|c|l|}
\hline \multirow{2}{*}{ Régions } & $\begin{array}{c}\text { Nombre } \\
\text { de cas de } \\
\text { MLII } \\
\text { rapportés }\end{array}$ & $\begin{array}{c}\text { Porteur } \\
\text { hétérozygote }\end{array}$ & $\begin{array}{c}\text { Homozygote } \\
\text { muté }\end{array}$ & \multicolumn{1}{|}{ Source } \\
\hline SLSJ & $\mathbf{1 1}$ & $\mathbf{1 / 4 5}$ & $\mathbf{1 / 8 1 5 9}$ & Prévost, 2006 \\
\hline Portugal & 7 & - & $1 / 123,457$ & Pinto et al, 2004 \\
\hline Japon & 21 & - & $1 / 252,525$ & Okada et al, 1985 \\
\hline Australie & $13^{*}$ & $1 / 285^{*}$ & $1 / 325,000^{*}$ & Meikle et al, 1999 \\
\hline Pays-Bas & 6 & - & $1 / 625,000$ & Poorthuis et al, 1999 \\
\hline Inde & 1 & - & - & Kabra et al, 2000 \\
\hline Thaïlande & + & - & - & Wasant et al, 1999 \\
\hline Chili & 1 & - & - & Aracena et al, 2003 \\
\hline Cuba & 1 & - & - & Menéndez et al, 1998 \\
\hline Rép. Tchèque & 1 & - & - & Elleder et al, 1997 \\
\hline Grèce & 1 & - & - & Michelakalis et al, 1995 \\
\hline Russie & $13^{*}$ & - & - & Krasnopolskaya et al, 1993 \\
\hline
\end{tabular}

*inclus les cas de MLIII

$\uparrow$ Nombre de cas de MLII non chiffré

Au SLSJ, durant la période de 1980 à 2004, 11 cas de MLII ont été rapportés sur les 89744 naissances (Prévost, 2006). Ainsi, durant cette période, l'incidence était de un cas par 8159 naissances. En utilisant la formule de l'équilibre d'Hardy-Weinberg $\left(\mathrm{p}^{2}+\mathrm{q}^{2}+2 \mathrm{pq}=1\right.$, où $\mathrm{p}$ et q représentent la fréquence de deux allèles), cela est associé à un taux de porteur estimé à une personne sur 45 (Prévost, 2006). Ce chiffre (1/45) reflète une estimation qui serait plus près de la réalité que le taux de 1/39 rapporté ultérieurement, qui était calculé sur une plus courte période, soit celle de 1975 à 1986 (De Braekeleer, 1991a), selon le conseil génétique du CSSSC (Prévost, 2006).

Grâce à cette brève revue, il est aisé de constater que la région du SLSJ semble former un bassin de population où l'on retrouverait la plus forte incidence de MLII, tous pays confondus. 


\subsection{Phénotype de la mucolipidose de type II}

\subsubsection{La morphologie particulière}

Les individus atteints de la MLII présentent une morphologie particulière, permettant de suspecter la maladie lors d'un examen clinique. On peut noter au niveau de la tête que le visage est grossier, d'aspect vieillot, avec une hypertrophie des gencives, des narines antéversées, des paupières épaisses ainsi qu'un épicanthus (figures 1 et 2) (Leroy et al, 1971; Okada et al, 1985; Kabra et al, 2000; Walbaum et al, 2000; Lee et O’Donnell, 2003; Unger et al, 2005). Ils présentent une dislocation congénitale de la hanche, une hypotonie généralisée ainsi qu'une peau épaisse (Leroy et al, 1971). Des délais au niveau du développement psychomoteur et statural (nanisme) sont également notés. Parfois, l'individu peut présenter une hernie inguinale ou encore une hépatomégalie (Güngor et al, 1994; Kabra et al, 2000).

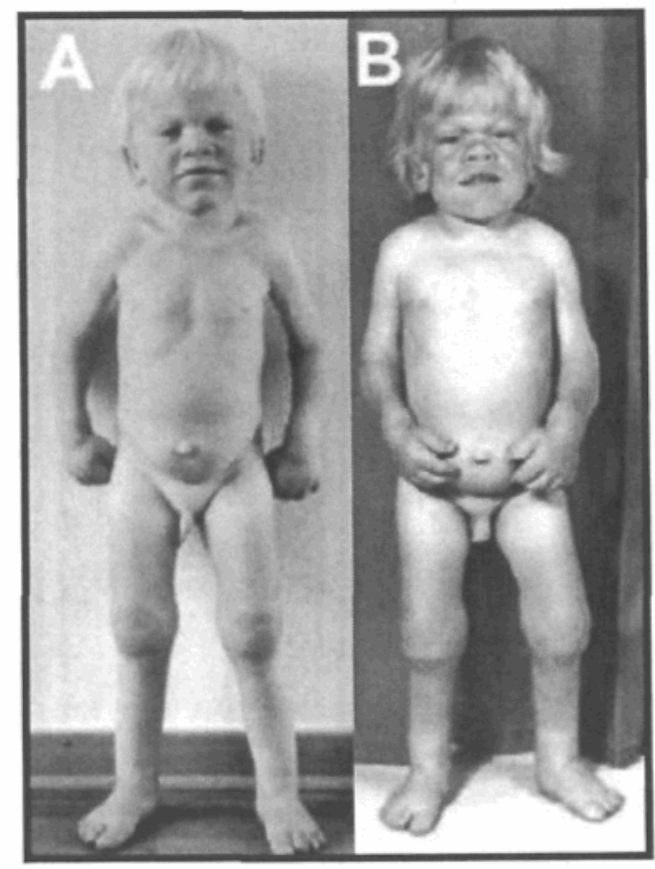

Figure 1. Mucolipidose de type II chez un sujet à l'âge de 7 ans (A) et 12 ans (B) (tirée de Tiede et al, 2006)

L'enfant atteint de la MLII présente un visage vieillot, des narines antéversées, un nanisme, en plus d'avoir les épaules, genous et doigts en flexion, causé par la contracture articulaire. 


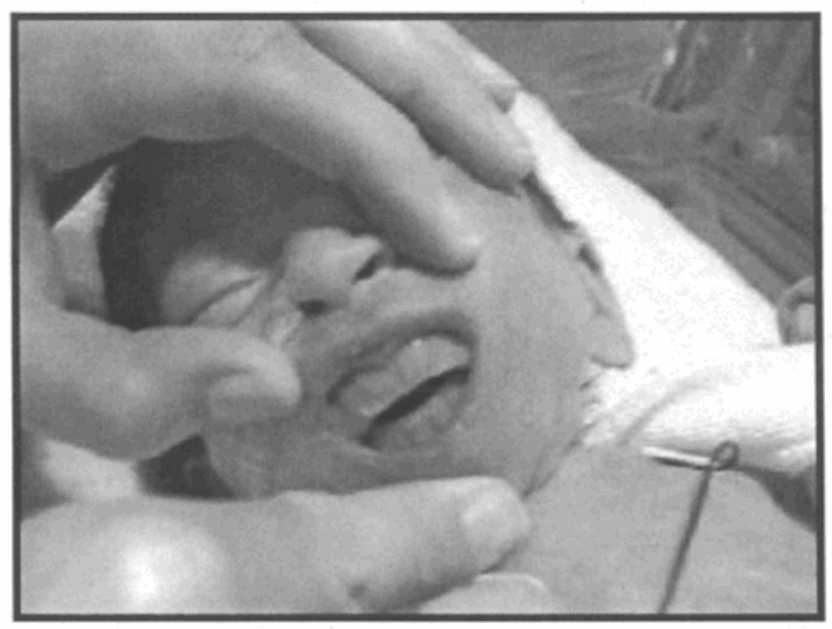

Figure 2. Hypertrophie des gencives typique du nouveau-né atteint de la MLII (tirée de Unger et al, 2005)

\subsubsection{Les études enzymologiques et cytologiques}

Chez les individus atteints de MLII, les niveaux sériques d'enzymes lysosomales (iduronate sulfatase, arylsulfatase A, $\beta$-glucuronidase, $\alpha$-mannosidase, hexoaminidase A, $\beta$ galactosidase, glycosylasparaginase) sont 5 à 50 fois plus élevés que la normale, ainsi que dans d'autres fluides corporels tels que les larmes, le liquide amniotique (Hall et al, 1978; Güngor et al, 1994; Ylikangas et Mononen, 1998), le liquide céphalorachidien et l'urine (Leroy et Van Elsen, 1973). Dans les fibroblastes, le niveau d'activité de l'arylsulfatase, l'iduronidase, l'hexoaminidase $\mathrm{A}$ et la $\beta$-galactosidase est très bas (Ylikangas et Mononen, 1998; Hall et al, 1978). Cependant, la concentration des enzymes lysosomales est normale dans la plupart des tissus et dans les leucocytes (Hall et al, 1978). La mucopolysaccharie urinaire normale permet d'exclure le syndrome de Hurler (Leroy et al, 1971).

Les tissus principalement touchés par la MLII sont ceux d'origine mésenchymateuse (d'Azzo, 1982 dans Glew et al, 1985; Elleder et Martin, 1998; Kornfeld et Sly, 2001; Vellodi, 2004). Ainsi, les fibroblastes de la peau, les cellules endothéliales et les cellules de Schwann des fibres nerveuses non-myélinisées montrent des altérations morphologiques significatives. Cela n'est pas le cas de certains types cellulaires, tels que les cellules épithéliales, les neurones (Elleder et Martin, 1998), les leucocytes, les cellules de Kupffer (foie), les cellules de la rate, les cellules du rein et celles du cerveau, qui contiennent des 
niveaux normaux d'enzymes lysosomales, malgré qu'elles aient un déficit en $\mathrm{N}$ acétylglucosamine-1-phosphotransférase (GlcNAcPT) (d'Azzo, 1982 dans Glew et al, 1985; Waheed et al, 1982; Kornfeld et Sly, 2001). Ces niveaux normaux d'enzymes lysosomales dans certains types cellulaires de sujets atteints de la MLII s'expliquent par la présence d'une voie de transport des enzymes qui n'utilise pas le mannose-6-phosphate (M6P) (Sly, 2000; Ylikangas et Mononen, 1998; Kornfeld et Sly, 2001).

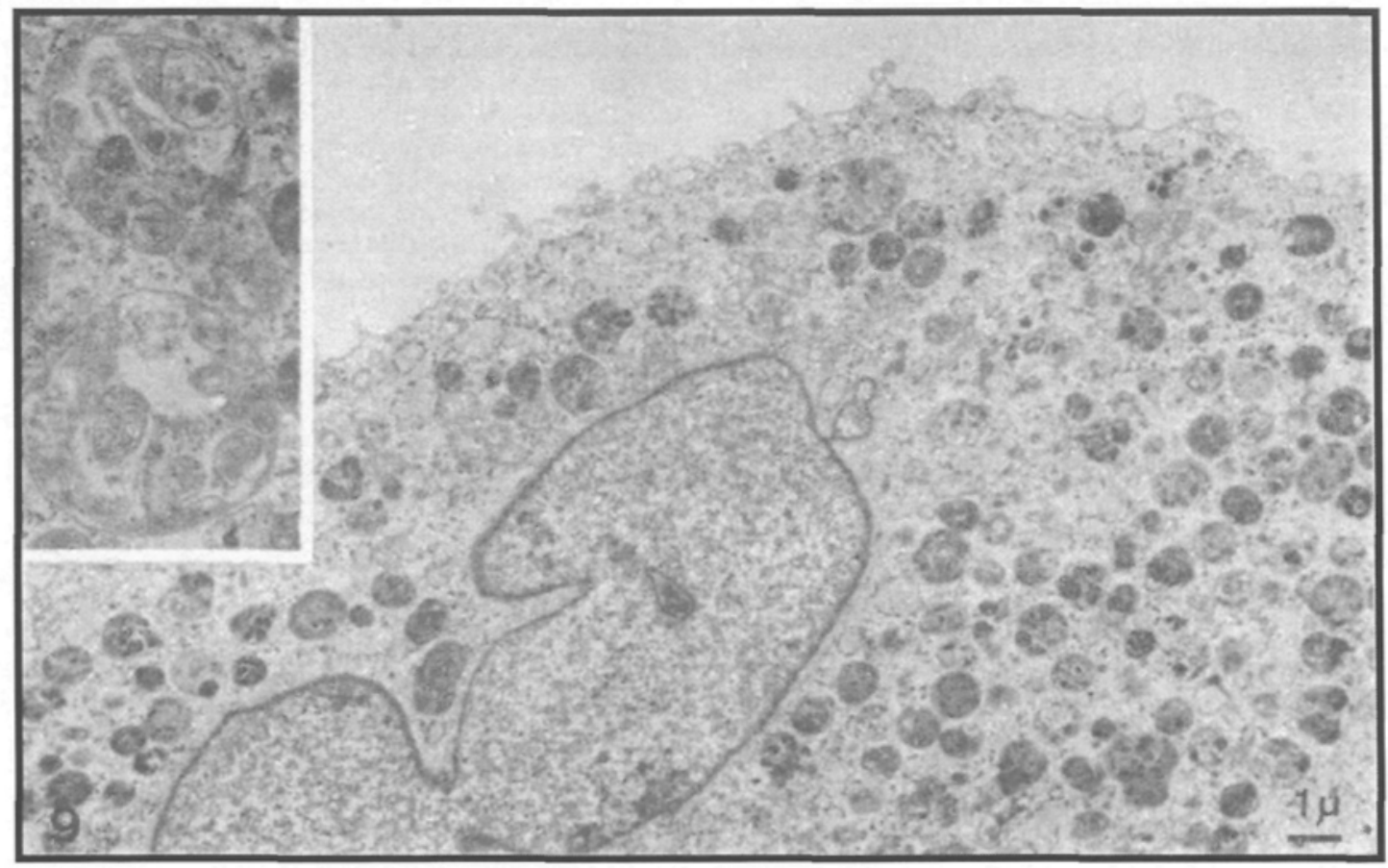

Figure 3. Fibroblaste de culture d'un sujet atteint de la mucolipidose de type II (tirée de Van Hoof, 1974)

Le cytoplasme du fibroblaste contient de nombreuses granules de différentes densités. L'image encadrée montre le contenu de ces granules qui sont en fait un agrégat de débris accumulés par phagocytose ou autophagie.

Les changements morphologiques cellulaires incluent la forme qui peut être très allongée ou arrondie et la présence de vacuoles (figure 3) (Maroteaux et al, 1970). De larges vacuoles sont présentes dans les cellules pancréatiques exocrines et celles des glandes exocrines séreuses (trachéales, bronchiques, sublinguales) (Elleder et Martin, 1998). Les lymphocytes et les hépatocytes ont aussi le cytoplasme vacuolé (Maroteaux et al, 1970; Tondeur, 1971 dans Leroy et Van Elsen, 1973; Elleder et Martin, 1998). Ces vacuoles sont des lysosomes remplis de matières non dégradées composées principalement de lipides et de mucopolysaccharides (Leroy et al, 1971; Van Hoof, 1972). À titre d'exemple, dans les 
fibroblastes de sujets atteints, ces lysosomes de MLII sont six fois plus nombreux et sont également $60 \%$ plus larges que ceux observés dans les fibroblastes normaux (Van Hoof, 1974).

\subsubsection{L'atteinte cardiaque}

La dysfonction du système cardio-vasculaire rencontrée chez les sujets atteints de MLII est possiblement causée par l'accumulation progressive de métabolites dans les fibroblastes des tissus conjonctifs des valves, de l'endocarde, du myocarde et des régions périvasculaires (Okada et al, 1985). Parfois, une hypertrophie ventriculaire gauche est remarquée et des murmures systoliques sont audibles à l'auscultation des patients ayant la MLII (Leroy et al, 1971; Güngor et al, 1994; Okada et al, 1985). De plus, on observe des plaques lipidiques dans l'aorte et les gros vaisseaux (Gilbert-Barness et Barness, 1993).

\subsubsection{L'atteinte neurologique}

Contrairement aux autres types de mucolipidose, où l'on rencontre des troubles majeurs au niveau cérébral, les patients atteints de la MLII ont une altération morphologique des systèmes nerveux central et périphérique minime (Gilbert-Barness et Barness, 1993). Dans certains cas, le cerveau des patients a un poids sous la normal (Gilbert-Barness et Barness, 1993). Le nombre de neurones est diminué dans le cortex cérébral et il y a une certaine perte de cellules de Purkinje et de neurones granulaires (Gilbert-Barness et Barness, 1993). Les méninges sont épaisses, opaques et gélatineuses (Gilbert-Barness et Barness, 1993). Une légère atrophie du cortex cérébral et du vermis cérébelleux est également observée. La pie arachnoïde est infiltrée par les histiocytes, surtout autour des vaisseaux (Gilbert-Barness et Barness, 1993). Une ventriculomégalie et une atrophie du lobe antérieur ont pu être identifiées chez certains patients grâce à l'imagerie par résonance magnétique (Breningstall et Tubman, 1994). 


\subsubsection{L'atteinte respiratoire}

Les infections des voies respiratoires supérieures, incluant les rhinites et les otites, sont fréquentes (Leroy et al, 1971; Okada et al, 1985). La bronchite et la pneumonie surviennent à répétition (Leroy et al, 1971). Enfin, la présence de granulomes lipidiques est notée partout dans le parenchyme pulmonaire (Gilbert-Barness et Barness, 1993).

\subsubsection{L'atteinte musculaire}

L'étude des cellules musculaires squelettiques de patients atteints de MLII révèle qu'en ce qui a trait à l'aspect microscopique (inclusions) et aux enzymes, les cellules n'ont pas les mêmes particularités que celles observées dans les fibroblastes présentant la MLII (Shanske et al, 1981). Cependant, in vitro, la capacité des fibres musculaires à se régénérer est réduite et ceci conjugué à un problème d'organisation de la plaque motrice pourrait expliquer, du moins en partie, les difficultés neuromusculaires des patients atteints de MLII (Kula et al, 1984).

\subsubsection{L'atteinte du système squelettique}

Les signes radiologiques de la MLII se confondent avec l'ostéomalacie (chez le nouveauné) et avec la mucopolysaccharidose de Hurler (à l'âge de quelques mois), quoique le bilan sanguin montre des taux normaux de calcium et de phosphore (Maroteaux et al, 1970; Walbaum et al, 1973). Toutefois, le taux sérique des phosphatases alcalines est élevé (Maroteaux et al, 1970). Une déminéralisation de l'ensemble du squelette, plus souvent nommée «dysostose », ce qui signifie "dystrophie osseuse », est généralement observée (Maroteaux et al, 1970; Güngor et al, 1994). Le thorax est étroit, les côtes sont larges et les os sont souvent courts. La voûte du crâne est épaisse et le crâne est brachycéphale, c'est-àdire large, court et aplati à sa face postérieure. Un important retard staturo-pondéral est souvent présent chez les patients (Maroteaux et al, 1970). Enfin, la scoliose (figure 4) ou la cyphoscoliose, ainsi que la dislocation de la hanche ne sont pas rares (Leroy et al, 1971; Walbaum et al, 1973; Güngor et al, 1994; Okada et al, 1985; Kabra et al, 2000). 


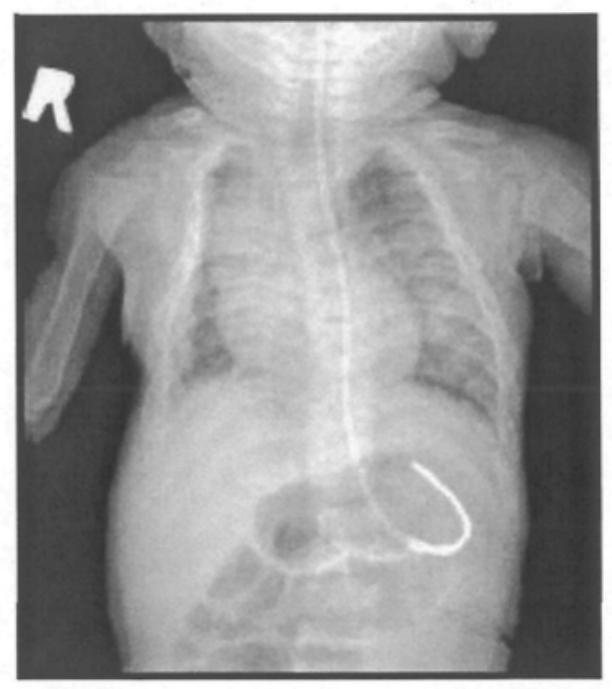

Figure 4. Radiographie du thorax d'un enfant de quatre mois ayant la mucolipidose de type II (tirée de Unger et al, 2005)

La radiographie montre la présence d'une scoliose, d'un thorax étroit et de larges côtes, qui sont des traits typiques de la MLII.

\subsubsection{Le pronostic}

L'état de santé des enfants atteints de MLII décline rapidement dans le temps, menant habituellement à la mort entre les âges de $2 \frac{1}{2}$ et 8 ans (Leroy et al, 1971). Les causes les plus communes sont liées aux complications de maladies cardiaques ou d'infections pulmonaires (Leroy et al, 1971; Okada et al, 1985; Güngör et al, 1994). 


\subsection{Les lysosomes - Activité normale}

\subsubsection{La physiologie des lysosomes}

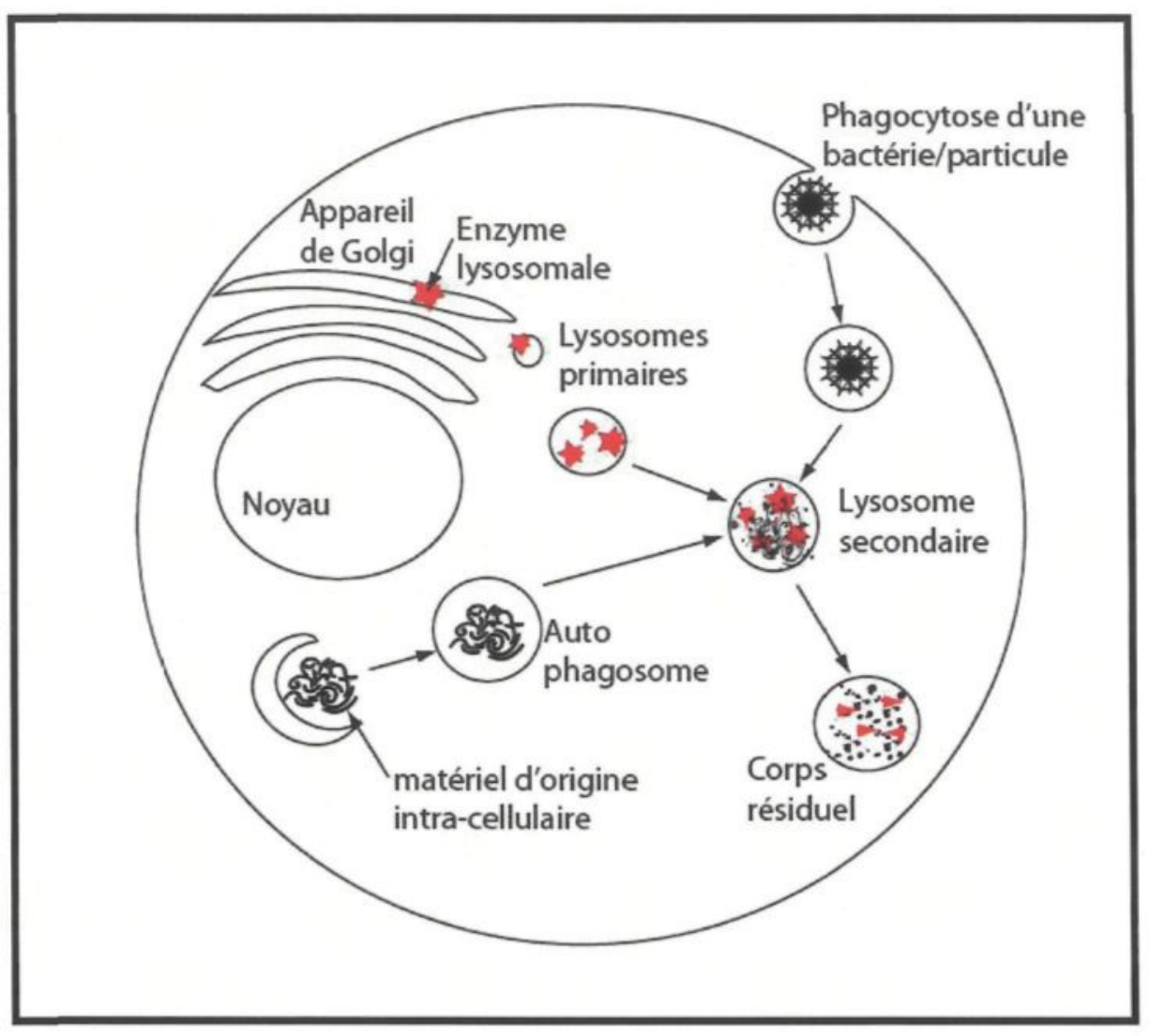

Figure 5: Localisation intracellulaire des lysosomes et activité de phagocytose (inspirée de Kornfeld, 1987, Lingappa, 1989 et Vellodi, 2004)

Les enzymes lysosomales sont synthétisées par les ribosomes au niveau du réticulum endoplasmique rugueux et elles sont marquées d'un mannose-6-phosphate (M6P) dans l'appareil de Golgi, ce qui permet aux enzymes de se lier à un récepteur du M6P. Une fois liées aux récepteurs, les enzymes lysosomales bourgeonnent de l'appareil de Golgi et forment des lysosomes primaires. Les lysosomes primaires sont des vésicules contenant les enzymes lysosomales et lorsqu'ils fusionnent avec un (auto-)phagosome, ils sont appelés lysosomes secondaires. Les lysosomes secondaires sont le lieu de digestion cellulaire, où l'acidité permet l'activité optimale des enzymes lysosomales.

Les lysosomes sont des organites constitués d'une membrane faite d'une simple couche lipidique et qui provient du bourgeonnement de la membrane du réseau trans-golgien (Maillet, 2002). Il renferment environ une quarantaine d'hydrolases acides qui sont responsables principalement du catabolisme des acides nucléiques, des protéines, des 
lipides, des glucides et des produits de faibles poids moléculaires absorbés par la cellule par autophagie, phagocytose ou endocytose (figure 5) (Holtzman, 1989; Maillet, 2002). De façon plus générale, les enzymes lysosomales catalysent les réactions de type A-B $+\mathrm{H}_{2} \mathrm{O} \rightarrow$ A-H + B-OH (Maillet, 2002). Ainsi, le rôle des lysosomes est principalement la digestion de particules. Par exemple, la digestion des organites nonfonctionnels, du glycogène stocké, des tissus devenus inutiles (palmure entre les doigts et les orteils du fotus, couche superficielle de l'endomètre lors de la menstruation) ou encore la digestion du tissus osseux par les ostéoclastes pour libérer du calcium $\left(\mathrm{Ca}^{2+}\right)$ dans le sang sont assurées par l'activité des lysosomes (Marieb, 1993). Au cours de leur maturation et par l'action des pompes à proton $\left(\mathrm{H}^{+}\right)$de leur membrane, les lysosomes s'acidifient jusqu'à atteindre un $\mathrm{pH}$ situé entre 4.5 et 5.5, ce qui permet l'activité optimale de la plupart des hydrolases acides (Holtzman, 1989). La présence de glycoprotéines membranaires protège la cellule contre les enzymes et l'acidité intra-lysosomale, empêchant ainsi l'autodigestion cellulaire (Maillet, 2002).

\subsubsection{La synthèse des hydrolases acides}

Les hydrolases acides contenues dans les lysosomes sont synthétisées par les ribosomes situés sur le réticulum endoplasmique rugueux (RER). Les ribosomes se fixent au RER et les enzymes en cours de traduction sont incorporées au RER grâce à un complexe de translocation. Une fois la synthèse terminée, la protéine est glycosylée par les glucosidases I et II ainsi que par la mannosidase du RE pour être ensuite transférée à la face cis de l'appareil de Golgi (Alberts et al, 2005; Lingappa, 1989).

\subsubsection{L'adressage des hydrolases acides}

Dans l'appareil de Golgi, l'hydrolase acide est modifiée dans les saccules cis et médian par les enzymes mannosidase-I, UDP-N-acétylglucosamine-1-phosphotransférase (GlcNAcPT, EC 2.7.8.17) et la $\mathrm{N}$-acetylglucosamine-1-phosphodiester $\alpha$-N-acetylglucosaminidase (EC 3.1.4.45) (Alberts et al, 1995; www.expasy.org/enzyme). La première étape se déroule dans le saccule cis et consiste à éliminer trois résidus mannose sur l'hydrolase acide grâce à la 
mannosidase-1. Ensuite, la GlcNAcPT ajoute un UDP-N-acétylglucosamine à un résidu mannose d'un oligosaccharide de l'hydrolase acide, et une autre enzyme, la Nacetylglucosamine-1-phosphodiester $\alpha$-N-acetylglucosaminidase libère le GlcNAc pour enfin produire une hydrolase acide marquée d'un M6P (figure 6) (Holtzman, 1989). Le M6P permet à l'hydrolase acide d'être reconnue et liée à un récepteur du M6P dans le réseau trans-golgien (Alberts et al, 1995). Enfin, la membrane de l'appareil de Golgi bourgeonne et forme une vésicule renfermant les enzymes lysosomales liées à leur récepteur du M6P (Holtzman, 1989) (figure 7).

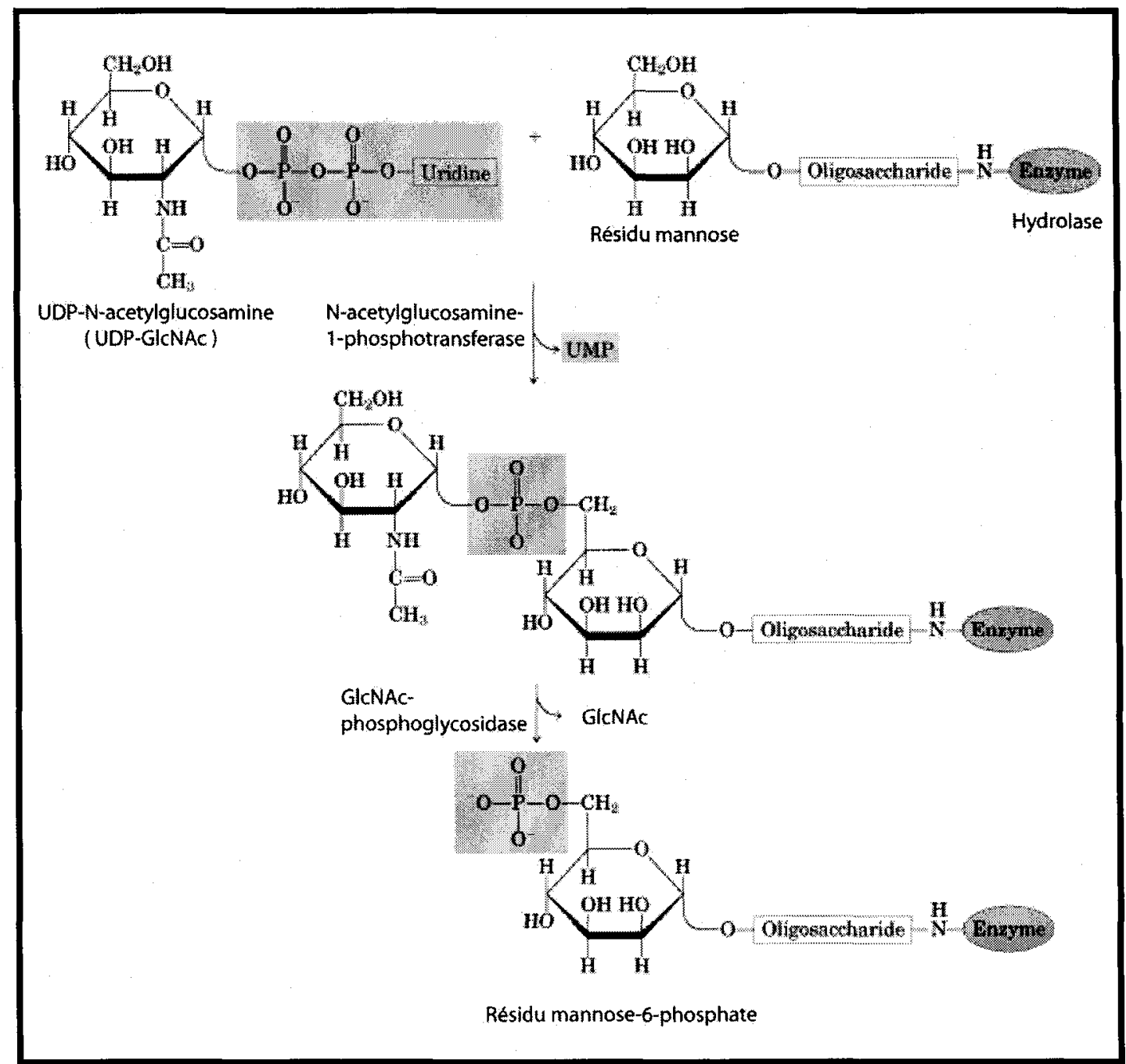

Figure 6. La phosphorylation des enzymes lysosomales (tirée de http://opbs.okstate.edu)

La réaction entre l'hydrolase glycosylée et l'UDP-N-acétylglucosamine est catalysée par la $\mathrm{N}$-acétylglucosamine-1-phosphotransférase. La molécule résultante libère une glucosamine sous l'action de la N-acétylglucosamine-phosphoglycosidase, ce qui a pour conséquence de phosphoryler le carbone en position 6 du résidu mannose (M6P) de l'hydrolase acide. 


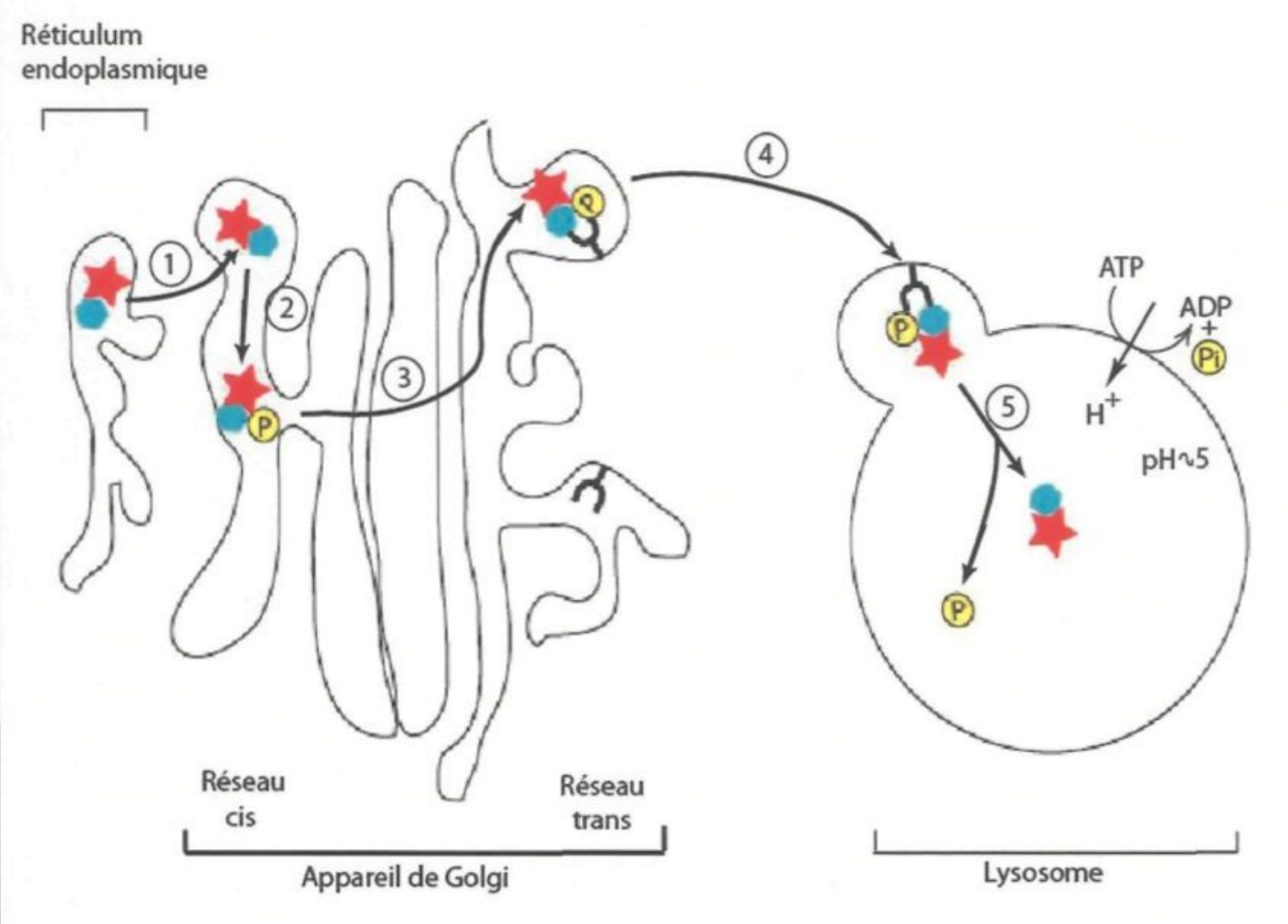

Figure 7 : Trajet cellulaire des enzymes lysosomales (adaptée de Alberts et al, 1995)

Étape 1: Les hydrolases acides migrent du réticulum endoplasmique rugueux (RER) au réseau cis de l'appareil de Golgi.

Étape 2: Les enzymes sont marqués d'un mannose-6-phosphate (M6P) lors de leur passage dans les réseaux cis et médian de l'appareil de Golgi.

Étape 3: Les enzymes liées à un M6P se déplacent dans le réseau trans où elles se lient aux récepteurs du M6P.

Étape 4: Une vésicule contenant les enzymes bourgeonne et fusionne avec un lysosome.

Étape 5: Le pH à l'intérieur du lysosome permet de relarguer le phosphate (P). L'acidité intra-lysosomale permet aussi l'activité optimale des hydrolases acides. 


\subsection{Pathophysiologie des lysosomes en relation avec la MLII}

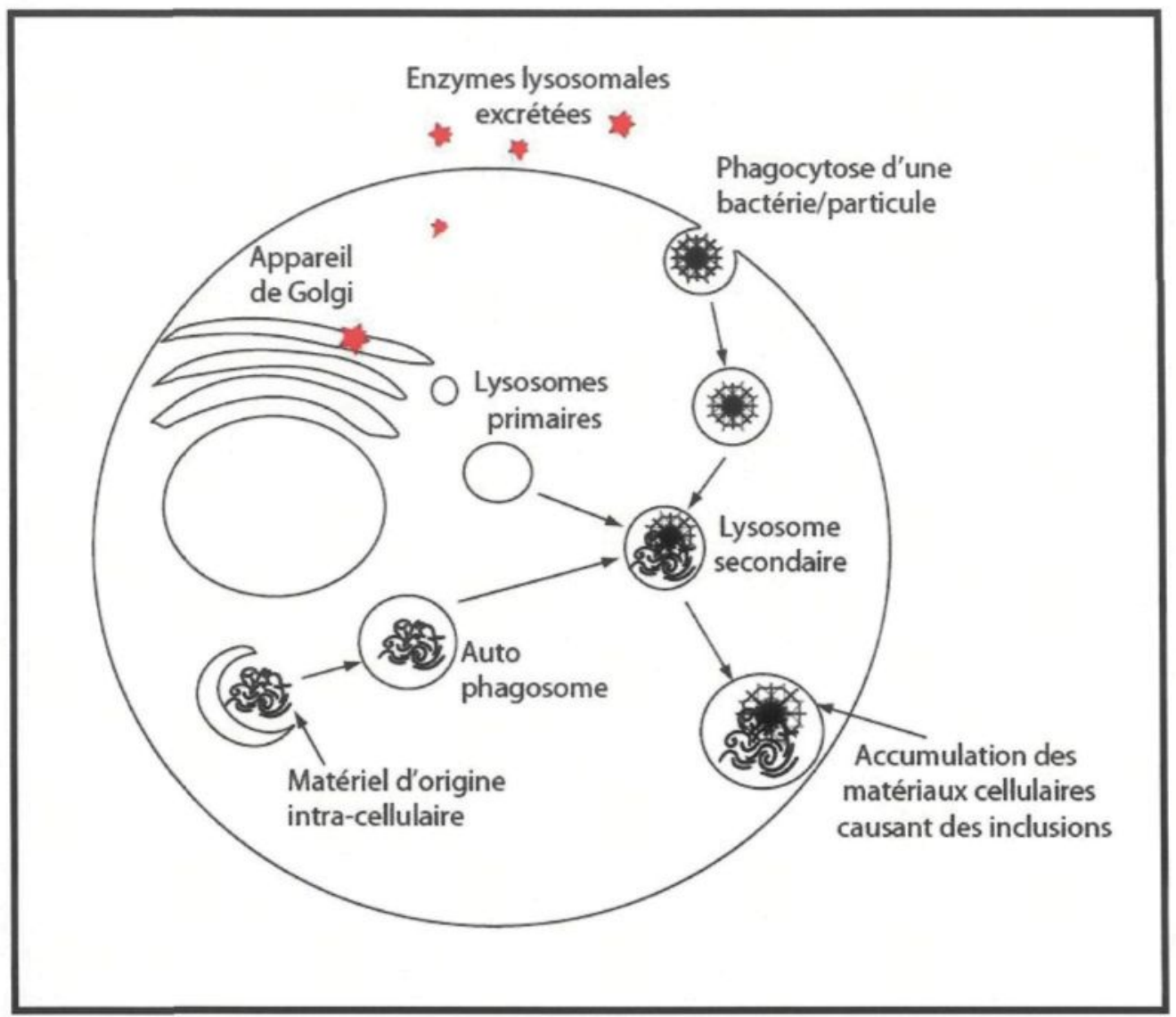

Figure 8. Cellule d'un individu ayant la mucolipidose de type II (inspirée de Kornfeld, 1987, Lingappa, 1989 et Vellodi, 2004)

Chez le sujet atteint de la MLII, la N-acétylglucosamine-1-phosphotransférade est absente, ce qui empêche les enzymes lysosomales d'être adéquatement marquées avec un mannose6-phosphate et adressées aux lysosomes. Par conséquent, les enzymes lysosomales sont excrétées de la cellule et elles sont donc absentes des lysosomes. Les lysosomes sont incapables d'effectuer la digestion, ce qui mène à l'accumulation de matériaux non digérés - inclusions - suite à une phagocytose ou une autophagocytose.

Chez les individus atteints de la MLII, les lysosomes n'ont pas les enzymes nécessaires à la dégradation de différents matériaux cellulaires. Au lieu d'être dirigés vers les lysosomes, les hydrolases acides sont excrétées à l'extérieur de la cellule (figure 8) (Kornfeld, 1986; Olkkonen et Ikonen, 2000). Par conséquent, les hydrolases acides sont retrouvées dans le sang, et très peu dans les lysosomes (Kornfeld, 1986). De plus, des vacuoles accumulent des matières hétérogènes et non-digérées, principalement des lipides et des 
mucopolysaccharides, ce qui a pour effet de causer des inclusions visibles par microscopie en contraste de phase (Leroy et De Mars, 1967; Spranger et Wiedemann, 1970; Leroy et al, 1971).

Dès le début des années 1970, des hypothèses furent publiées pour tenter d'expliquer la cause du taux élevé d'hydrolases dans le plasma. En 1971, on a proposé une théorie selon laquelle il y aurait une fuite des enzymes au travers de la membrane lysosomale (Wiesmann et al, 1971). Cependant, en 1972, de nouvelles observations ont permis d'amener une seconde hypothèse : l'absence d'un marqueur sur les enzymes lysosomales empêche ceuxci de pénétrer dans les lysosomes (Hickman et Neufeld, 1972). Les recherches effectuées appuient cette hypothèse (Hasilik et al, 1981; Reitman et al, 1981).

En effet, chez les individus ayant la MLII, l'activité de l'enzyme GlcNAcPT est absente (Hasilik et al, 1981; Reitman et al, 1981). Ainsi, l'hydrolase acide néo-synthétisée (destinée aux lysosomes) n'a pas de M6P et ne peut être reconnue par le récepteur M6P (Reitman et al, 1981). Conséquemment, les hydrolases acides ne sont pas triées correctement dans l'appareil de Golgi et se retrouvent sécrétées à l'extérieur de la cellule (Kornfeld, 1987).

La conséquence de la sécrétion des enzymes lysosomales dans l'espace extracellulaire s'observe lors des examens sanguins. Le sujet atteint de la MLII aura une plus haute concentration sanguine d'enzymes lysosomales que la normale. Aussi, on remarque une augmentation d'enzymes lysosomales dans le milieu de cultures cellulaires (leucocytes ou fibroblastes), alors que la concentration de ces mêmes enzymes est plus basse à l'intérieur des cellules (Hall, 1978; Varki et al, 1982; Kornfeld, 1987).

\subsection{Diagnostic de la MLII}

Le diagnostic de la MLII en période prénatale ou après la naissance repose sur des analyses enzymatiques ou microscopiques, afin de détecter des anomalies caractéristiques de la MLII. Brièvement, les anomalies recherchées concernent surtout une hausse de l'activité enzymatique dans le milieu de culture cellulaire ou dans le liquide amniotique, une baisse 
de l'activité enzymatique dans les cellules, habituellement des fibroblastes ou des cellules amniotiques ou chorioniques et la présence ou non de vacuoles élargies (accumulation de dépôts dans les lysosomes) (Kornfeld et Sly, 2001).

\subsubsection{Le diagnostic prénatal par les analyses enzymatiques}

\section{Détection de la GlcNAcPT}

Une première façon d'effectuer le diagnostic prénatal de MLII consiste à détecter la réduction de l'activité de la GlcNAcPT dans les cellules des villosités chorioniques, suite à une biopsie chorionique (Ben-Yoseph et al, 1988). Cette technique est efficace, fiable et permet un diagnostic précoce (premier trimestre), mais présente comme désavantages la complexité de la technique ainsi qu'un risque d'avortement supérieur à une amniocentèse (Stanc et al, 1997).

\section{Détection des enzymes lysosomales}

Une deuxième façon repose sur la mesure de l'activité des enzymes lysosomales. Cette mesure s'effectue à la suite d'une amniocentèse, une technique habituellement utilisée au cours du deuxième trimestre, soit entre la $15^{\text {ième }}$ et la $18^{\text {ième }}$ semaine de grossesse (Stank et al, 1997). Malgré cela, Besley et collaborateurs ont étudié une amniocentèse précoce pratiquée sur une patiente et ont démontré que l'examen des enzymes lysosomales dans le liquide amniotique et la culture de cellules amniotiques semblent être efficaces pour le diagnostic prénatal précoce, i.e. à 10 semaines de grossesse (Besley et al, 1990).

L'évalutation de l'activité des enzymes lysosomales s'effectue tout d'abord par l'observation d'une diminution de l'activité des enzymes lysosomales dans les cultures cellulaires amniotiques et chorioniques, principalement l'hexosaminidase, l' $\alpha$-fucosidase, l' $\alpha$-mannosidase, la $\beta$-galactosidase, la $\beta$-glucosidase et la $\beta$-glucuronidase (Gehler et al, 1976; Owada et al, 1980; Poenaru et al, 1984; Ben-Yoseph et al, 1988; Besley et al, 1990). Une deuxième constatation notable est la détection d'un haut niveau d'activité de ces 
mêmes enzymes, en plus de l'arylsulfatase, dans le liquide amniotique (Huijing et al, 1973; Gehler et al, 1976; Owada et al, 1980; Besley et al, 1990). Cependant, l'utilisation du liquide amniotique pour fin d'analyse ne peut se faire qu'à la condition que les sujet témoins aient un âge gestationnel semblable, puisqu'il y a des variations importantes du niveau des enzymes lysosomales dans le liquide amniotiques au cours de la grossesse (Butterworth et al, 1972; Huijing et al, 1973). Il est aussi documenté que la haute activité de l'hexoaminidase dans le sérum de la femme enceinte pourrait permettre le diagnostic prénatal (Hug et al, 1984).

Bien que l'amniocentèse (détection des enzymes lysosomales) soit une méthode plus facile à exécuter et moins à risque d'avortement, la biopsie chorionique (détection de la GlcNAcPT) est considérée comme la méthode de choix pour le diagnostic prénatal, par sa fiabilité et ses résultats plus rapide à obtenir (Kornfeld et Sly, 2001).

\subsubsection{Le diagnostic prénatal par l'analyse microscopique}

Enfin, la microscopie électronique de tissus des villosités chorioniques constitue une méthode additionnelle de détection de la MLII (Carey et al, 1999). Elle s'est avérée efficace pour détecter la MLII en se basant sur l'observation d'une importante vacuolisation dans les cellules des villosités chorioniques de trois grossesses (Carey et al, 1999). Cette vacuolisation fût aussi décelée dans la couche syncytiotrophoblastique des villosités chorioniques et des cellules mésenchymales chorioniques de trois placentas issus de trois grossesses successives d'une femme ayant déjà eu un enfant atteint de la MLII (Rapola et Aula, 1977).

L'observation des villosités chorioniques par microscopie électronique se révèle être une méthode non seulement efficace, mais aussi beaucoup plus rapide que l'analyse enzymatique d'une amniocentèse qui peut prendre de deux à trois semaines, alors qu'il en requiert seulement deux à trois jours pour un diagnostic par microscopie (Carey et al, 1999). Aussi, Carey et ses collaborateurs suggèrent de faire une culture cellulaire et une 
analyse enzymatique seulement si le résultat de la microscopie électronique est ambigu (Carey et al, 1999).

\subsubsection{Le diagnostic des nouveaux-nés}

Le diagnostic des nouveaux-nés s'effectue soit par le prélevement et la culture subséquente de fibroblastes soit par l'analyse sanguine. Ici, comme pour le diagnostic prénatal, on recherche un taux d'activité pathologique des enzymes lysosomales dans la culture cellulaire (intra- et extra-cellulaire) (Leroy et al, 1972). L'analyse sanguine, quant à elle, se fonde sur l'analyse du niveau d'activité de la GlcNAcPT des leucocytes (Varki et al, 1982; Hwu et al, 1994). Récemment, l'examen de la carte de Guthrie (bandelette de papier sur lequel on recueille quelques gouttes de sang) a permis la confirmation du diagnostic de MLII (Meikle et al, 2006). Les enzymes étudiées pour la MLII sont la sphingomyelinase acide, l'arylsulfatase $\mathrm{A}$ et l'iduronate-2-sulfatase, qui sont en concentration de plus de 10 fois le niveau des sujets témoins (Meikle et al, 2006).

\subsubsection{Dépistage des hétérozygotes}

Si l'activité de différentes enzymes lysosomales dans le sérum d'individus hétérozygotes obligatoires était intermédaire, cela pourrait servir au dépistage des hétérozygotes. Or, les valeurs entre les hétérozygotes et les témoins s'entrecoupent, ce qui rend le diagnostic irréalisable (Leroy et Van Elsen, 1973). De plus, certaines conditions physiologiques, comme la grossesse et d'autres conditions cliniques non reliées, causent une augmentation de l'activité enzymatique (Leroy et Van Elsen, 1973).

Par contre, l'analyse de la GlcNAcPT permet d'identifier des hétérozygotes. Ainsi, les hétérozygotes obligatoires, soit les parents d'un enfant atteint de la MLII, ont une activité intermédiaire de la GlcNAcPT (culture de fibroblastes), donc une activité qui se situe entre celle des individus normaux et celles des patients atteints de MLII (Varki et al, 1982; Mueller et al, 1985). Il est aussi possible d'identifier le fœtus hétérozygote, par son activité de la GlcNAcPT, qui est à 50\% de la valeur de contrôle (Ben-Yoseph et al, 1988). 


\subsection{Génétique de la mucolipidose de type II}

\subsubsection{La localisation du gène défectueux}

Les premières études cherchant à localiser le gène défectueux responsable de la MLII furent menées dans les années 1980 (Vidgoff et al, 1982; Mueller et al, 1987). Le chromosome 4 était à ce moment le plus souvent assigné : une liaison possible avec le locus du système du groupe sanguin MN (Vidgoff et al, 1982), ainsi qu'avec une région située entre le locus du système du groupe sanguin MNS et le locus codant l'alpha-globuline liant la vitamine $\mathrm{D}$ (gène $G C$ ) (Mueller et al, 1987). Ainsi, en combinant ces données, le locus recherché serait situé au chromosome 4q21-23 (OMIM : www.ncbi.nlm.nih.gov).

Par ailleurs, en 1998, les travaux de Canfield et ses collaborateurs localisaient le gène responsable de la MLII sur le chromosome 12. L'analyse de la séquence génomique a permis de localiser le gène responsable sur le chromosome 12q23.3 (figure 9) (Tiede et al, 2005). 


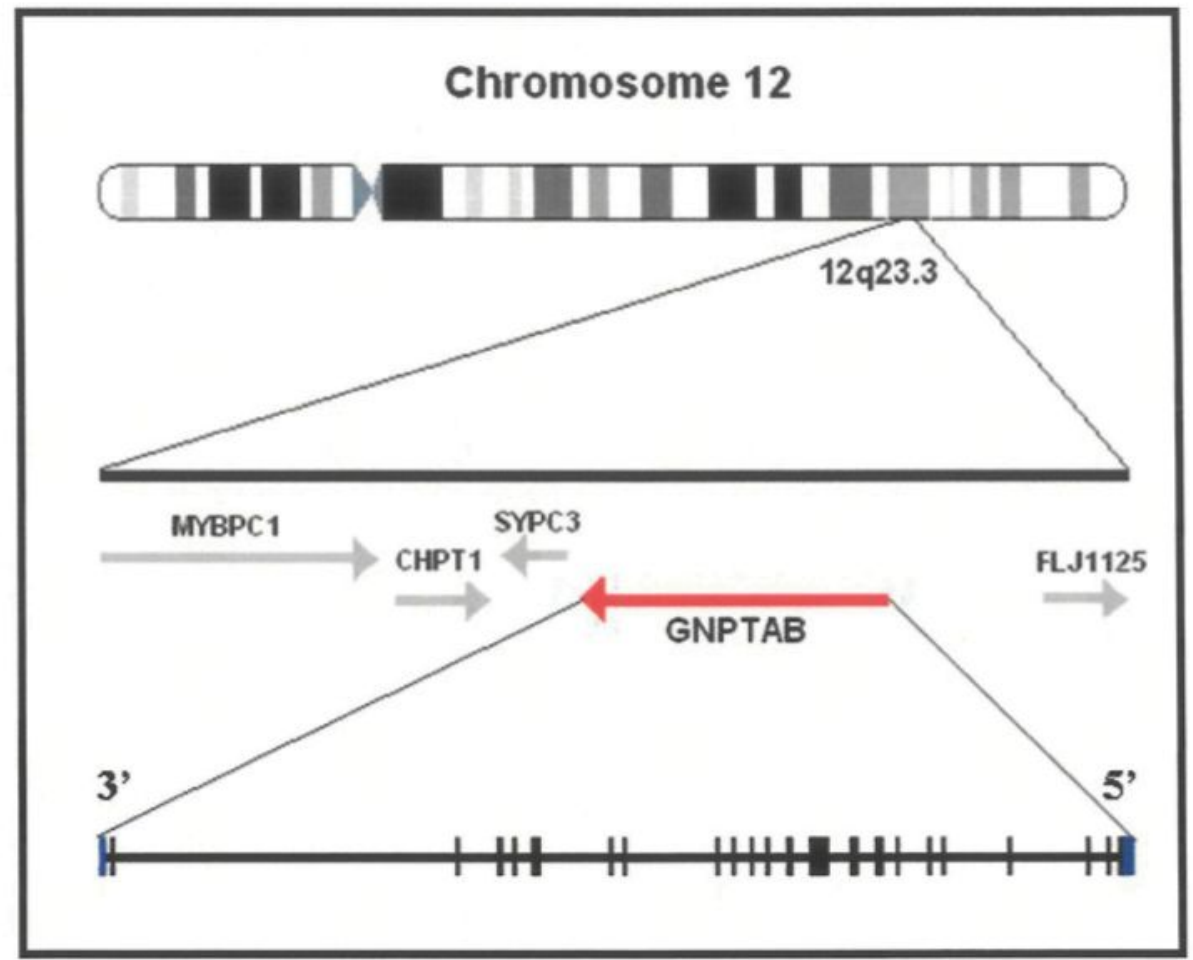

Figure 9. Localisation chromosomique du gène de la sous-unité $\alpha$ et $\beta$ de la N-acétylglucosamine-1-phosphotransférase (GNPTAB) (réalisée par l'intégration de NCBI EntrezGene (www.ncbi.nlm.nih.gov ) et Kudo et al, 2006)

Le gène codant la $\mathrm{N}$-acétylglucosamine-1-phosphotransférase se situe sur le chromosome 12 , à la position q23.3. Il s'étend sur $85 \mathrm{~kb}$, code pour 1256 acides aminés et compte 21 exons.

\subsubsection{La structure et le produit du gène GNPTAB}

Déjà, en 1985, Mueller et collaborateurs suspectaient que la GlcNAcPT était le produit de trois gènes (Mueller et $\mathrm{al}, 1985)$ ). Les études récentes montrent la consistance de leur hypothèse, à l'exception qu'il s'agit de trois sous-unités codées par deux gènes. En effet, la GlcNAcPT est une protéine constituée de six polypeptides formant une unité de reconnaissance et une unité catalytique (figure 10) (Kornfeld et Sly, 2001; Bao et al, 1996). L'unité de reconnaissance est constituée de deux sous-unités $\gamma$ associées de façon covalente (pont disulfure), codée par le gène GNPTG situé sur le chromosome 16 (Bao et al, 1996; Raas-Rothschild et al, 2000). L'unité de reconnaissance est manquante chez les patients ayant la MLIII (Raas-Rothschild et al, 2000). 


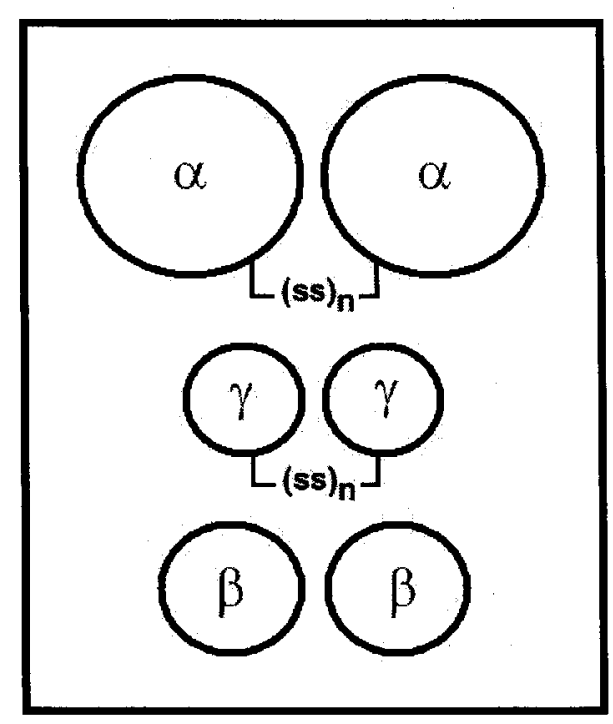

Figure 10. Schéma de la structure de la $\mathbf{N}$-acétylglucosamine-1-phosphotransférase (modifiée de Bao et al, 1996)

La N-acétylglucosamine-1-phosphotransférase (GlcNAcPT) est constitué de trois types de sous-unités. L'unité de reconnaissance est formée de deux sous-unités $\gamma$ liées par un pont disulfure et permet à la GlcNAcPT de reconnaître les hydrolases acides. L'unité catalytique est responsable de la liaison d'un M6P à l'hydrolase acide et elle est constituée de deux sous-unités $\beta$ et un homodimères de sous-unités $\alpha$ (liées par un pont disulfure). L'ensemble de ces six sous-unités permet le fonctionnement adéquat de la GlcNAcPT.

La portion de l'enzyme concernée par la MLII est l'unité catalytique (Tiede et al, 2005; Kudo et al, 2006). Elle est composée d'un homodimère de sous-unités $\alpha$ (liées par un pont disulfure) et de deux sous-unités $\beta$, qui sont codées par le gène GNPTAB (figure 9) (Kudo et al, 2005). Ce dernier s'étend sur 85,3 kb et contient 21 exons qui codent un ARNm produisant un polypeptide de 1256 acides aminés (figure 9) (Tiede et al, 2005). Depuis la découverte du locus GNPTAB, plusieurs mutations causant la MLII ont été identifiées (Paik et al, 2005; Steet et al, 2005; Tiede et al, 2005; Kudo et al, 2006) et sont présentées au tableau 2 avec la nomenclature proposée par Den Dunnen et Antonarakis (Den Dunnen et Antonarakis, 2000). Ces mutations touchent des individus de diverses nationalités, telles que la population israélienne, palestinienne (arabe musulmane), turque, irlandaise et française (Bargal et al, 2006).

Ainsi, la GlcNAcPT, dont la structure générale est $\alpha_{2} \beta_{2} \gamma_{2}$ (figure 10), est un exemple dérogeant à la loi de Beadle-Tatum, hypothèse à l'origine du lien entre les gènes et les 
réactions enzymatiques et menant au principe selon lequel un gène code une enzyme (Kudo et al, 2006; Beadle et Tatum, 1941).

La séquence du gène GNPTAB de l'humain s'est montrée similaire à celle d'autres organismes, tels que Mus musculus, Dictostelium discoideum et Drosophila melanogaster (Kudo et al, 2005). Il est intéressant de noter qu'un modèle félin de la MLII est connu et pourrait être utile pour la recherche (Bosshard et al, 1996; Mazrier et al, 2003). En effet, le modèle félin de la MLII a des caractéristiques cliniques, radiologiques et enzymatiques semblables à la forme humaine de la maladie, ce qui pourrait faciliter la recherche de nouvelles stratégies thérapeutiques contre la MLII. 
Tableau 2. Mutations répertoriées associées à la MLII

\begin{tabular}{|c|c|c|c|c|}
\hline $\begin{array}{l}\text { Intron } \\
\text { /Exon }\end{array}$ & Locus sur l'ADNe & $\begin{array}{l}\text { Conséquence } \\
\text { protéinique }\end{array}$ & $\begin{array}{l}\text { Nombre de } \\
\text { cas de MLII } \\
\text { porteurs de } \\
\text { la mutation }\end{array}$ & Référence \\
\hline $\mathrm{I} 1$ & $118-2 A>G$ & $\begin{array}{l}\text { IVS1-2A>G } \\
\text { (R68fsX8) }\end{array}$ & 1 & Bargal et al, 2006 \\
\hline E3 & $310 \mathrm{C}>\mathrm{T}$ & Q104X & 1 & Paik et al, 2005 \\
\hline E6 & 609_612delCAGA & T206YfsX6 & 2 & Kudo et al, 2006 \\
\hline E8 & 848delA & T284LfsX5 & 1 & Kudo et al, 2006 \\
\hline E12 & $1580 \mathrm{delC}$ & C528VfsX19 & 1 & Kudo et al, 2006 \\
\hline E13 & $1625 \mathrm{insC}$ & E542AfsX4 & 1 & Tiede et al, 2005 \\
\hline E13 & 1738_1741 tripTATA & S581IfsX8 & 1 & Kudo et al, 2006 \\
\hline E13 & $2188 \mathrm{~T}>\mathrm{AAA}$ & L730KfsX8 & 1 & Kudo et al, 2006 \\
\hline E13 & $2533 \mathrm{C}>\mathrm{T}$ & Q845X & $\begin{array}{l}1 \\
1 \\
\end{array}$ & $\begin{array}{l}\text { Tiede et al, } 2005 \\
\text { Bargal et al, } 2006 \\
\end{array}$ \\
\hline E13 & $2681 \mathrm{G}>\mathrm{A}$ & W894X & 1 & Paik et al, 2005 \\
\hline E15 & 2916insT & $\begin{array}{l}\text { Saut de l'exon } 15 \\
+ \text { M972IfsX3 }\end{array}$ & 1 & Bargal et al, 2006 \\
\hline E16 & 3145 insC & G1049RfsX16 & 1 & Tiede et al, 2005 \\
\hline E16 & $3173 \mathrm{C}>\mathrm{G}$ & S1058X & 1 & Paik et al, 2005 \\
\hline E16 & 3231_3234dupCTAC & Y1079LfsX3 & 1 & Kudo et al, 2006 \\
\hline $\mathrm{I} 17$ & $3249+1 \mathrm{G}>\mathrm{A}$ & $\begin{array}{c}\text { IVS17+1G>A } \\
\text { (saut de l'exon 17) }\end{array}$ & $\begin{array}{l}1 \\
1 \\
1\end{array}$ & $\begin{array}{l}\text { Bargal et al, } 2006 \\
\text { Tiede et al, } 2005 \\
\text { Kudo et al, 2006 }\end{array}$ \\
\hline E17 & 3252 delA & P1085RfsX6 & 1 & Tiede et al, 2005 \\
\hline E18 & $3434+1 \mathrm{G}>\mathrm{A}$ & Saut de l'exon 18 & 5 & Bargal et al, 2006 \\
\hline E19 & 3474_3475delTA & H1158QfsX15 & 1 & Paik et al, 2005 \\
\hline E19 & 3501_3502delTC & L1168QfsX5 & $\begin{array}{c}8 \\
11\end{array}$ & $\begin{array}{l}\text { Kudo et al, 2006 } \\
\text { Bargal et al, } 2006\end{array}$ \\
\hline E19 & $3565 \mathrm{C}>\mathrm{T}$ & R1189X & 2 & Paik et al, 2005 \\
\hline E19 & 3566insA & R1189QfsX9 & 1 & Tiede et al, 2005 \\
\hline E20 & $3613 \mathrm{C}>\mathrm{T}$ & R1205X & $\begin{array}{l}1 \\
1\end{array}$ & \begin{tabular}{|l|} 
Tiede et al, 2005 \\
Bargal et al, 2006 \\
\end{tabular} \\
\hline E21 & $3707 \mathrm{~A}>\mathrm{T}$ & $\mathrm{K} 1236 \mathrm{M}$ & 1 & Tiede et al, 2006 \\
\hline
\end{tabular}




\subsubsection{Les études fonctionnelles}

Des mutations sont communes à la MLII et la MLIII (Kudo et al, 2006). Kudo et ses collaborateurs ont distingué deux «types» de mutations, l'une sévère (mutation qui empêche la production d'une enzyme active), l'autre bénigne (mutation qui permet la production d'une enzyme active), et ils suggèrent que les combinaisons expliqueraient la différence entre le phénotype des MLII et MLIII (Kudo et al, 2006).

La démonstration de l'effet des mutations a été effectuée au moyen de la transfection de mutations dans des cellules 293T (Kudo et al, 2006). Le type sévère produit une sous-unité $\alpha$ tronquée et l'absence de la sous-unité $\beta$, causant l'absence d'activité de la GlcNAcPT. La forme bénigne, quant à elle, produit une sous-unité $\alpha$ intacte et une troncation de la sousunité $\beta$, ce qui entraîne une réduction de l'activité de la GlcNAcPT par rapport à l'absence de mutation (Kudo et al, 2006). Cette étude fonctionnelle explique l'observation d'un poids moléculaire diminué de la GlcNAcPT chez les patients atteints de la MLII (Ben-Yoseph et al, 1987).

Ainsi, selon ces recherches, un sujet ayant ses deux allèles présentant chacun une mutation sévère souffrirait de MLII. Un sujet ayant une mutation de chaque type (une mutation sévère et une mutation bénigne) ou encore deux mutations bénignes présenterait une MLIIIA (Kudo et al, 2006).

\subsubsection{Le lien entre la MLII et les autres mucolipidoses}

Il y a 20 ans, le terme de mucolipidose et la classification de cette maladie ont été documentés dans la littérature. Aujourd'hui, les recherches effectuées permettent de préciser la classification de ces maladies. Ainsi, comme on peut le noter au tableau 3, la sialidose de type 2 est le terme remplacant maintenant « mucolipidose de type I » et touche la neuraminidase, une protéine qui participe au catabolisme intra-lysosomal des sialyloligosaccharides (OMIM: www.ncbi.nlm.nih.gov). Les MLII et MLIIIA sont 
désormais identifiées comme étant des maladies semblables, la MLII étant de nature plus grave que la MLIIIA, mais les deux ayant une/des mutation(s) au niveau du même gène, le GNPTAB (Kudo et al, 2006). La MLIIIC, quant à elle, touche la même protéine, mais à une sous-unité différente (sous-unité $\gamma$ ) (Raas-Rothschild et al, 2000). La MLIIIB est lié à une seule souche cellulaire dans une étude de complémentation et elle a été perdue, donc aucune investigation génétique n'a pu être effectuée (Muller et al, 1983; Kudo et al, 2006). Les MLII et MLIII produisent une GlcNAcPT ayant une activité réduite ou absente. La MLIV est la conséquence d'un défaut de la mucolipine-1, un canal calcique, empêchant la fusion efficace entre le lysosome et l'endosome (Bargal et al, 2000).

En parcourant la littérature, on constate que même si ces maladies sont regroupées sous le terme de mucolipidose, il n'y a guère de lien elles, exception faite de la MLII, MLIIIA et MLIIIC. Le seul point commun à l'ensemble des mucolipidoses constitue le fait que ce sont toutes des maladies de surcharge lysosomale. Cette surcharge est le résultat d'un défaut enzymatique à différents niveaux du métabolisme cellulaire et la conséquence se réflète dans les différents phénotypes exprimés par chacune des mucolipidoses.

Tableau 3. Différenciation des mucolipidoses sur la base génique et protéinique

\begin{tabular}{|c|c|c|c|}
\hline Mucolipidose & Autres nominations & Gène impliqué & Protéine affectée \\
\hline I & $\begin{array}{c}\text { Lipomucopolysaccharidose } \\
\text { Sialidose type 2 }\end{array}$ & $\begin{array}{c}\text { NEU1 } \\
\text { (Chr6p21.3) }\end{array}$ & Neuraminidase \\
\hline II & "I-cell disease » & GNPTAB & GlcNAc-P \\
\hline IIIA & - & GNPTAB & GlcNAc-P \\
\hline IIIB & - & $?$ & $?$ \\
\hline IIIC & Pseudo-polydystrophie de & GNPTG & GlcNAc-P \\
& Hurler & (Chr16p) & Mucolipine-1 \\
IV & Sialolipidose & MCOLN & \\
& & (Chr19p13.3- & \\
& & p13.2) & \\
\hline
\end{tabular}

\subsection{Thérapies actuelles}

Actuellement, il n'existe pas de traitement contre la MLII (Kornfeld et Sly, 2001). L'intervention clinique ne traite que les symptômes associés à cette maladie. Les 
antibiotiques sont prescrits pour traiter les infections respiratoires. La physiothérapie aide à maintenir la fonction articulaire et la mobilité. La transplantation de moelle osseuse pourrait présenter une intervention qui réduirait la symptomatologie pour les enfants atteints de la MLII (Kurobane et al, 1986; Grewal et al, 2003).

En effet, la greffe de moelle osseuse s'est avérée efficace pour améliorer l'hépatomégalie et la peau épaisse et serrée, ainsi que pour arrêter la progression de l'opacité cornéenne (Kurobane et al, 1986). Elle a aussi réduit la progression de la cardiomyopathie et la fréquence des infections pulmonaires et certains travaux rapportent une amélioration neurocognitive (Grewal et al, 2003). L'ensemble de ces améliorations résulte d'un mécanisme d'action qui reste cependant non documenté (Kurobane et al, 1986; Grewal et la, 2003).

Une autre possibilité serait l'utilisation de la greffe du sang de cordon ombilical, qui est une autre source de cellules souches lorsqu'il est impossible de trouver un donneur de moelle osseuse compatible avec le malade (Staba et al, 2004). Cette méthode a été utilisée pour le syndrome de Hurler, mais est une avenue encore inexplorée dans le cas de la MLII (Staba et al, 2004).

\subsection{La structure de la population du SLSJ}

La littérature montre plusieurs exemples de populations à effet fondateur (Norio, 2003; Helgason et al, 2000; Tipping et al, 2001). L'étude des différentes maladies génétiques présentes au SLSJ permet de constater que l'effet fondateur est souvent mis en cause pour en expliquer l'incidence élevée. L'examen de la situation particulière du SLSJ, tant sur le plan géographique que sur le plan démohistorique, permet la compréhension de la structure génétique de la population de cette région. En effet, le SLSJ est une région relativement isolée, située à $200 \mathrm{~km}$ au nord-est de la ville de Québec.

Aujourd'hui, la population du SLSJ atteint 275427 habitants (Institut de la Statistique du Québec, 2004). Elle est issue d'un triple effet fondateur, comme en fait foi son histoire de 
colonisation et sa structure génétique (Bouchard et De Braekeleer, 1992). D'abord, un premier effet fondateur est survenu au cours de la colonisation de la Nouvelle-France. Au début du $17^{\text {ième }}$ siècle, la France y envoie Samuel de Champlain (Harris et al, 1987). Celuici fonde la ville de Québec en 1608 et la colonisation commence dans la Vallée du StLaurent. Entre 1608 et la Conquête Britannique en 1759, 8500 personnes viennent s'établir en Nouvelle-France, dont $80 \%$ sont des hommes et seulement $4 \%$ ne sont pas d'origine française (Charbonneau et al, 1987). Ces 8500 fondateurs représentent les ancêtres de la plupart des 6 millions de Franco-québecois d'aujourd'hui. Après 1759, l'immigration de la France s'atténue grandement et la population francophone connaît une augmentation de ses effectifs principalement par un accroissement naturel (Charbonneau et al, 1987; Laberge et al, 2005).

Le deuxième effet fondateur apparait lors de la colonisation de la région de Charlevoix, vers la fin du $17^{\text {ième }}$ siècle. À partir de 1675 , plusieurs immigrants de la région de Québec et de la Côte-de-Beaupré viennent s'établir dans Charlevoix. La population connait une forte fécondité et vers 1842 , à cause d'un surpeuplement et du manque de terre cultivable, des habitants de Charlevoix se déplacent vers le SLSJ (Gauvreau et al, 1991).

La population de cette nouvelle région augmente principalement par l'immigration familiale et un accroissement naturel. De l'ouverture du territoire du SLSJ à 1870, 80\% des immigrants proviennent de Charlevoix, mais ce chiffre diminue à moins de 50\% après 1880 (Pouyez et Lavoie, 1983; Gauvreau et al, 1991). Plusieurs phénomènes ont structuré le bassin génétique de la population du SLSJ. Entre autre, l'immigration était de type familial et les Charlevoisiens étaient plus portés à s'enraciner au SLSJ que les immigrants d'autres provenances (Roy et al, 1988; Gauvreau et al, 1991; Bouchard, 1996). De plus, les Charlevoisiens établis au SLSJ avait plus d'enfants que les autres immigrants, et leurs enfants avaient plus tendance à s'établir dans la région (Roy et al, 1988; Gauvreau et al, 1991). Ainsi, un troisième effet fondateur s'est manifesté au SLSJ, par l'immigration familiale, l'enracinement, la descendance utile importante, la forte fécondité et l'isolation géographique de la région. D'ailleurs, l'étude de l'apparentement entre le SLSJ et 
Charlevoix atteste de la présence d'un lien fort entre ces deux régions et qui pourraient même être envisagées comme une seule entité génétique (Vézina et al, 2005b).

La structure de cette population aura donc été marquée par son histoire, dont l'origine est récente. Cela est notable actuellement par une fréquence plus élevée de certaines maladies héréditaires autosomales récessives, comme la neuropathie sensitivomotrice avec ou sans agénésie du corps calleux, la fibrose kystique, la tyrosinémie héréditaire de type 1, l'ataxie spastique de Charlevoix-Saguenay et l'acidose lactique, alors que d'autres maladies sont pratiquement absentes, par exemple la thalassémie, la maladie de Tay-Sachs, la phénylcétonurie et l'ataxie de Friedreich (Bouchard, 1991; De Braekeleer, 1991b). Ce même phénomène n'est pas unique au SLSJ, puisqu'on l'observe aussi une forte incidence de maladies génétiques associés à un effet fondateur dans d'autres régions du monde, telles la Finlande, l'Islande et l'Afrique du Sud, pour n'en nommer que quelques-unes (Norio, 2003; Helgason et al, 2000; Tipping et al, 2001). 


\title{
CHAPITRE 2
}

\author{
LA MUCOLIPIDOSE DE TYPE 2 : \\ UNE SEULE MUTATION DANS LE GÈNE DE LA \\ N-ACÉTYLGLUCOSAMINE-1-PHOSPHOTRANSFÉRASE (GNPTAB) \\ EST IDENTIFIÉE AU SEIN D'UNE POPULATION CANADIENNE \\ FRANÇAISE À EFFET FONDATEUR
}

Article soumis à la revue Clinical Genetics en mars 2007 


\subsection{Avant-propos}

Le présent chapitre contient le manuscrit qui rapporte les résultats d'une recherche visant à identifier la mutation causant la MLII au Saguenay-Lac-St-Jean, entreprise dans le cadre du présent projet de maitrise. L'étude s'est effectuée aux laboratoires du Centre de médecine génique communautaire (CMGC) de l'Université de Montréal situé au Centre de santé et de services sociaux de Chicoutimi (CSSSC) et du Centre d'Innovation de Génome Québec (CIGQ) et de l'Université McGill, ainsi qu'au Projet BALSAC qui se situe à Saguenay. Il s'agit donc d'une recherche interdisciplinaire qui comporte des aspects de génétique moléculaire et de génétique des populations.

L'écriture de cet article, dont je suis première auteure, constitue le résultat d'un travail accompli grâce à l'implication d'équipes de recherche de différentes spécialités. La réalisation de cette étude m'a permis de compléter chaque étape de la recherche, débutant par le contact avec les comités d'éthique (CSSSC et Université du Québec à Chicoutimi (UQAC)), la rencontre des sujets pour remplir les formulaires de consentement et questionnaires, l'extraction de l'ADN des lymphocytes au laboratoire, le séquençage du gène GNPTAB, l'analyse des séquences, l'assistance à l'étude généalogique et enfin, l'écriture de cet article scientifique. Toutes ces étapes ont été faites sous la supervision de ma directrice de maîtrise, Catherine Laprise. Catherine Laprise, professeure-chercheure à l'UQAC et au CMGC, est responsable du profil méthodologique de ce projet.

L'intérêt suscité par le pédiatre Charles Morin pour la MLII dans la région du SLSJ a été le point de départ de ce projet. Il a fourni l'expertise médicale, identifié les hétérozygotes obligatoires et a permis de dresser la liste des porteurs obligatoires au SLSJ. Il a contacté Catherine Laprise et ensemble, ils ont amorcé cette étude visant à trouver la mutation responsable de la MLII au SLSJ, dans le but de pouvoir offrir les tests de dépistage aux familles à risque.

L'article est actuellement en révision par le journal Clinical Genetics. Sa soumission a été faite en mars 2007. Chaque coauteur a effectué une part de l'ensemble du travail. Sébastien 
Claveau, asssitant de recherche de Catherine Laprise, a participé au séquençage du gène d'intérêt (ciblé par Catherine Laprise et Pierre Lepage). Pierre Lepage, directeur de l'unité de génotypage et de séquençage au CIGQ, a fourni l'expertise quant à l'identification du gène et de la mutation et le travail technique fait dans le CIGQ a été effectué par Sébastien Brunet et David Roquis. Hélène Vézina, professeure-chercheure de l'UQAC, et son assistante de recherche au Projet BALSAC, Ève-Marie Lavoie ont réalisé les analyses généalogique et démographique. Enfin, tous les coauteurs ont révisé le manuscript et sont d'accord avec la version proposée. 


\section{Mucolipidosis type II: A single causal mutation in the $\mathrm{N}$ - acetylglucosamine-1-phosphotransferase gene (GNPTAB) in a French Canadian Founder Population}

Mylène Plante ${ }^{1}$, Sébastien Claveau ${ }^{3}$, Pierre Lepage ${ }^{2}$, Ève-Marie Lavoie ${ }^{1}$, Sébastien Brunet ${ }^{2}$, David Roquis ${ }^{2}$, Charles Morin ${ }^{3}$, Hélène Vézina ${ }^{1}$, Catherine Laprise ${ }^{1,3}$

1) Université du Québec à Chicoutimi, 555 boulevard de l'Université, Chicoutimi, Qc, Canada, G7H 2B1

2) McGill University and Genome Quebec Innovation Centre, Montreal, Qc, Canada, H3A $1 \mathrm{~A} 4$

3) Centre de santé et de services sociaux de Chicoutimi, Community genomic medicine centre, 315 rue St-Vallier, Chicoutimi, Qc, Canada, G7H 3 Y8

Corresponding Address:

Catherine Laprise, Ph.D.

Chaire de recherche du Canada sur l'étude des déterminants génétiques de l'asthme Université du Québec à Chicoutimi

Centre de médecine génique communautaire de l'Université de Montréal

Centre affilié universitaire (CAU) régional de Chicoutimi

305 St-Vallier

Chicoutimi, Qc, G7H 5H6

Canada

Phone: (418) 541-1077

Fax: (418) 541-1116

E-mail: Catherine_laprise@uqac.ca 


\subsection{Résumé}

La mucolipidose de type II (MLII, MIM252500) est une maladie autosomale récessive présente dans la population à effet fondateur du Saguenay-Lac-Saint-Jean (SLSJ), où la prévalence des porteurs (hétérozygotes) a été estimée à 1/39 par le conseil génétique local. La MLII est une maladie métabolique de surcharge lysosomale qui est causé par la déficience d'une enzyme, la N-acetylglucosamine-1-phosphotransferase (GlcNAcPT), qui permet l'identification et le transport approprié des enzymes lysosomales. Afin de déterminer si la MLII est causée par une (des) mutation(s) dans le gène précurseur des sous-unités $\alpha / \beta$ (GNPTAB) de la GlcNAcPT, nous avons séquencé les exons du gène GNPTAB de 27 parents et quatre frères/soeurs d'un enfant atteint de la MLII au SLSJ. Nous avons aussi procédé à la reconstruction généalogique de chaque parent pour tenter d'identifier un noyau d'ancêtres communs, ce qui pourrait expliquer la haute fréquence de la MLII au SLSJ. Nous avons identifié 12 variants génétiques parmi tous les sujets. Seulement une mutation a été identifiée parmi tous les porteurs. Il s'agit de la mutation c.3501_3502delTC (p.L1168QfsX5), qui cause un décalage de lecture et mène à une protéine tronquée à l'acide aminé 1168. Aucun des témoins n'avait cette mutation. En évoquant l'étude publiée récemment par Kudo et ses collaborateurs (Kudo et al, 2006) et nos résultats, nous considérons que cette mutation est l'unique allèle causant la MLII au SLSJ. Les données généalogiques indiquent que six fondateurs (trois couples) pourraient avoir transmis la mutation dans la population du SLSJ, expliquant la fréquence élevée de cet allèle. 


\subsection{Abstract}

Background: Mucolipidosis type II (I-Cell disease [MIM252500]) is a lysosomal storage disorder known to be caused by a deficiency in the lysosomal enzyme Nacetylglucosamine-1-phosphotransferase, which adds a marker for proper lysosomal enzyme sorting. It is an autosomal recessive disease with a carrier rate estimated at 1/39 in Saguenay-Lac-St-Jean (Quebec, Canada), which is the highest frequency documented worldwide. To determine if MLII is caused by mutations in the GlcNAcphosphotransferase $\alpha / \beta$ subunits precursor gene, we sequenced GNPTAB exons in 27 parents and four siblings of affected children from the SLSJ region. We also performed a genealogical reconstruction for each parent of affected children to evaluate consanguinity levels as well as the genetic contribution of ancestors; our goal was to identify which parameters could explain the high MLII frequency observed in the SLSJ population. Results: We identified 12 genetic variants from 27 pedigrees. Only one mutation, a frameshift mutation c.3501_3502delTC (p.L1168QfsX5) causing a truncation at amino acid 1168 , has been identified in each MLII carriers. The mutation was not detected in genomic DNA of 50 unrelated controls. Genealogical data show 6 founders ( 3 couples) with a higher probability of having introduced the mutation in the population. The frequency of the mutation was increased as a consequence of this founder effect and of the resulting population structure. Conclusions: According to the present results and the work recently reported in the literature, we suggest that c.3501_3502delTC is a unique allele causing MLII in the SLSJ population. The high carrier rate observed in that population is most likely explained by a founder effect. 


\section{$2.4 \quad$ Introduction}

Mucolipidosis type II (MLII) [MIM252500] or I-cell disease (ICD) is a rare autosomal recessive lysosomal storage disorder caused by a deficiency in the UDP-acetylglucosaminephosphotransferase (GlcNAc-phosphotransferase, EC 2.7.8.15) activity, an enzyme required for the mannose-6-phosphate (M6P) marker tagging to newly synthesized lysosomal enzymes [1]. This initial step is essential for proper intracellular targeting of lysosomal hydrolases to the lysosome [2]. Lysosomal deposits are recognized to cause the spectrum of clinical manifestations described in the literature [3]. These include severe neurocognitive delay, short stature, coarse facial features with hyperplastic gums, dysostosis multiplex, dislocation of the hips, generalized hypotonia and thick and tight skin [3]. Patients rarely survive the first decade of life [4].

GlcNAc-phosphotransferase is a hexameric enzyme made of three distinct subunits $(\alpha 2, \beta 2$, $\gamma 2$ ). It is encoded by two separate genes [5]: GNPTAB, encoding the $\alpha 2 / \beta 2$ subunits and GNPTG, which codes for the $\gamma 2$ subunit. A frame shift mutation in GNPTG was shown to segregate with mucolipidosis of type IIIC [6]. GNPTAB spans $85 \mathrm{~Kb}$ on chromosome 12q23.3 and contains 21 exons [7]. A spectrum of mutations in GNPTAB was recently reported to cause MLII and MLIIIA [7, 8, 9, 10, 11, 12]. The first study of importance on GNPTAB mutations was reported by Tiede and coworkers [7] and identified seven MLII causing mutations in six patients. Another study from Kudo and coworkers (2006) on 18 pedigrees with MLII or MLIIIA identified 15 mutations of which, distinct combinations allowed to define each of these two disorders [12].

The prevalence of the MLII in the world is quite rare. It is estimated at 1/123,457 live birth in Portugal [13], 1/252,525 live birth in Japan [14] and 1/625,000 live birth in Netherland [15]. In the young founder population of the northeastern region of Quebec (SaguenayLac-Saint-Jean (SLSJ)), a high MLII prevalence at birth of 1/6,184 with an estimated carrier rate of $1 / 39$ was found [16]. The aim of the present study was to identify the MLII causal mutation in this SLSJ population. Sequencing of the GNPTAB gene highlighted a unique single mutation in exon 19 that appears to be responsible for the MLII disease in 
this population. With genealogical reconstructions and ancestor genetic contributions calculations, we were then able to characterize these mutation origins and to explain its high frequency observed in the SLSJ population. 


\subsection{Methods}

\subsubsection{Mucolipidosis type II carriers}

The parents of 16 children diagnosed with MLII at the pediatric clinic of SLSJ (Quebec, Canada) were contacted by the Genetic council services of the Chicoutimi Hospital and were asked to participate in the present study. A total of 27 obligatory carrier parents (84\%) and four unaffected proband siblings agreed to donate a blood sample for genomic DNA isolation and to provide family informations for genealogical reconstruction. The Chicoutimi Hospital local ethics committee approved the study and all subjects (or their parents) provided their informed consent.

\subsubsection{Isolation of genomic DNA and sequencing}

Genomic DNA from parents and from siblings was extracted from leukocytes by the standard Qiagen DNA extraction columns (Qiagen, CA) according to the manufacturer's instructions.

PCR primers for all 21 coding exons were designed with the Primer3 software [17]. Table 4 presents the annealing temperatures optimized for each set of primers. PCR reactions were performed in a total volume of $25 \mu \mathrm{L}$ with $100 \mathrm{ng}$ of genomic DNA, 20 pmol of each PCR primers, $1 \mathrm{U}$ of Taq polymerase (Qiagen, CA), $1.5 \mathrm{mM}$ of $\mathrm{MgCl}_{2}$ and $200 \mu \mathrm{M}$ of each dNTP. The PCR conditions were as follows: $15 \mathrm{~min}$ at $94^{\circ} \mathrm{C}, 35$ cycles of $20 \mathrm{sec}$ at $94^{\circ} \mathrm{C}$, $20 \mathrm{sec}$ at $53-63^{\circ} \mathrm{C}$ and $20 \mathrm{sec}$ at $72^{\circ} \mathrm{C}$, and a final extension of $5 \mathrm{~min}$ at $72^{\circ} \mathrm{C}$. Unincorporated dNTPs and primers were removed by filtration through Montage PCR96 filter plates (Millipore, Bedford, MA). Sequencing of filtered PCR products was done with Big Dye Terminator v3.1 (Applied Biosystems, CA) and analyzed on the ABI Prism $3100 \AA$ Genetic Analyzer (Applied Biosystems, CA). Sequences were processed with the Sequencing Analysis version 5.0 software (Applied Biosystems, CA), assembled and analysed with the Phred/Phrap/Consed package $[18,19]$. 
All coding regions were sequenced in 12 parents. Heterozygous variants present in all 12 parents were subsequently sequenced in all other parents and unaffected sibs $(n=31)$. The same variants were also sequenced in DNA from 50 unaffected control individuals selected from the CEPH (Centre d'étude du polymorphisme humain [20]) Utah HapMap samples (derived from US residents with northern and western European ancestry). These samples were provided by the National Institute of General Medical Sciences (NIGMS) Human Genetic Cells Repository at the Coriell Institute for Medical Research (Camdem, NJ).

\subsubsection{Genealogical reconstruction}

Genealogical reconstruction relied on the BALSAC population registry and on the BALSAC-RETRO database that contains linked genealogical information on nearly 375,000 individuals married in Quebec between the beginning of the $17^{\text {th }}$ century and the present day [21]. Genealogy of each of the 27 obligatory carriers was completed as far back as sources allowed for, which was back to the first European settlers in most instances. For the comparison purposes, 27 control individuals were selected in the BALSAC-RETRO database. They were matched to cases according to place and year of marriage of their parents. All ascending genealogies were validated and checked for consistency in order to minimize the occurrence of false links [22].

Descriptive parameters were calculated on both cohorts to ensure they were similar and amenable to comparison of their demogenetic characteristics. These parameters included genealogical links and ancestors counts, completeness index and mean genealogical depth. Genetic structure was analysed using frequency distribution and genetic contribution of ancestors to probands and to controls. The goal was to see if a subset of ancestors with a higher probability of having introduced the mutation in the Quebec population could be identified. Inbreeding coefficients among children of obligate carriers were also measured in order to see if an increased frequency of consanguineous unions among carriers could explain at least in part the diffusion pattern of the mutation. Since the genealogy of both parents is necessary to measure the inbreeding coefficient of their children, these coefficients could be calculated only when both parents accepted to participate to the study 
(22 out of 27 carriers forming 11 couples). To estimate if this frequency was increased, it was compared to the consanguinity coefficients of a set of 11 control couples selected in the BALSAC-RETRO database and matched for date and place of marriage. All genealogical indices were computed as described previously [23, 24]. 


\subsection{Results}

\subsubsection{Mutation identification}

Direct Sequencing of the 21 exons of GNPTAB gene was done on PCR products amplified from genomic DNA. DNA samples were obtained for 31 subjects: 27 parents and 4 siblings of probands. The parents DNA were assumed to have one mutant allele in the GNPTAB gene based on the MLII transmission model (autosomal recessive disorder) [3]. CEPH DNA samples were sequenced as GNPTAB wild-type control for electrophoregram comparison. Sequence analysis led to the identification of 12 mutations that are shown in figure 11. Mutation identification is based on the nomenclature suggested by den Dunnen and Antonarakis $[25,26]$ and complemented with the dbSNP rs number when it is available.

\subsubsection{Mutation analysis}

- The mutations and the genotype frequency observed in the sampled population are listed in Table 5. Among the 12 mutations identified, seven were previously reported in dbSNP [27]. These mutations are located into introns except for one synonymous mutation in exon 13 (rs10778148), which is not expected to have a deleterious effect on the encoded protein. The implication of these seven mutations in MLII was ruled out by the presence of wildtype alleles observed in DNA samples of obligate carriers of MLII causal mutation. The five remaining mutations were investigated considering their location in the gene, their predicted effect on mRNA or encoded protein and their prevalence in the sample. A threenucleotide deletion located in the 5'UTR was identified (c.-41_-39delGGC) in the sequenced samples of MLII probands relatives, seven were heterozygotes for this mutation and four were homozygotes. The CEPH control sample was also homozygote for this deletion and therefore this mutation was not suspected to be a causative mutation of MLII. Some mutations were observed in single individuals, a non-synonymous mutation (p.R46Q), a substitution into intron 2 (IVS2+40A>G) and a substitution in the 3'UTR (c. $4966 \mathrm{~A}>\mathrm{C})$. Although the effects of these mutations on mRNA have not been 
investigated, their low prevalence in proband relative samples prevented their association with MLII phenotype. A mutation located in exon 19 was present in all parents $(n=27)$ as well as in sibling tested $(n=4)(100 \%)$. The electrophoregram showed a two-nucleotide deletion (c.3501_3502delTC) causing a frameshift mutation which led to a premature stop codon (p.L1168QfsX5). All parents were heterozygote regarding this deletion. None of the $50 \mathrm{CEPH}$ control subjects presented the deletion. In addition, this mutation has been reported by Kudo and coworkers [12] as being responsible for a truncated mRNA coding for a protein lacking GlcNAc-phosphotransferase activity. According to the Kudo et al. study [12] and the carrier status of all parents (a typical electrophoregram of heterozygote carrier and wild-type sequence is shown in figure 12), this mutation can cause a deleterious effect of the GNPTAB gene resulting in MLII phenotype in the probands. Thus c.3501_3502delTC is the causal mutation of MLII in the sampled population.

\subsubsection{Genealogical results}

Descriptive parameters are summarised in table 6. For the MLII and control groups respectively, 172,195 and 155,205 genealogical links were identified. However, since many ancestors appear several times in the genealogies, this corresponds to 12,153 and 13,587 distinct ancestors. Genealogical depth is slightly lower for controls with a mean of 10.8 generations instead of 11.1 for carriers. Completeness is also very similar among both groups remaining higher than $80 \%$ until the $11^{\text {th }}$ generation and decreasing rapidly afterwards. Table 3 also indicates that the mean number of appearances of ancestors in the genealogies is slightly higher among carriers (14.2) than among controls (11.4) pointing to a higher level of genetic homogeneity among carriers.

Figure 13 shows inbreeding curves for children with MLII and for controls. In both groups, there is no consanguinity before the $4^{\text {th }}$ generation of ancestry. At this generation, one child with MLII has common ancestors in its maternal and paternal lineages indicating that his parents are second degree cousins. No consanguinity was found in the controls' genealogies before the $7^{\text {th }}$ generation. Mean inbreeding coefficients are higher in the MLII group at all generations starting from the $4^{\text {th }}$ and, at the maximum depth, consanguinity is almost 
double that of controls $(0.0130$ vs 0.0067$)$. The difference between both groups reaches significance only for generations $13(t=2.096 ; p=0.048)$ and $14(t=2.104 ; p=0.047)$ but this could be explained by the small size of the sample.

For each of the 18,612 ancestors found in the genealogies, the number of carriers and controls to which they were related and the genetic contribution to each group were calculated. The goal was to identify ancestors who were most likely to have introduced the mutation on the Quebec territory based on the hypothesis that the MLII mutation was introduced by a single founder (or founder-couple). The 166 ancestors who appeared in each of the 27 carriers' genealogies were identified and the genetic contribution of each of these ancestors to both groups was calculated and compared. Based on our knowledge of the population structure, we consider that potential introducers should have a high frequency among carriers in terms of number of appearances and of genetic contribution and should also be more specific to carriers than to controls for these two characteristics. Based on these criteria, many of these 166 ancestors could have introduced the mutation albeit with highly variable probabilities and on table 7 results are presented for the six ancestors (three couples) who came out as being the most likely candidates.

Couple A married in Côte-de-Beaupré in 1685. Spouses were children or grandchildren of immigrants from the Perche and Aunis regions in France. Thirteen of their children married and 11 of them are found in the carriers' genealogies. Couple $\mathrm{C}$ originated from the region of Perche and married in 1654 in Quebec City. Seven of their children married in the regions of Charlevoix and Côte-de-Beaupré and 5 of them are found in the carriers' genealogies. Couple B married in 1661 in Côte-de-Beaupré. Spouses were also children or grandchildren of immigrants and their ancestors came from the Normandie region in France except for the maternal grandfather of the wife who came from Scotland. Couple B had 14 married children, 11 of which appear in the carriers' genealogies. Most of the married children of these three couples settled in the Côte-de-Beaupré and Charlevoix regions.

The last set of genealogical analyses aimed at estimating the genetic contribution of these three couples to the regional populations of Quebec to see the extent of variability in these 
contributions. Genealogical data used for these calculations came from an ongoing project on the demogenetic characteristics of the regional populations of Quebec [23]. Figure 15 shows the genetic contribution of the 3 couples to 6 regional groupings. In each case, the highest genetic contribution is in the North East grouping which includes the regions of Charlevoix, Saguenay-Lac-St-Jean and Côte-Nord. The neighbouring region of Quebec displays the second highest genetic contribution but it is three times lower than in the North East region. In the four other groupings, the genetic contributions are much lower. 


\subsection{Discussion}

The present study reports on a GNPTAB mutation in 27 MLII obligatory carriers (parents of affected children) and 4 siblings. To date, this is the first time that a single mutation is pointed out to cause MLII in a founder population. GNPTAB mutations associated with MLII were recently reported in several studies, in populations of various origins. Overall, 23 different mutations are known to cause MLII, which are listed in table 8. Of these references, only four mutations (609_612delCAGA, 3249+1G>A, 3501_3502delTC, $3565 \mathrm{C}>\mathrm{T}$ ) were found to be identical in more than one pedigree, while 3501_3502delTC mutation is reaching the highest pedigree frequency. Moreover, 3501_3502delTC is present in different populations, such as Israeli and Palestinian Arab-Muslim, Turkish, Irish as well as French [11].

The 3501_3502delTC mutation was the only one found in all tested carriers from SLSJ population. It is described as a null allele, which means that protein coded (p.L1168QfsX5) do not produce any GlcNAc-phosphotransferase activity [12]. The mutation yields intact $\alpha$ subunits, but truncated $\beta$-subunits and a functional study through transient transfection of L1168QfsX5 plasmid in 293T cells has not shown any increase in GlcNAcphoshotransferase activity [12]. According to that functional study, the presence of a homozygous 3501_3502delTC mutation is sufficient to produce MLII disease.

High inbreeding levels and founder effect are two possible explanations to elevated prevalence of genetic diseases in populations. Both hypotheses have been investigated in SLSJ population using genealogical data. Consanguinity was somewhat higher among cases than controls when we considered many generations of ancestry (remote consanguinity) but close inbreeding (3-4 generations of ancestry) was low and very similar in both groups. A low level of close inbreeding in the SLSJ population was observed in a comparative study of the Quebec regional populations [23]. Moreover, close inbreeding coefficients in the MLII group were similar to levels previously reported for different genetic disorders found in Quebec [28]. However, this study also indicates that remote inbreeding coefficients were most of the time higher in disease groups than in control 
groups. Our data showed the same evidences. Hence, the high MLII frequency found in SLSJ region is not explained by a close inbreeding phenomenon, but rather by a founder effect and the resulting population structure.

European settlement in Quebec started with the arrival of French pioneers at the beginning of the $17^{\text {th }}$ century. Altogether some 10,000 immigrants settled in the St. Lawrence valley between 1608 and the British Conquest of 1759. There was, however, sustained demographic growth due to an important excess of births over deaths, giving rise to a founder population undergoing rapid expansion [29]. During the $19^{\text {th }}$ century, this demographic growth led to land shortage and prompted the opening of new regions to agriculture and settlement [30]. This is the case of the Saguenay-Lac-St-Jean region (pop. 274,779 in 2005) which is located $200 \mathrm{~km}$ north of Quebec City (figure 14). Settlement in this region started around 1840 with the arrival of inhabitants coming first mostly from the nearby Charlevoix region (east of Quebec City) and afterwards from other regions of the Laurentian valley [31]. It is estimated that between 1840 and $1910,75 \%$ of the 30000 immigrants to SLSJ came from Charlevoix. Moreover, the family type of their migration contributed to give them an advantage by facilitating their settlement [32]. For these reasons and because they both share an increased frequency of some otherwise rare inherited disorders, Charlevoix and SLSJ's inhabitants are often considered as belonging to the same genetic pool (see for a review [33, 34]).

The founder effect increases incidence of recessive disorders and decreases non-allelic heterogeneity in monogenic disorders [35]. It is the underlying basis to the high prevalence of SLSJ genetic diseases. It is noteworthy that more than one mutation can cause each disease in SLSJ [33, 36, 37]. Hence, if a disease is the result of multiple mutations, more than one ancestor is involved. This has been reported elsewhere, for different SLSJ genetic diseases [33, 36, 37]. However, all the SLSJ MLII parents were heterozygotes for the same mutation. This indicates that there is either one founder responsible for the introduction of the mutation in the Quebec population or the same mutation appeared fortuitously de novo amongst ancestors. Nonetheless, we suppose more probable the one founder/one gene hypothesis suggesting that one founder introduced the mutation in the population. Along 
with a strong population growth, it has been consistent to explain the high frequency of other SLSJ autosomal recessive disorders [38].

We identified three couples of founders with a higher likelihood of having introduced the MLII mutation in the contemporary SLSJ population. Two of them had ancestors that came from Perche and the other from Normandie. This is in accordance with previous studies, where a strong genetic contribution of Perche immigrants was observed and explained by their earliest settlement in Nouvelle-France [39, 40]. Moreover, the contribution of these ancestors to SLSJ gene pool is homogeneous, as demonstrated by its lack of specificity: disease and control groups are linked to these common founders [40]. It would be interesting to know the French distribution of MLII and whether French MLII subjects share common ancestors, but to our knowledge, no such study has been conducted. Nevertheless, genetic contribution of each of these three couples is greater in the NorthEast grouping and this could explain why there is a higher prevalence of MLII in SLSJ compared with other Quebec regions. However, since these couples also contributed to the gene pool of other regions of Quebec, it does not rule out the presence of the MLII mutation outside the North-East regions. Indeed, some cases have been identified in other regions of Quebec. 


\subsection{Conclusions}

In conclusion, the MLII mutation in SLSJ region is now identified. Indeed, our results show that only one mutation (3501_3502delTC) is present in 100\% (27/27) of MLII obligatory carriers of SLSJ origin and is responsible for MLII in that population. As already reported in the literature, the SLSJ region counts some hereditary disorders with high frequencies of carriers attributed to founder effect and characteristic of its settlement history [40]. These factors also explain the high prevalence of MLII and the identification of only one mutation among all obligate carriers in the present study. Using this information, we can confirm prenatal diagnosis earlier in the pregnancy, and determine carrier status of people of SLSJ ancestry, which is of great importance for genetic counseling, since there is currently no mean to cure MLII. Further analysis would be necessary to determine whether this mutation is also present in other ethnic populations and see if there could be any link between the SLSJ population structure and those populations. 


\subsection{Acknowledgements}

We thank all parents for their enthusiastic participation in this study. The authors would like to thanks Josée Villeneuve and Claude Prévost from the Centre de santé et de services sociaux de Chicoutimi's Genetic council for their valuable help in carrier recruitment. C.Laprise is the chairholder of the Canada Research Chair for genetic determinants in asthma (www.chairs.gc.ca) and director of the genetic thematic of Quebec respiratory network of the FRSQ. This work was supported by the Corporation de recherche et d'action sur les maladies héréditaires (www.coramh.org). 


\subsection{References}

1. Reitman ML, Varki A, Kornfeld S : Fibroblasts from patient with I-cell disease and pseudo-Hurler polydystrophy are deficient in uridine 5'-diphosphate- $\mathrm{N}$ acetylglucosamine:glycoprotein $\mathbf{N}$-acetylglucosaminylphosphotransferase activity. J Clin Invest 1981, 67:1574-1579.

2. Olkkonen VM, Ikonen $\mathrm{E}$ : Genetic defects of intracellular-membrane transport. $N$ Engl J Med 2000, 343:1095-1104.

3. Kornfeld S, Sly WS : I-cell disease and pseudo-Hurler polydystrophy : disorders of lysosomal enzyme phosphorylation and localization. In The metabolic and molecular bases of inherited disease. $8^{\text {th }}$ edition. Edited by Scriver CR, Beaudet AL, Sly WS, Valle D. New York : McGraw-Hill; 2001:3469-3482.

4. Leroy JG, Spranger JW, Feingold M, Opitz JM, Croker AC : I-cell disease : A clinical picture. $J$ Pediat 1971, 79:360-365.

5. Bao M, Booth L, Elmendorf J, Canfield WM : Bovine UDP-N-acetylglucosamine : lysosomal-enzyme- N-acetylglucosamine-1-phosphotransferase: I. Purification and subunit structure. $J$ Biol Chem 1996, 271:31437-31445.

6. Raas-Rothschild A, Cormier-Daire V, Bao M, Genin E, Salomon R, Brewer K, Zeigler M, Mandel H, Toth S, Roe B, Munnich A, Canfield WM : Molecular basis of variant speudo-Hurler polydystrophy (mucolipidosis IIIC). $J$ Clin Invest 2000, 105:673-681.

7. Tiede S, Sortch S, Lübke T, Henrissat B, Bargal R, Raas-Rothschild A, Braulke T : Mucolipidosis II is caused by mutations in GNPTA encoding the $\alpha / \beta$ GleNAc-1phosphotransferase. Nat Med 2005, 11:1109-1112.

8. Kudo M, Bao M, D'Souza A, Ying F, Pan H, Roe BA, Canfield WM : The $\boldsymbol{\alpha}$ - and $\beta$-subunits of the human UDP-N-acetylglucosamine:lysosomal enzyme phosphotransferase are encoded by a single cDNA. $J$ Biol Chem 2005, 280:36141-36149.

9. Paik KH, Song SM, Ki CS, Yu H-W, K, JS, Min KH, Chang SH, Yoo EJ, Lee IJ, Kwan EK, Han SJ, Jin D-K : Identification of mutations in the GNPTA (MGC4170) gene coding for GleNAc-phosphotransferase $\alpha / \beta$ subunits in Korean patients with mucolipidosis type II or type IIIA. Hum Mutat 2005, 26:308-314. 
10. Tiede S, Muschol N, Reutter G, Cantz M, Ullrich K, Braulke T : Missense mutations in $\mathbf{N}$-acetylglucosamine-1-phosphotransferase alpha/beta subunit gene in a patient with mucolipidosis III and a mild clinical phenotype. $\mathrm{Am} J$ Med Genet A 2005, 137:235-240.

11. Bargal R, Zeigler M, Abu-Libdeh B, Mandel H, Ben Neriah Z, Stewart F, Nursel E, Hindi T, Merrer ML, Bach G, Raas-Rothschild A : When mucolipidosis III meets mucolipidosis II : GNPTA gene mutations in 24 patients. Mol Genet Metab 2006, 88:359-363.

12. Kudo M, Brem MS, Canfield WM : Mucolipidosis II (I-Cell Disease) and mucolipidosis IIIA (Classical Pseudo-Hurler Polydystrophy) are caused by mutations in the GleNAc-phosphotransferase $\alpha / \beta$-subunits precursor gene. $\mathrm{Am}$ $J$ Hum Genet 2006, 78:451-463.

13. Pinto R, Caseiro C, Lemos M, Lopes L, Fontes A, Ribeiro H, Pinto E, Silva E, Rocha S, Marcao A, Ribeiro I, Lacerda L, Ribeiro G, Amaral O, Sa Miranda MC : Prevalence of lysosomal storage disease in Portugal. Eur J Hum Genet 2004, 12:87-92.

14. Okada S, Owada M, Sakiyama T, Yutaka T, Ogawa M : I-cell disease : clinical studies of 21 japanese cases. Clin genet 1985, 28:207-215.

15. Poorthuis BJ, Wevers RA, Kleijer WJ, Groener JEM, De Jong JGN, Van Weely S, Niezen-Koning $\mathrm{K}$, Van Diggelen OP : The frequency of lysosomal storage diseases in The Netherlands. Hum Genet 1999, $105: 151-156$.

16. De Braekeleer M : Hereditary disorders in Saguenay-Lac-St-Jean (Quebec, Canada). Hum Hered 1991, 41:141-146.

17. Steve Rozen and Helen J. Skaletsky Primer3 on the WWW for general users and for biologist programmers. In: Krawetz S, Misener S (eds) Bioinformatics Methods and Protocols: Methods in Molecular Biology. Humana Press, Totowa, NJ, 2000, pp 365-386

18. Ewing B, Hilier L, Wendl MC, Green P: Base-calling of automated sequencer traces using phred. I. Accuracy assessment. Genome Res 1998, 8:175-185.

19. Gordon D, Abajian C, Green P : Consed: a graphical tool for sequence finishing. Genome Res 1998, 8:195-202.

20. CEPH [http://www.cephb.fr]

21. Projet BALSAC : Annual report. Chicoutimi ; 2005. [http://www.uqac.ca/balsac]

22. Bouchard $G$ : The processing of ambiguous links in computerized family reconstruction. Hist Methods 1986, 19:9-19. 
23. Vezina $H$, Tremblay $M$, Houde $L$ : Mesures de l'apparentement biologique au Saguenay-Lac-St-Jean (Québec, Canada) à partir de reconstitutions généalogiques. Ann Demogr Hist 2005, 2:67-84.

24. Lavoie EM, Tremblay M, Houde L, Vézina H: Demogenetic study of three populations within a region with strong founder effects. Community Genet 2005, 8:152-160.

25. Den Dunnen JT, Antonarakis $S$ : Mutation nomenclature extensions and suggestions to describe complex mutations: a discussion. Hum Mutat 2000, 15:712.

26. Human genome variation society [http://www.hgvs.org/mutnomen/recs-prot.html]

27. Database of single nucleotide polymorphism [http:/www.ncbi.nlm.nih.gov]

28. Vézina $H$ : Démographie génétique et maladies héréditaires au Québec : l'état des recherches. Cah Québ Démogr 1996, 25 :293-322.

29. Legare J, Charbonneau H, Desjardins B, Denis H : The Population of the St. Lawrence Valley, 1608-1760. In A Population History of North America. Edited by Haines M, Steckel R. Cambridge : Cambridge University Press; 2000:99-142.

30. Bouchard G, Tremblay $M$ : Le peuplement francophone au Canada : survol historique et géographique (17ième-20ième siècle). In Français de France et Français du Canada. Les parlers de l'Ouest de la France, du Québec et de l'Acadie. Edited by Centre d'études linguistiques Jacques Goudet. Lyon : Université Lyon III, Jean Moulin; 1995:309-343.

31. Pouyez C, Lavoie Y : Les Saguenayens : Introduction à l'histoire des populations du SaguenayXVIe-XXe siècles. Quebec : Presses de l'Université du Québec; 1983.

32. Roy R, Bouchard G, Declos M : La première generation de Saguenayens : provenance, apparentement, enracinement. Cah québ démo 1988, 17:113-134.

33. Scriver CR : Human genetics : Lessons from Quebec populations. Annu Rev Genomics Hum Genet 2001, 2:69-101.

34. Laberge AM, Michaud J, Richter A, Lemyre E, Lambert M, Brais B, Mitchell GA : Population history and its impact on medical genetics in Quebec. Clin Genet 2005, 68:287-301.

35. Sheffield VC, Stone EM, Carmi R : Use of isolated inbred human population for identification of disease genes. Trends Genet 1998, 14:391-396. 
36. Richter A, Rioux JD, Bouchard JP, Mercier J, Mathieu J, Ge B, Poirier J, Julien D, Gyapay G, Weissenbach J, Hudson TJ, Melançon SB, Morgan K : Location score and haplotype analyses of the locus for autosomal recessive spastic ataxia of Charlevoix-Saguenay, in chromosome region 13q11. Am J Hum Genet 1999, 64:768-775.

37. Yotova V, Labuda D, Zietkiewick E, Gehl D, Lovell A, Lefebvre JF, Bourgeois S, Lemieux-Blanchard E, Labuda M, Vezina H, Houde L, Tremblay M, Toupance B, Heyer E, Hudson TJ, Laberge C : Anatomy of a founder effect : myotonic dystrophy in Northeastern Quebec. Hum Genet 2005, 117:177-187.

38. Heyer $\mathrm{H}$ : One founder/one gene hypothesis in a new expanding population : Saguenay (Quebec, Canada). Hum Biol 1999, 71:99-109.

39. De Braekeleer M, Dao TN : Hereditary disorders in the French canadian population of Quebec. I. In search of founders. Hum Biol 1994, 66:205-223.

40. Heyer E, Tremblay M, Desjardins B : Seventeenth-century European origins of hereditary diseases in the Saguenay population (Quebec, Canada). Hum Biol 1997, 69:209-225.

41. Tiede S, Cantz M, Spranger J, Braulke $T$ : Missense mutation in the $\mathbf{N}$ acetylglucosamine-1-phophostransferase gene (GNPTA) in a patient with mucolipidosis II induces changes in the size and cellular distribution of GNPTG. Hum mutat 2006, 27:830-831. 


\subsection{Figures}

Figure 11 - Location of mutations identified in GNPTAB gene by sequencing of probands relatives DNA. Mutations are identified according to their position in GNPTAB cDNA or their rs number, mutations changing the protein sequence are identified below when it applies. Allele frequency relative to number of individual sequenced is shown in parentheses.

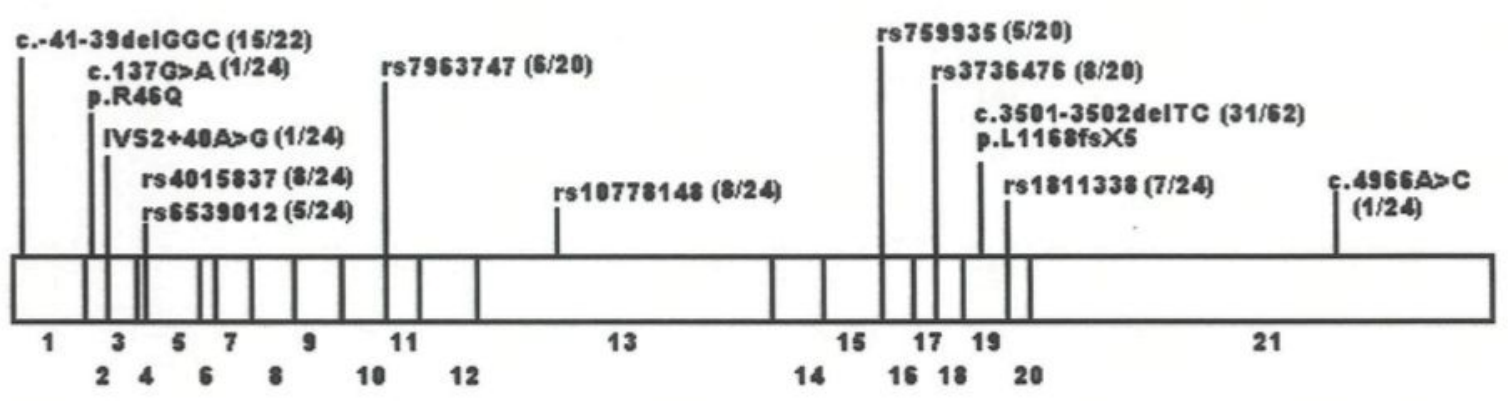

Figure 12 - Part of electrophoregram of GNPTAB exon 19.

The electrophoregrams of a MLII proband (above) and a control (below) showing a twonucleotide deletion causing a frameshift mutation responsible for MLII.

ATGCTCAG ACAGTG A AG GCTGTTCNCGGGNANNTNTNAGACNCNGTGNNC

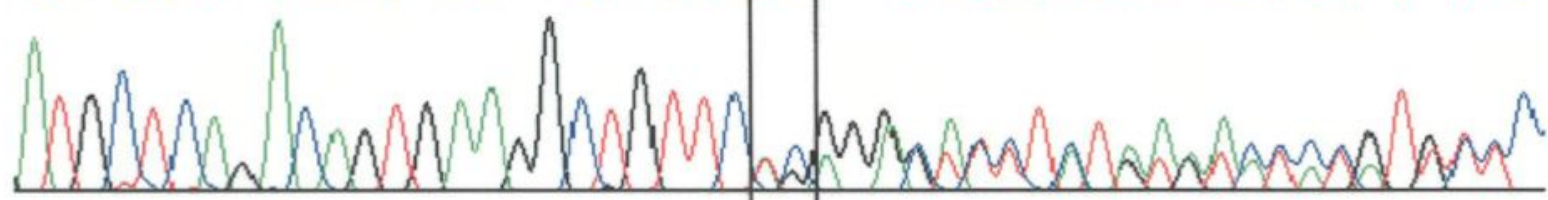

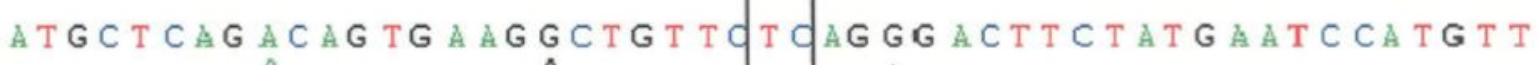

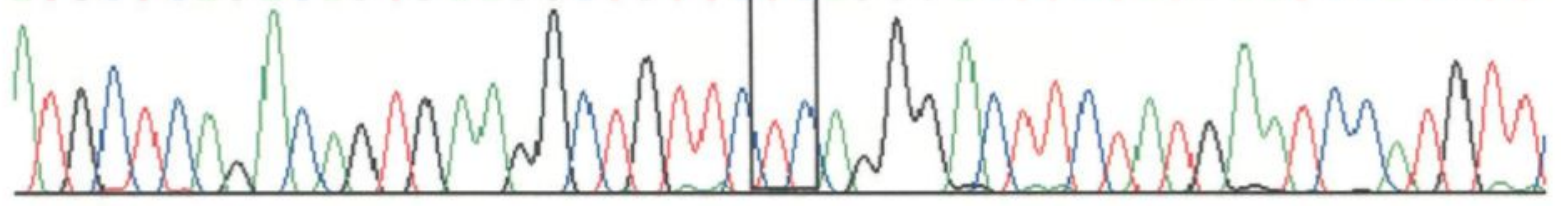


Figure 13 - Mean inbreeding coefficients for subjects with mucolipidosis II and controls.

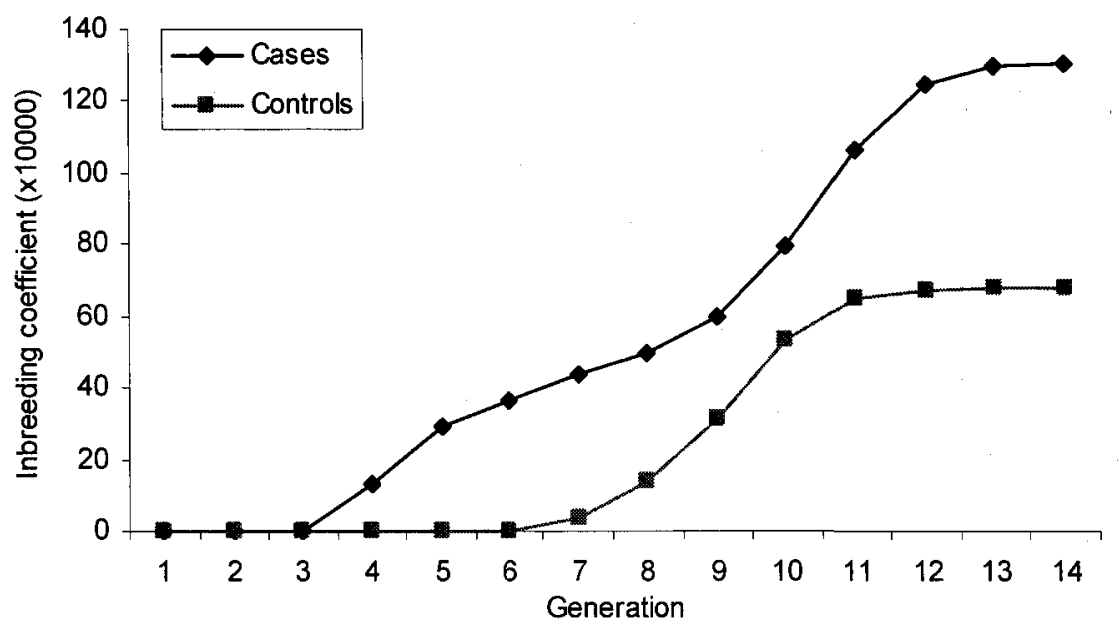

Figure 14 - Localization of Saguenay-Lac-St-Jean.

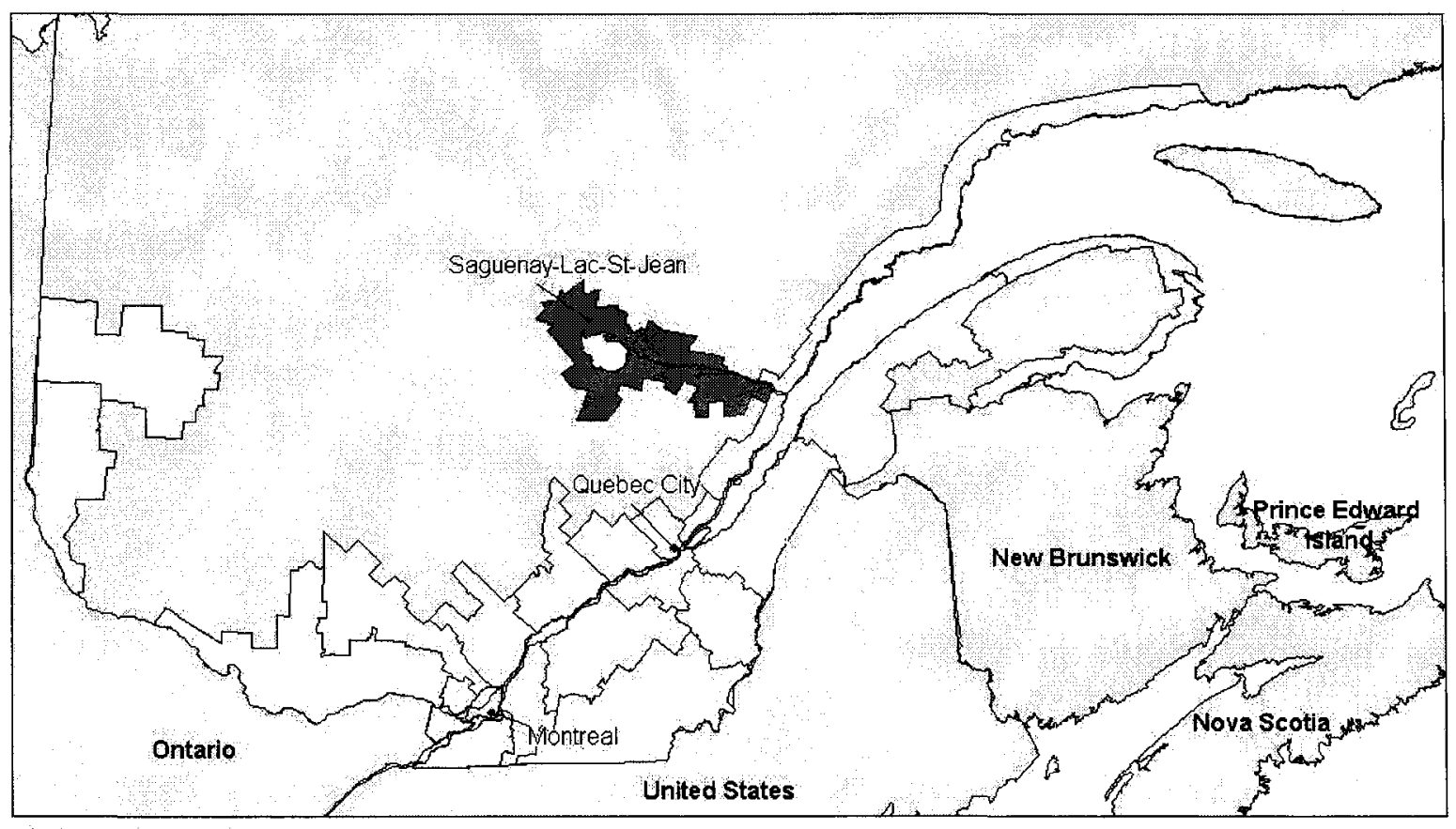

Source: GRIG, UQAC and CIEQG-Laval 
Figure 15 - Genetic contribution of potential introducers of the mucolipidosis II mutation to regional populations of Quebec.

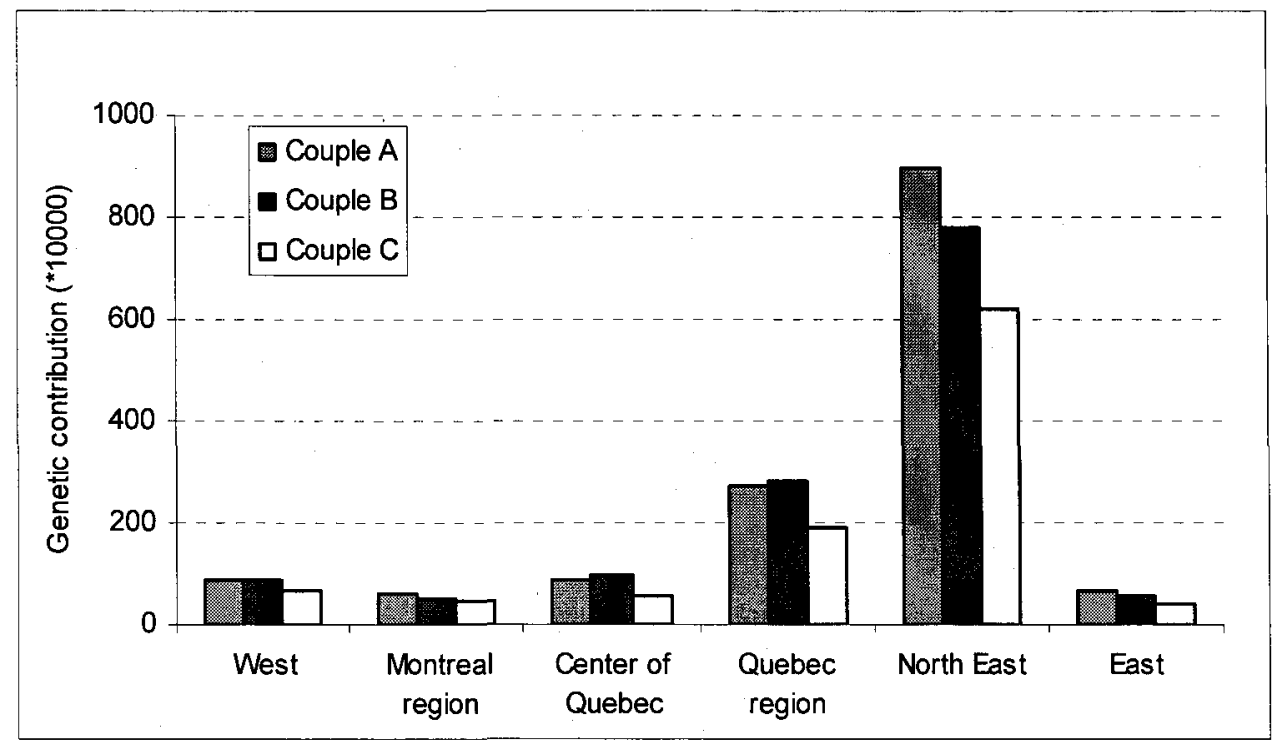




\section{Tables}

Table 4 - Oligonucleotide primers sequences and annealing temperature used for PCR of the 21 exons of the GNPTA gene.

\begin{tabular}{|c|c|c|c|}
\hline Exon & Forward primer & Reverse primer & $\begin{array}{l}\text { Annea- } \\
\text { ling temp } \\
\left({ }^{\circ} \mathrm{C}\right)\end{array}$ \\
\hline $\begin{array}{l}1+5^{2} \\
\text { UTR }\end{array}$ & $5^{2}$-GTCGCCGGAGCTGCAATG-3' & $\begin{array}{l}5^{2} \text { - } \\
\text { CATACTGTATCGGGGCATCG-32 }\end{array}$ & 58 \\
\hline 2 & $5^{3}$-GACCTGGGGAGACAGAAAATG-3 & $\begin{array}{l}5^{2}- \\
\text { CACACAGTTGCCCTGAAACA-3 }\end{array}$ & 58 \\
\hline 3 & 5'-GTCTCACTCTGTCACCCAAG-3' & 5'-CTCTACTTCACCCACGAACA-3' & 58 \\
\hline 4 & 5'-CTCTAACCCTCCCCAGTGC-3' & 5'-GCCCACAGACTTGTTTCCAT-3' & 58 \\
\hline 5 & $5^{\prime}$-CCAGGTATGTTCTGCCCAAA-3' & 5'-TGCCTCCTTCCTAATCTGTCC-3' & 61 \\
\hline 6 & $5^{2}$-CCACTCAGGAAAGCCAAATC-3' & $5^{\prime}$-CAGCAGCACCCAATGAACT-3' & 60 \\
\hline 7 & $\begin{array}{l}5^{2}- \\
\text { CTGGTTACTACTTGGATGGGAGAC-3' }\end{array}$ & 5'-TGGAGGGGCTACTTGGTATG-3 $^{\prime}$ & 60 \\
\hline 8 & $5^{3}$-CTTTCCTTCTGCCCGTCTG-3 ${ }^{3}$ & 5'-CGGAGGTTGAGGTGAGCA-3' & 61 \\
\hline $9-10$ & $5^{\prime}$-GACAGGGGTCTCACTATGCTTC-3' & $\begin{array}{l}5^{\prime}- \\
\text { GGACAAAGAGGAGGAGGTATGAC-3’ }\end{array}$ & 60 \\
\hline 11 & 5'-ACTCCTGGCCTCAAGCACT-3' & $5^{\prime}$-CTTCCCACCAGCTTTGACAT-3' & 61 \\
\hline 12 & 5'-GCAAGGCTGGTAAAGGGATA-3' & 5'-TGTTTTCGTGCTCCTCCA-3' & 56 \\
\hline 13 & $\begin{array}{l}\text { i) 5'-ATGCCACTTCCCACTCTCC-3' } \\
\text { ii) } 5^{2} \text {-GGAGCCACCAAACTGTCATT-3' }\end{array}$ & $\begin{array}{l}\text { i) } 5^{3} \text {-CTTCCAAAAGACGCCCAGT-3' } \\
\text { ii) 5'-TGCCTACTTCAGCAGCACAT-3' }\end{array}$ & $\begin{array}{l}62 \\
60 \\
\end{array}$ \\
\hline 14 & 5'-CCAGTGTTCGGATTTCTCTG-3' & $5^{2}$-TCCAGTTGAGTCCTGCTAAGTC-3' & 56 \\
\hline 15 & $\begin{array}{l}5^{2}- \\
\text { CTAGCCACACCTGAAGTCCTAGA-3 }\end{array}$ & $\begin{array}{l}5^{3}- \\
\text { CATCTCTGCAAATGTTAGATACG G-3' }\end{array}$ & 56 \\
\hline 16 & $5^{\prime}$-TAATCACCCACTGCCCCTAC-3' & $5^{\prime}$-GGAAAAGAGCCAGACCATACC-3' & 61 \\
\hline $17-18$ & $\begin{array}{l}5^{2}- \\
\text { GCAACTCCTATCTCTCACTCAACC-3' }\end{array}$ & $5^{2}$-GACTATTTGTGGGTCGGGAAT-3² & 56 \\
\hline 19 & 5'-ACACCTGTAATCCCAGCACTTT-3' & 5'-TTCCCCCAGAGAATCATATCAG-3' & 56 \\
\hline 20 & $5^{\prime}$-AGGAAGCGTGAAAGAGAGGA-3' & $5^{\prime}$-GGCAAGTCATCAGTCAGCAT-3' & 58 \\
\hline $\begin{array}{l}21- \\
\text { 3'UTR }\end{array}$ & $\begin{array}{l}\text { i) } 5^{2} \text { - } \\
\text { CAGCACAGAACCTGATACACAG-3' } \\
\text { ii) } 5^{2} \text {-CCTGGGCAACAGAGAGAGAC-3 } \\
\text { iii) } 5^{3} \text {-GCTGGCATAGGCTTCTCCTA-3 }\end{array}$ & $\begin{array}{l}\text { i) 5'-GTACAAAAACTGCCCACCAG-3' } \\
\text { ii) 5'-GCTCATGGACCTGTCATCCT-3' } \\
\text { iii) 5'-CCTGCCTCCTCCTACAGATG-3' }\end{array}$ & $\begin{array}{l}60 \\
60 \\
55\end{array}$ \\
\hline
\end{tabular}


Table 5 - SLSJ mutations identified in GNPTAB gene.

\begin{tabular}{|c|c|c|c|c|}
\hline Mutation $^{1}$ & Location & $\begin{array}{c}\text { Predicted effect } \\
\text { on mRNA and } \\
\text { protein }^{2}\end{array}$ & $\begin{array}{l}\text { Number of } \\
\text { relatives } \\
\text { sequenced }^{3} \\
\end{array}$ & $\begin{array}{l}\text { Genotype } \\
\text { distribution }\end{array}$ \\
\hline c. $-41-39 \mathrm{delGGC}$ & $5^{\prime}$ UTR & ND & 11 & 7 hetero, 4 homo \\
\hline c. $137 \mathrm{G}>\mathrm{A}$ & Exon 2 & \begin{tabular}{|l|} 
Non-synonymous \\
mutation p.R46Q
\end{tabular} & 12 & $11 \mathrm{wt}, 1$ hetero \\
\hline IVS $2+40 \mathrm{~A}>\mathrm{G}$ & intron 2 & ND & 12 & $11 \mathrm{wt}, 1$ hetero \\
\hline $\begin{array}{l}\text { IVS4ins100_102CA } \\
(\mathrm{rs} 4015837)\end{array}$ & intron 4 & ND & 12 & $4 \mathrm{wt}, 8$ hetero \\
\hline $\begin{array}{l}\text { IVS4-233T>C } \\
\text { (rs6539012) }\end{array}$ & intron 4 & ND & 12 & $7 \mathrm{wt}, 5$ hetero \\
\hline $\begin{array}{c}\text { IVS10-167C }>\text { T } \\
(\mathrm{rs} 7963747)\end{array}$ & intron 10 & ND & 10 & $4 \mathrm{wt}, 6$ hetero \\
\hline $\begin{array}{c}\mathrm{c} .1932 \mathrm{G}>\mathrm{A} \\
(\mathrm{rs} 10778148)\end{array}$ & exon 13 & $\begin{array}{l}\text { Synonymous } \\
\text { mutation }\end{array}$ & 12 & 4 wt, 8 hetero \\
\hline $\begin{array}{l}\text { IVS15+5T }>C \\
(\text { rs759935) }\end{array}$ & intron 15 & ND & 10 & $5 \mathrm{wt}, 5$ hetero \\
\hline $\begin{array}{l}\text { IVS17-25G }>A \\
(\mathrm{rs} 3736476)\end{array}$ & intron 17 & ND & 10 & $2 \mathrm{wt}, 8$ hetero \\
\hline c.3501_3502delTC & exon 19 & $\begin{array}{c}\text { Frameshift, } \\
\text { premature stop } \\
\text { codon } \\
\text { p.L1168QfsX5 }\end{array}$ & 31 & 31 hetero \\
\hline $\begin{array}{c}\text { IVS19-344G }>\mathrm{T} \\
(\mathrm{rs} 1811338)\end{array}$ & intron 19 & ND & 12 & $5 \mathrm{wt}, 7$ hetero \\
\hline c. $4966 \mathrm{~A}>\mathrm{C}$ & 3' UTR & ND & 12 & $11 \mathrm{wt}, 1$ hetero \\
\hline
\end{tabular}

${ }^{1}$ Identified relative to the first nucleotide in the ATG start codon of cDNA as nucleotide +1 (Genbank accession number NM_024312). Intron mutation identification is described in accordance with ensembl v37 accession number ENST00000299314

${ }^{2} \mathrm{ND}=$ not determined

${ }^{3}$ including parents and not affected siblings 
Table 6 - Descriptive parameters of the genealogies.

\begin{tabular}{|l|c|c|}
\hline & Cases & Controls \\
\hline Number of genealogies & 27 & 27 \\
\hline Total ancestral links & 172,195 & 155,205 \\
\hline Distinct ancestors & 12,153 & 13,587 \\
\hline Mean number of occurrences & 14,2 & 11,4 \\
\hline Mean genealogical depth & 11,1 & 10,8 \\
\hline Maximum genealogical depth & 17 & 17 \\
\hline
\end{tabular}

Table 7 - Description of the three couples of ancestors with the highest probability of having introduced the mucolipidosis mutation in the French Canadian population.

\begin{tabular}{|c|c|c|c|c|c|}
\hline \multirow{2}{*}{} & \multicolumn{2}{|c|}{$\begin{array}{c}\text { Nb of genealogies } \\
\text { where couples appear }\end{array}$} & \multicolumn{3}{c|}{ Genetic Contribution $\left(\times 10^{4}\right)$} \\
\cline { 2 - 6 } Couples & $\begin{array}{c}\text { Among } \\
\text { carriers }\end{array}$ & $\begin{array}{c}\text { Among } \\
\text { controls }\end{array}$ & To carriers & To controls & Difference (\%) \\
\cline { 4 - 6 } & 27 & 27 & 9169,92 & 7333,98 & $(\mathrm{~b})$ \\
\hline A & 27 & 27 & 8132,32 & 6872,56 & 15,49 \\
\hline B & 27 & 27 & 6369,63 & 5357,67 & 15,89 \\
\hline C & 27 & &
\end{tabular}


Table 8 - Location of documented GNPTAB mutations causing MLII.

\begin{tabular}{|c|c|c|c|c|}
\hline $\begin{array}{l}\text { Intron } \\
\text { /Exon }\end{array}$ & cDNA locus & $\begin{array}{c}\text { Protein } \\
\text { consequence }\end{array}$ & $\begin{array}{c}\text { Number of } \\
\text { pedigree affected }\end{array}$ & Reference \\
\hline I1 & $118-2 A>G$ & $\begin{array}{l}\text { IVS1-2A>G } \\
{[\text { R68fs X8] }}\end{array}$ & 1 & 11 \\
\hline $\mathrm{E} 3$ & $310 \mathrm{C}>\mathrm{T}$ & Q104X & 1 & 9 \\
\hline E6 & 609_612delCAGA & T206YfsX6 & 2 & 12 \\
\hline E8 & 848delA & T284LfsX5 & 1 & 12 \\
\hline E12 & 1580delC & C528VfsX19 & 1 & 12 \\
\hline E13 & 1625 insC & E542AfsX4 & 1 & 7 \\
\hline E13 & 1738_1741tripTATA & S581IfsX8 & 1 & 12 \\
\hline E13 & $2188 \mathrm{~T}>\mathrm{AAA}$ & L730KfsX8 & 1 & 12 \\
\hline E13 & $2533 \mathrm{C}>\mathrm{T}$ & Q845X & $\begin{array}{l}1 \\
1 \\
\end{array}$ & $\begin{array}{c}7 \\
11 \\
\end{array}$ \\
\hline E13 & $2681 \mathrm{G}>\mathrm{A}$ & W894X & 1 & 9 \\
\hline E15 & 2916ins T & $\begin{array}{l}\text { Skipping exon } 15 \\
+[\mathrm{M} 9721 \mathrm{fs} X 3] \\
\end{array}$ & 1 & 11 \\
\hline E16 & 3145 insC & G1049RfsX16 & 1 & 7 \\
\hline E16 & $3173 \mathrm{C}>\mathrm{G}$ & $\mathrm{S} 1058 \mathrm{X}$ & 1 & 9 \\
\hline E16 & 3231_3234dupCTAC & Y1079LfsX3 & 1 & 12 \\
\hline I17 & $3249+1 \mathrm{G}>\mathrm{A}$ & $\begin{array}{l}\text { Skipping exon } 17 \\
+[\mathrm{R} 1112 \mathrm{fs} X 2]\end{array}$ & $\begin{array}{l}1 \\
1 \\
1 \\
\end{array}$ & $\begin{array}{c}11 \\
7 \\
12 \\
\end{array}$ \\
\hline E17 & 3252 delA & P1085RfsX6 & 1 & 7 \\
\hline E18 & $3434+1 \mathrm{G}>\mathrm{A}$ & Skipping exon 18 & 5 & 11 \\
\hline E19 & 3474_3475delTA & H1158QfsX15 & 1 & 9 \\
\hline E19 & 3501_3502delTC & L1168QfsX5 & $\begin{array}{c}8 \\
11 \\
\end{array}$ & $\begin{array}{l}12 \\
11 \\
\end{array}$ \\
\hline E19 & $3565 \mathrm{C}>\mathrm{T}$ & R1189X & 2 & 9 \\
\hline E19 & 3566insA & R1189QfsX9 & 1 & 7 \\
\hline E20 & $3613 \mathrm{C}>\mathrm{T}$ & $\mathrm{R} 1205 \mathrm{X}$ & $\begin{array}{l}1 \\
1 \\
\end{array}$ & $\begin{array}{c}7 \\
11 \\
\end{array}$ \\
\hline E21 & $3707 \mathrm{~A}>\mathrm{T}$ & $\mathrm{K} 1236 \mathrm{M}$ & 1 & 41 \\
\hline
\end{tabular}




\section{CHAPITRE 3}

\section{DISCUSSION}

Ce chapitre discute de manière plus détaillée les résultats obtenus et présenté au chapitre précédent. Il traite des résultats moléculaires et généalogiques issus des recherches menées au SLSJ sur la MLII.

\subsection{Analyse moléculaire}

\subsubsection{La mutation responsable de la MLII au SLSJ}

Une seule mutation dans le gène GNPTAB qui code la GlcNAcPT et susceptible de pouvoir causer la MLII a été découverte dans notre cohorte de porteurs obligatoires du SLSJ. Cette mutation, 3501_3502delTC, est présente à l'état hétérozygote chez tous les parents ayant eu un enfant atteint $(n=27)$ et tous les frères/sœurs des sujets atteints de MLII évalués $(\mathrm{n}=4)$. Puisque les échantillons des patients atteints de la MLII étaient inaccessibles, il n'a pas été possible de confirmer qu'il s'agissait bien de la mutation causale. Néanmoin, puisque tous les parents ont une seule et même mutation, il a été déterminé que cette mutation est vraisemblablement celle causant la MLII chez les sujets atteints du SLSJ.

Plusieurs mutations associées à la MLII dans le gène GNPTAB ont été publiées dans des différentes populations. Des 23 différentes mutations connues, seulement quatre mutations (609_612delCAGA, IVS17+1G $>$ A, 3501_3502delTC, 3565C $>$ T) sont présentes dans plus d'une généalogie et la mutation 3501_3502delTC est la plus fréquente retrouvée dans la littérature. De plus, cette dernière est présente dans différentes populations, comme la 
population israélienne, palestinienne (arabe musulmane), turque, irlandaise et française (Bargal et al, 2006). Bien que plusieurs mutations aient été décrites dans chacune des populations, jusqu'à présent, la littérature ne rapporte aucun cas de MLII dans une population dite à effet fondateur. Ainsi, le SLSJ constitue une exception par l'unique mutation retrouvée au sein de sa population à effet fondateur.

\subsubsection{Les études fonctionnelles}

La mutation 3501_3502delTC cause un décalage de lecture (à l'acide aminé 1168) et mène à une protéine tronquée au niveau de l'acide aminé 1172. La traduction de l'ARNm muté produit une sous-unité $\alpha$ tronquée et l'absence de la sous-unité $\beta$ (Kudo et al, 2006). Dans la littérature existante, deux études ont utilisé une même lignée cellulaire issue d'un individu ayant la MLII et homozygote quant à la mutation 3501_3502delTC (individu GM01586, provenant du Coriell Institute for Medical Research (Camden, New Jersey)).

L'étude fonctionnelle menée par Kudo et ses collaborateurs démontre que la transfection d'un plasmide L1168QfsX5 dans une cellule 293T (lignée de cellules rénales embryonnaires humaines) n'entraine aucune augmentation de l'activité de la GlcNAcPT (Kudo et al, 2006). Cela signifie donc que la GlcNAcPT codée (p.1168QfsX5) ne produit aucune activité chez les porteurs homozygotes de la mutation. Pour cette raison, la mutation 3501_3502delTC est décrite comme un allèle nul (Kudo et al, 2006).

Étudiant aussi l'individu GM01586, Ho et ses collaborateurs ont effectué des PCR en temps réel afin de mesurer la quantité relative d'ADNc des fragments $\alpha / \beta$ ou $\gamma$ du GNPTAB présent dans les fibroblastes. L'examen a révélé que l'expression de la sous-unité $\alpha / \beta$ dans une lignée cellulaire humaine (atteint de MLII) était réduite de $80 \%$, alors qu'elle était réduite d'environ $75 \%$ dans le cas de la sous-unité $\gamma$ (Ho et al, 2006). Ensuite, ils ont évalué le rôle des sous-unités $\alpha / \beta$ et $\gamma$ en supprimant chaque sous-unité au moyen d'ARN interférents (ARNi) dans des fibroblastes normaux de souris. Des vacuoles cytoplasmiques typiques de la MLII étaient observées dans les fibroblastes de souris transfectés avec des ARN interférents contre les sous-unités $\alpha, \beta$ et $\gamma$. Cependant, peu importe le niveau 
d'expression des sous-unités $\alpha / \beta$, la suppression de la sous-unité $\gamma$ empêchait la formation de vacuoles anormales et l'augmentation d'une enzyme lysosomale ( $\beta$-galactosidase) dans l'espace extra-cellulaire d'une culture de fibroblastes de souris (Ho et al, 2006). Cette étude a conclu qu'une balance dans l'expression des sous-unités $\alpha / \beta$ et $\gamma$ joue un rôle important dans la génèse des vacuoles observées chez les sujets atteints de MLII.

Cette absence d'activité de la GlcNAcPT causée par la mutation L1168QfsX5 est donc compatible avec l'absence d'activité de la GlcNAcPT détectée dans les fibroblastes des patients ayant la MLII au SLSJ. De plus, cette mutation affecte la sous-unité $\beta$ et semble être suffisante dans la génèse des vacuoles cytoplasmiques chez les sujets atteints de MLII. Par conséquent, la présence de la mutation 3501_3502delTC à l'état homozygote, telle qu'observée au SLSJ, est suffisante pour expliquer la MLII.

\subsection{Analyse généalogique}

L'existence d'une seule mutation causale pour la MLII au SLSJ peut s'expliquer par l'analyse généalogique de la cohorte étudiée. Il s'agit d'étudier les généalogies et la démographie de la région afin de mieux comprendre comment un allèle a pu apparaître au sein de la population et présenter une prévalence élevée dans la population actuelle. Il faut donc étudier certains phénomènes démogénétiques, telle la dérive génétique, qui se rencontre dans les petites populations, où il $\mathrm{y}$ a en quelque sorte un hasard d'échantillonnage, ce qui mène à des fluctuations aléatoires des fréquences alléliques d'une génération à l'autre et éloigne la population de l'équilibre d'Hardy-Weinberg (Jobling et al, 2004). Un autre phénomène est celui de l'effet fondateur, une forme de dérive génétique, où une nouvelle colonie émerge d'une population mère. La petite taille de cette colonie et un manque quant à la panmixie garantissent pratiquement que la fréquence allélique ne sera pas identique à celle de la population mère. Par exemple, l'effet fondateur rencontré lors de la colonisation d'un territoire isolé causera la fixation ou non de certains variants génétiques ainsi qu'une diversité limitée quant au bassin génique. Il en est de même s'il y a isolation de la population, peu importe qu'elle soit de nature géographique, linguistique ou religieuse, car cela restreint l'échange de variants génétiques avec d'autres populations, ce 
qui entraîne encore une fois une réduction de la variabilité génétique (homogénéisation) (Pardo, 2005).

\subsubsection{Analyse généalogique descriptive}

Dans ce projet, nous avons étudié deux groupes de généalogies, soit 27 parents hétérozygotes pour la MLII et 27 témoins recrutés dans la base de données (BALSAC) par rapport à leur date et lieu de mariage. L'analyse généalogique descriptive a permis de constater que le nombre d'ancêtres distincts retracés était moins élevé chez le groupe MLII que chez les témoins. La profondeur généalogique était la même pour les deux groupes. Par contre, le nombre d'ancêtres retrouvés du groupe MLII était supérieur au groupe témoin, ce qui démontre qu'il y aurait une plus grande homogénéité dans le groupe MLII. Ces résultats sont semblables en termes de concentration des ancêtres (le nombre d'ancêtres retrouvés divisé par le nombre d'ancêtres distincts), d'occurrence des ancêtres et de profondeur généalogique moyenne à ceux obtenus dans d'autres cohortes du SLSJ (Ouhna, 2001; Lambert, 2002).

\subsubsection{Consanguinité}

En plus de faire l'analyse généalogique, nous avons vérifié l'existence ou non d'une consanguinité élevée parmi les individus de notre cochorte MLII. La forte prévalence de maladies génétiques dans une population déterminée peut être causée par l'effet fondateur, par un fort coefficient de consanguinité mais aussi par une combinaison de ces deux paramètres. Nous avons donc calculé les coefficients de consanguinité de nos cohortes MLII et témoin et les résultats montrent que la consanguinité était nulle pour les trois premières générations, ce qui est comparable à d'autres études (Lambert, 2002; Lavoie, 2003; Tremblay, 2004; Vézina et al, 2005b; Yotova et al, 2005). Par contre, contrairement à nos résultats, une étude portant sur la consanguinité d'une cohorte regroupant 17 maladies autosomales récessives du SLSJ rapporte que la quasi-majorité des proposants pour ces 17 maladies ont un coefficient de consanguinité non-nul (Gauthier, 1992). De plus, dans cette même étude, un groupe composé de 11 individus atteints de MLII possède un coefficient de 
consanguinité non-nul. Cela résulte probablement de la présence d'un seul individu de leur groupe issu d'une union de type 3:3 (cousins au second degré ou petits cousins) qui fait augmenter la valeur du coefficient de consanguinité du groupe entier. Vraisemblablement, cet individu est absent de notre cohorte MLII, puisque nous avons obtenu un coefficient de consanguinité nul.

Les données receuillies ici suggèrent qu'au SLSJ, l'effet fondateur serait l'explication la plus probable à la fréquence observée de la MLII au SLSJ, puisque les coefficients de consanguinité proche évalués y sont très faibles. La consanguinité proche (jusqu'à 5 ou 6 générations) de notre cohorte du SLSJ a des valeurs comparables à celle des autres régions du Québec, ce qui constitue une confirmation des nombreuses recherches faites au SLSJ : la population de cette région ne montre pas plus consanguinité proche que le reste du Québec (Vézina et al, 2005b). D'ailleurs, les coefficients obtenus dans cette région sont très bas dans la population actuelle, ainsi que dans les générations passées, ce qui constitue une observation comparable à celle d'autres régions du Québec, telles que l'Abitibi, le Témiscamingue et la Beauce (Bergeron, 2001; Bilodeau 2002). Une comparaison à l'échelle du Québec a aussi révélé que le SLSJ a le plus bas coefficient de consanguinité à la cinquième génération, ce qui indique donc qu'il a une valeur de consanguinité proche inférieure à toutes les régions de la province (Vézina et al, 2005b).

Nous avons aussi calculé les coefficients de consanguinité plus éloignée, à partir de la quatrième génération. Les coefficients augmentent dans les groupes MLII et témoin à mesure que les générations se succèdent, et ceux du groupe MLII demeurent supérieurs à ceux du groupe témoin. Un plafonnement s'observe à la $11^{\text {ième }}$ ou $12^{\text {ième }}$ génération, conséquemment à la perte d'information survenue lors de la reconstruction généalogique. Ces résultats sont représentatifs de ce qui a déjà été publié concernant le SLSJ (De Braekeleer, 1991b; De Braekeleer et Gauthier, 1996; Lambert, 2002; Lavoie, 2003; Tremblay, 2004; Vézina et al, 2005b; Yotova et al, 2005). Il faut cependant noter que la comparaison avec les cohortes des autres études peut se faire à titre indicatif seulement, car les individus sélectionnés ne sont pas nés exactement au cours de la même période que nos deux groupes. 
Concernant la consanguinité éloignée, l'étude menée par Vézina et ses collaborateurs a mentionné qu'à la $13^{\text {ième }}$ génération, le SLSJ figure au cinquième rang de la consanguinité globale, devançant la plupart des autres régions (Vézina et al, 2005b). Il est donc évident que la population actuelle du SLSJ n'est guère plus consanguine que les autres régions du Québec, mais la composante éloignée de la consanguinité au SLSJ s'accroît à mesure que l'on remonte les générations, ce qui s'explique en partie par l'histoire du peuplement propre à cette région telle que décrite précédemment. Cette dernière observation est donc compatible avec le modèle d'effets fondateurs séquenciels qui a été suggéré pour expliquer la diffusion des gènes d'autres maladies autosomales récessives fréquentes au SLSJ (De Braekeleer, 1991b). C'est aussi ce qui a été mis en lumière lors de l'analyse généalogique de notre cohorte, qui a révélé l'existence de liens dans le passé, c'est-à-dire la présence d'une consanguinité plus marquée lorsque les analyses sont faites au moment de la colonisation. En d'autres mots, la fréquence élevée de la mutation peut s'expliquer partiellement par une endogamie dont les liens généalogiques sont très éloignés, comme il a déjà été rapporté (De Braekeleer et al, 1993). Ainsi, cette consanguinité éloignée associée à la démographie historique fait du SLSJ un exemple typique de population à effet fondateur récent.

Considérant la structure génétique de la population du SLSJ conséquente à l'effet fondateur, la probabilité d'un couple originaire du SLSJ d'avoir un enfant atteint de la MLII est relativement élevée (1/45) malgré l'absence de lien généalogique entre les deux parents jusqu'à cinq ou six générations, une conclusion émise précédemment concernant d'autres maladies autosomales récessives au SLSJ (Bouchard et al, 1985).

\subsubsection{L'origine des individus ayant introduit la MLII}

Convenant que l'effet fondateur est à l'origine de la prévalence élevée des cas de MLII au SLSJ, il est possible de se questionner sur la provenance de l'unique mutation causale présente dans cette région. L'hypothèse selon laquelle plus d'un ancêtre peut avoir introduit une mutation dans la population du SLSJ a déjà été proposée pour d'autres maladies 
génétiques (Yotova et al, 2005; De Braekeleer et al, 1993). Souvent, plus d'une mutation étaient à l'origine de ces maladies, ce qui indique que plusieurs individus ont introduit une même maladie génétique. Cependant, en ce qui concerne la MLII au SLSJ, tous les parents étudiés étaient hétérozygote pour la même mutation. Cela indique que soit un seul individu a introduit la mutation au SLSJ, soit la même mutation est apparue de novo de façon fortuite parmi les ancêtres.

Néanmoins, nous supposons que la thèse « un gène/un fondateur » avancée par Heyer est la plus probable pour expliquer l'unicité ainsi que la fréquence de la mutation de la MLII au SLSJ (Heyer, 1999). Ainsi, nous considérons que seulement quelques ancêtres européens porteurs de la mutation de la MLII sont venus au Canada et que le nombre de porteurs s'est multiplié en raison des effets fondateurs, phénomène qui augmente l'incidence des maladies génétiques récessives et diminue l'hétérogénéité allélique dans les maladies monogéniques (Sheffield et al, 1998). Cette hypothèse est appuyée par les résultats de notre étude, où nous avons observé que parmi tous les fondateurs retrouvés par l'analyse des généalogies ascendantes, seulement quelques noyaux familiaux sont plus susceptibles d'avoir introduit la mutation de la MLII au SLSJ. Il s'agit de couples provenant de la France qui se sont établis en Nouvelle-France au cours du $17^{\text {ième }}$ siècle. Ce résultat n'est pas surprenant étant donnée le nombre de mutations retrouvées dans la population canadiennefrançaise qui remonterait au temps de la Nouvelle-France (De Braekeleer et Dao, 1994; Couture et al, 2001; Laberge et al, 2005; Vézina et al, 2005a; Yotova et al, 2005).

Il n'est pas non plus étonnant que la contribution génétique des ancêtres des différents noyaux ancestraux soit semblable. En effet, une étude publiée sur la contribution génétique de fondateurs pour des maladies autosomales récessives connues au SLSJ (tyrosinémie héréditaire de type 1 (OMIM \#276700), ataxie spastique de Charlevoix-Saguenay (OMIM \#270550), neuropathie sensitivomotrice avec ou sans agénésie du corps calleux (OMIM $\# 218000$ ) et fibrose kystique (OMIM \#219700)) a montré que près de $80 \%$ du bassin génique des proposants provient d'ancêtres qui se sont établis en Nouvelle-France au cours du $17^{\text {ième }}$ siècle (Heyer et Tremblay, 1995). Aussi, seulement 15\% des fondateurs ont réussi à expliquer la contribution génétique totale (Heyer et Tremblay, 1995). Par conséquent, il 
est normal qu'aucun sous-groupe de fondateurs ne soit plus spécifique à une maladie particulière. Il en est de'même pour les noyaux ancestraux de notre étude sur la MLII : la contribution génétique des ancêtres de chaque noyaux ancestraux peut être grande à l'échelle de la région du SLSJ, sans être spécifique à notre cohorte de MLII.

Puisque les fondateurs de la population francophone du Québec proviennent en majorité de la France et que la cohorte étudiée semble avoir ses origines en France, il serait intéressant de savoir si la mutation 3501_3502delTC y est présente. Or, les cas de MLII ne sont pas chiffrés en France. Comme dans la majorité des populations, la MLII est une maladie rare en France et les cas semblent répartis uniformément sur le territoire français (Le Merrer, 2006). Néanmoins, la littérature rapporte un sujet français (région de l'Artois) atteint de la MLIII ayant la mutation retrouvée au SLSJ, 3502_3503delCT (Bargal et al, 2006; Le Merrer, 2006), mais aucun cas de MLII en France n'y est mentionné. 


\section{CONCLUSION}

Par la recherche effectuée dans le cadre de cette maîtrise, nous avons pu atteindre l'objectif principal, soit l'identification de la mutation responsable de la MLII dans la région du SLSJ. La mutation c.3501_3502delTC a été retrouvée chez tous les individus de notre cohorte de porteurs, mais aucun des $50 \mathrm{ADN}$ de sujet témoin ne possédait la dite mutation. Il s'agit d'une mutation déjà répertoriée comme cause de la MLII et de la MLIII (en combinaison avec un autre type de mutation) dans d'autres populations.

Dans un deuxième temps, nous avons tenté d'identifier l'origine de la mutation. Cela a été rendu possible grâce aux données généalogiques remises par les sujets. Ces données étudiées au Projet BALSAC a permis de remonter jusqu'au temps de la colonisation de la région, de Charlevoix et parfois même aux premiers fondateurs de la Nouvelle-France. L'étude des mesures démogénétiques a permis d'identifier des noyaux familiaux ancestraux. Ainsi, il est très probable que la MLII ait été introduite par seulement quelques noyaux d'ancêtres. La mutation a donc pu atteindre la fréquence actuelle dans la région dû à l'effet fondateur conjugué à la grande taille des familles et l'immigration de type familiale.

La connaissance acquise par ce projet a permis de déterminer qu'une seule mutation explique l'ensemble des cas de MLII dans la région et a récemment permis la mise au point d'un test moléculaire permettant le dépistage prénatal ou encore celui des porteurs, dans les familles à risque, ce qui est d'une grande utilité pour le service de conseil génétique. Cette découverte a donc un impact positif immédiat pour plusieurs familles du SLSJ, et peut-être pour le reste du Québec, car il n'est pas exclu que les autres cas de MLII chez les Québecois francophones puissent être causés par la même mutation. 


\section{PERSPECTIVES}

En perspective, il serait intéressant de connaître les mutations causant la MLII sur le territoire français et plus particulièrement dans les régions d'origine des couples fondateurs identifiés (Perche, Aunis et Normandie). Ces régions de la France sont connues pour leur forte contribution génétique à la population canadienne-française contemporaine.

En ce qui a trait au plan moléculaire, il serait intéressant de procéder à l'étude moléculaire de sujets atteints de la MLII au Québec afin de valider la mutation trouvée dans notre cohorte de porteurs. Il y aurait en effet intérêt à évaluer les cas de MLII à l'extérieur de la région du SLSJ, tant sur le plan moléculaire que généalogique, car il $\mathrm{y}$ a de fortes probabilités que la mutation 3501_3502delTC soit la seule présente dans la population canadienne-française et il serait peut-être possible de restreindre l'origine de la mutation à un plus petit nombre de fondateurs.

Finalement, rappellons que les études fonctionnelles ont montré que la GlcNAcPT mutée (p.1168QfsX5) ne produit aucune activité. Parcontre, la raison de cette inactivité reste non documentée. Est-ce que l'enzyme mutée est touchée au niveau d'un domaine transmembranaire? Est-ce que la mutation nuit à l'interaction entre les sous-unités $\alpha / \beta$ et $\gamma$ ? Bref, l'appronfondissement au niveau de la protéomique fonctionnelle pourrait mettre en lumière la cause exacte du dysfonctionnement de la GlcNAcPT mutée et permettre d'effectuer des études pharmacologiques. 


\section{ANNEXE 1}

Courriel reçu le 8 mars 2007 suite à la soumission de l'article à Clinical Genetics.

Dear Ms. Plante:

Thank you for submitting your manuscript entitled "Mucolipidosis type II: A single causal mutation in the N-acetylglucosamine-1-phosphotransferase gene (GNPTAB) in a French Canadian Founder Population" for review. For internal purposes, we have assigned it the internal reference number CGE-00126-2007. Please refer to this number in any future correspondence you may send regarding this submission.

Authors are requested to send a list of four names of potential reviewers, including their email addresses. If you have not already done so, please email the editorial office with this information at your earliest convenience.

In addition, we request that a signed copy of the Clinical Genetics Exclusive Licence Form be sent to us as soon as possible. The form can be accessed at our site http://clinicalgenetics.manuscriptcentral.com/ by clicking onto the "Instructions and Forms" icon at the top right-hand corner of the site.

We recommend that you send us the signed form electronically. Alternatively, you can fax it to (604) 875-3840 marked Attn: Sunita Wiebe, Editorial Coordinator.

Please note that we cannot proceed with the publication of your manuscript otherwise.

Finally, if there are colour figures in your manuscript, please fax a signed colour costs to our office at your earliest convenience. The The form can be accessed at www.blackwellpublishing.com/pdf/Sub3000_X_CoW.pdf

We will get back to you shortly with our review of the manuscript.

Yours sincerely,

Michael R. Hayden, MD, PhD, FRSC

Editor-in-Chief 


\section{BIBLIOGRAPHIE}

Aracena M, Mabe P, Mena M, Andreani S, Daza C (2003). Mucolipidoses type II. Case report. Rev Med Chil. 131(3), 314-319.

Alberts B, Bray D, Lewis J, Raff M, Roberts K, Watson JD (1995). Biologie moléculaire de la cellule, 3ième édition. Paris, Flammarion Médecine-Science, 1294 p.

Bao M, Booth JL, Elmendorf BJ, Canfield WM (1996). Bovine UDP-N-acetylglucosamine1-phosphotransferase. 1. Purification and subunit structure. J Biol Chem. 271(49), 3143731445.

Bargal R, Avidan N, Ben-Asher E, Olender Z, Zeigler M, Frumkin A, Raas-Rothschild A, Glusman G, Lancet D, Bach G (2000). Identification of the gene causing mucolipidosis type IV. Nature Genet. 26, 118-121.

Bargal R, Zeigler M, Abu-Libdeh B, Mandel H, Ben Neriah Z, Stewart F, Nursel E, Hindi T, Merrer ML, Bach G, Raas-Rothschild A (2006). When mucolipidosis III meets mucolipidosis II : GNPTA gene mutations in 24 patients. Mol Genet Metab. 88, 359-363.

Beadle GW, Tatum EL (1941). Genetic control of biochemical reactions in Neurospora. Prot Natl Acad Sci USA. 27, 499-506.

Ben-Yoseph Y, Mitchell DA, Nadler HL (1988). First trimester prenatal evaluation for Icell disease by N-acetylglucosamine 1-phosphotransferase assay. Clin Genet. 33(1), 38-43.

Ben-Yoseph Y, Potier M, Mitchell DA, Pack BA, Melançon SB, Nadler HL (1987). Altered molecular size of $\mathrm{N}$-acetylglucosamine-1-phosphotransferase in I-cell disease and pseudo-Hurler polydystrophy. Biochem J. 248, 697-701.

Bergeron MJ (2001). Étude généalogique de la schizophrénie et de la psychose maniacodépressive dans la région de la Beauce. Mémoire de maîtrise en médecine expérimentale (Université du Québec à Chicoutimi/Université Laval), Chicoutimi, Université du Québec à Chicoutimi, 75 p.

Besley GTN, Broadhead DM, Nevin NC, Nevin J, Dornan JC (1990). Prenatal diagnosis of mucolipidosis II by early amniocentesis. Lancet. 335, 1164-1165. 
Bilodeau M (2002). Caractéristiques démogénétiques des populations de l'Abitibi et du Témiscamingue. Mémoire de maitrise en médecine expérimentale (Université du Québec à Chicoutimi/Université Laval), Chicoutimi, Université du Québec à Chicoutimi, 83 p.

Bouchard G, De Braekeleer M (1992). Pourquoi des maladies héréditaires? Population et génétique au Saguenay-Lac-St-Jean. Éditions du Septentrion, Sillery, Québec, 184p.

Bouchard G, Laberge C, Scriver CR (1985). Hereditary tyrosinemia and vitamin-dependent rickets in Saguenay. A genetic and demographic approach. Union Med Can. 114(8):633-6.

Bouchard G (1991). Pour une approche historique et sociale du génome québecois. Dans Bouchard G, De Braekeleer M (éditeurs). Histoire d'un génome. Québec, Presse de l'Université du Québec. p.5-18.

Bouchard G (1996). Quelques arpents d'Amérique: Population, économie, famille au Saguenay :1838-1971. Boréal, Montréal, Canada, 635p.

Bosshard NU, Hubler M, Arnold S, Briner J, Spycher MA, Sommerlade HJ, von Figura K, Gitzelmann R (1996). Spontaneous mucolipidosis in a cat: an animal model of human I-cell disease. Vet Path, 33, 1-13.

Breningstall GN, Tubman DE (1994). Magnetic resonance imaging in a patient with I-cell disease. Clin Neurol Neurosurg. 96(2), 161-163.

Butterworth J, Sutherland GR, Bain AD, McCray WM (1972). Lysosomal enzymes in amniotic fluid. Clin Chim Acta. 39 :275-276.

Canfield WM, Bao M, Pan J, Brewer K, Pan H, Roe B, Raas-Rothschild A (1998). Mucolipidosis II and mucolipidosis IIIA are caused by mutations in the GlcNAcphosphotransferase alpha/beta gene on chromosome 12p. (Abstract) Am J Hum Genet. 63, A15.

Carey WF, Jaunzems A, Richardson M, Fong BA, Chin SJ, Nelson PV (1999). Prenatal diagnosis of mucolipidosis II - Electron microscopy and biochemical evaluation. Pren Diag. 19, 252-256.

Charbonneau H, Desjardins B, Guillemette A, Landry Y, Légaré J, Nault F (1987). Naissance d'une population: les Français établis au Canada au XVIIe siècle. Institut national d'études démographiques (Paris) et Presses de l'Université de Montréal, $232 \mathrm{p}$.

De Braekeleer M (1991a). Hereditary disorders in Saguenay-Lac-St-Jean (Quebec, Canada). Hum Hered. 41, 141-146.

De Braekeleer M (1991b). Les maladies autosomales récessives. Dans Bouchard G, De Braekeleer M (éditeurs). Histoire d'un génome. Québec, Presse de l'Université du Québec. p.427-459. 
De Braekeleer M, Dao TN (1994). Hereditary disorders in the French Canadian population of Quebec. I. In search of founders. Hum Biol. 66(2)205-223.

De Braekeleer M, Dallaire A, Mathieu J (1993). Genetic epidemiology of sensorimotor polyneuropathy with or without agenesis of the corpus callosum in northeastern Quebec. Hum Genet. 91:223-227.

De Braekeleer M, Gauthier S (1996). Autosomale recessive disorders in Saugenay-Lac-StJean, Quebec : Study of kinship. Hum Biol. 68(3), 371-381.

Den Dunnen JT, Antonarakis S (2000). Mutation nomenclature extensions and suggestions to describe complex mutations: a discussion. Hum Mutat. 15(1), 7-12.

Diukman R, Goldberg JD (1993). Prenatal diagnosis of inherited metabolic diseases. Fetal Med. 159, 374-381.

Elleder M, Matin JJ (1998). Mucolipidosis type II with evidence of a novel storage site. Virchows Archives. 433, 575-578.

Elleder M, Poupetova H, Zeman J, Hrebicek M, Ledvinova J, Baxova A, Podhola M (1997). Mucolipidosis II (I-cell disease). First case report in the Czech Republic and prenatal diagnosis in a family. Cas Lek Cesk. 136(22), 702-706.

Gauthier S (1992). Les maladies autosomales récessives au Saguenay-Lac-St-Jean : Étude de la consanguinité et de la parenté. Mémoire de maitrise en médecine expérimentale (Université du Québec à Chicoutimi/Université Laval), Chicoutimi, Université du Québec à Chicoutimi, $69 \mathrm{p}$.

Gauvreau D, Guérin M, Hamel M (1991). De Charlevoix au Saguenay: mesure et caractéristiques du mouvement migratoire avant 1911. Dans Bouchard G, De Braekeleer M (éditeurs). Histoire d'un génome. Québec, Presse de l'Université du Québec. p.147-159.

Gehler J, Cantz M, Stoeckenius M, Spraner J (1976). Prenatal diagnosis of mucolipidosis II (I-cell disease). Eur J Pediatr. 122(3), 201-206.

Gilbert-Barness EF, Barness LA (1993). The mucolipidoses. Perspect Pediatr Pathol. 17, 148-184.

Glew RH, Basu A, Prence EM, Remaley AT (1985). Biology of disease : Lysosomal storage diseases. Lab Invest. 53(3), 250-269.

Grewal S, Shapiro E, Braunlin E, Charnas L, Krivit W, Orchard P, Peters C (2003). Continued neurocognitive development and prevention of cardiopulmonary complications after successful BMT for I-cell disease : a long-term follow-up report. Bone Marrow Transplant. 32, 957-960. 
Güngor N, Coskun T, Akçören Z, Çaglar M (1994). I-Cell disease : A Case Report and Review of the Literature. Turk J Pediatr. 36, 145-152.

Hall CW, Liebaers I, Di Natale P, Neufeld EF (1978). Enzymatic diagnosis of the genetic mucopolysaccharide storage disorders. Methods enzymol. 50, 439-456.

Harris RC, Matthews GJ, Dechêne L (1987). Atlas historique du Canada. Vol 1: Des origines à 1800 . Montréal, Presses de l'Université de Montréal, 198 p.

Hartl DL, Clark AG (1997). Principles of population genetics. Sunderland (É-U), Sinauer associates Inc, $542 \mathrm{p}$.

Hasilik A, Waheed A, Von Figura K (1981). Enzymatic phosphorylation of lysosomal enzymes in the presence of UDP-N-acetylglucosamine. Absence of the activity in 1-cell fibroblasts. Biochem Biophys Res Commun. 98(3), 761-767.

Helgason A, Sigurðardóttir S, Gulcher JR, Ward R, Stefánsson K (2000). mtDNA and the origin of the Icelanders: Deciphering Signals of Recent Population History. Am J Hum Genet 66, 999-1016.

Heyer É, Tremblay M (1995). Variability of the genetic contribution of Quebec population founders associated to some deleterious genes. Am J Hum Genet. 56,970-978.

Hickman S et Neufeld EF (1972). A hypothesis for I-cell disease : defective hydrolases that do not enter lysosomes. Biochem Biophys Res Commun. 49, 992-999.

Ho CYS, Tang NLS, Yeung AKY, Lau AKC, Hui J, Lo AWI (2006). Abnormal expressions of the subunits of the UDP-N-acetylglucosamine:lysosomal enzyme, Nacetylglucosamine-1-phosphotransferase, result in the formation of cytoplasmic vacuoles resembling those of the I-cells. J Mol Med. 85(4), 351-360.

Holtzman E (1989). Lysosomes. Plenum Press, New York, 439p.

Hug G, Bove KE, Soukup S, Ryan M, Bendon R, Babcock D, Warren NS, Dignan PJ (1984). Increased serum hexoaminidase in a woman pregnant with a fetus affected by mucolipidosis II (I-cell disease). $N$ Engl J Med. 311(15), 988-989.

Huijing F, Warren RJ, McLeod AGW (1973). Elevated activity of lysosomal enzymes in amniotic fluid of a fetus with mucolipidosis II (I-cell disease). Clin Chim Acta. 44:453-455.

Hwu WL, Chuang SC, Wang WC, Wang TR (1994). Diagnosis of I-cell disease. Zhonghua Min Guo Wiao Er Ke Yi Xue Hui Za Zhi. 35(6), 508-513.

Jobling MA, Hurles ME, Tyler-Smith C (2004). Human evolutionary genetics : origins, peoples and disease. New York :Garland Science. 
Kabra M, Gulati S, Kaur M, Sharma J, Singh A, Chopra V, Menon PSN, Kalra V (2000). Icell disease (mucolipidosis II). Indian J Pediatr. 67(9), 683-687.

Kornfeld S (1986). Trafficking of lysosomal enzymes in normal and disease states. J Clin Invest. 77, 1-6.

Kornfeld S (1987). Trafficking of lysosomal enzyme. FASEB J. 1(6), 462-468.

Kornfeld S, Sly WS. I-cell disease and pseudo-Hurler polydystrophy : disorders of lysosomal enzyme phosphorylation and localization. Dans : Scriver CR, Beaudet AL, Sly WS, Valle D (2001). The metabolic and molecular bases of inherited disease, $8^{\text {ieme }}$ édition. McGraw-Hill: New York, pp. 3469-3482.

Krasnopolskaya KD, Mirenburg TV, Aronovich EL, Lebedeva TV, Odinokova ON, Demina NA, Kozlova VM, Kuznetsov MI (1993). Diagnosis and prevention of lysosomal storage disease in Russia. J Inher Metab Dis. 16, 994-1002.

Kudo M, Bao M, D'Souza A, Ying F, Pan H, Roe BA, Canfield WM (2005). The $\alpha$ - and $\beta$ subunits of the human UDP-N-acetylglucosamine:lysosomal enzyme phosphotransferase are encoded by a single cDNA. $J$ Biol Chem, 280(43), 36141-36149.

Kudo M, Brem MS, Canfield WM (2006). Mucolipidosis II (I-Cell Disease) and mucolipidosis IIIA (Classical Pseudo-Hurler Polydystrophy) are caused by mutations in the GlcNAc-phosphotransferase $\alpha / \beta$-subunits precursor gene. Am J Hum Genet 78(3), 451-463.

Kula RW, Shafiq SA, Sher JH, Qasi QH (1984). I-cell disease (mucolipidosis II). Differential expression in satellite cells and mature muscle fibres. J Neuro Sci, 63(1), 7584.

Kurobane I, Inoue S, Gotoh Y-I, Kato S, Tamura M, Narisawa K, Tada K (1986). Biochemical improvement after treatment by bone marrow transplantation in I-cell disease. Tohoku J Exp Med. 150, 63-68.

Laberge AM, Jomphe M, Houde L, Vézina H, Tremblay M, Desjardins B, Labuda D, StHilaire M, Macmillan C, Shoubridge EA, Brais B (2005). A « Fille du Roy » introduced the T14484C leber hereditary optic neuropathy mutation in French Canadians. Am J Hum Genet. 77, 313-317.

Laberge AM, Michaud, J, Richter A, Lemyre E, Lambert M, Brais B, Mitchell GA (2005). Population history and its impact on medical genetics in Quebec. Clin Genet, 68, 287-301.

Lambert JF (2002). Effet fondateur et origine de la mutation D9N du gène de la lipase lipoprotéique au sein de la population du Saguenay-Lac-St-Jean. Mémoire de maîtrise en médecine expérimentale (Université du Québec à Chicoutimi/Université Laval), Chicoutimi, Université du Québec à Chicoutimi, 92 p. 
Lavoie ÈM (2003). Étude comparative des caractéristiques démogénétiques des populations du Bas-Saguenay, du Haut-Saguenay et du Lac-St-Jean. Mémoire de maitrise en médecine expérimentale (Université du Québec à Chicoutimi/Université Laval), Chicoutimi, Université du Québec à Chicoutimi, $\mathrm{p}$.

Lee W, O'Donnell D (2003). Severe gingival hyperplasia in a child with I-cell disease. Int $J$ Paediatr Dent, 13(1), 15-20.

Le Merrer, M (2006). Hôpital Necker - Enfants malades, communication personnelle.

Leroy JG, DeMars R (1967). Mutant enzymatic and cytological phenotypes in cultured human fibroblasts. Science, 157, 804-805.

Leroy JG, Ho MW, MacBrinn MC, Wielke K, Jacob J, O'Brien JS (1972). I-cell disease : Biochemical studies. Pediat Res. 6, 752-757.

Leroy JG, Spranger JW, Feingold M, Opitz JM, Crocker AC (1971). I-cell disease: A clinical picture. J Pediatr. 79(3), 360-365.

Leroy JG, Van Elsen AF (1973). I-cell disease (mucolipidosis type II) serum hydrolases in obligate heterozygotes. Humangenetik. 20, 119-123.

Létourneau E, Mayer FM (1988). A model for analyzing ascending genealogies. Cah Que Demogr. 17(2):213-32.

Lingappa VR (1989). Intracellular traffic of newly synthesized proteins. $J$ Clin Invest. 83, 739-751.

Maillet M (2002). Biologie cellulaire, $9^{\mathrm{e}}$ édition. Masson, Paris, 558p.

Marieb EN (1993). Anatomie et physiologie humaines. St-Laurent (Québec), Éditions du renouveau pédagogique, $1014 \mathrm{p}$.

Maroteaux P, Hors-Cayla MC, Pont J (1970). La mucolipidose de type II. Presse Méd. 78(4), 179-181.

Mazrier H, Van Hoeven M, Wang P, Knox VW, Aguirre GD, Holt E, Wiemelt SP, Sleeper MM, Hubler M, Haskins ME, Giger U (2003). Inheritance, biochemical abnormalities, and clinical features of feline mucolipidosis II: the first animal model of human I-cell disease. $J$ Hered. 94, 363-373.

Meikle PJ, Grasby DJ, Dean CJ, Lang DL, Bockmann M, Whittle AM, Fietz MJ, Simonsen H, Fuller M, Brooks DA, Hopwood JJ (2006). Newborn screening for lysosomal storage disorders. Mol Genet Metab. 88, 307-314.

Meikle PJ, Hopwood JJ, Clague AE, Carey WF (1999). Prevalence of lysosomal storage disorders. JAMA. 281(3), 249-254. 
Menéndez, I, Menéndez C, Cepero F, Gutiérrez E (1998). Mucolipidosis II. Estudio clínico, bioquímico y genético. Rev Cubana Pediatr. 70(1), 53-58.

Michelakakis H, Dimitriou E, Tsagarakis S, Giouroukos S, Shulpis K, Bartsocas CS (1995). Lysosomal storage diseases in Greece. Genet Counseling. 6(1), 43-47.

Mueller OT, Little LE, Miller AL, Lozzio CB, Shows TB (1985). I-cell disease and pseudoHurler polydystrophy: heterozygote detection and characteristics of the altered $\mathrm{N}$-acetylglucosamine-phosphotransferase in genetic variants. Clin Chim Acta. 150, 175-183.

Muller OT, Honey NK, Little LE (1983). Mucolipidosis II and III: The genetic relationship between two disorders of lysosomal enzyme biosynthesis. J Clin Invest. 72, 1016-1023.

Mueller OT, Wasmuth JJ, Murray JC, Lozzio CB, Lovrien EW, Shows TB (1987). Chromosomal assignment of $\mathrm{N}$-acetylglucosaminylphosphotransferase, the lysosomal hydrolase targeting enzyme deficient in mucolipidosis type II and type III. (Abstract) Cytogenet Cel Genet. 46, 664.

Norio R (2003). Finnish Disease Heritage I: characteristics, causes, background. Hum Genet 112, 441-456.

Okada S, Owada M, Sakiyama T, Yutaka T, Ogawa M (1985). I-cell disease : clinical studies of 21 japanese cases. Clin Genet. 28, 207-215.

Olkkonen VM, Ikonen E (2000). Genetic defects of intracellular-membrane transport. $N$ Engl J Med. 343(15), 1095-1104.

Ouhna K (2001). Analyse généalogique de familles apparentées à un ou plusieurs asthmatiques dans la population du Saguenay. Mémoire de maîtrise en médecine expérimentale (Université du Québec à Chicoutimi/Université Laval), Chicoutimi, Université du Québec à Chicoutimi, 94 p.

Owada M, Nishiya O, Sakiyama T, Kitagawa T (1980). Prenatal diagnosis of I-cell disease by measuring altered $\alpha$-mannosidase activity in amniotic fluid. $J$ Inher Metab Dis. 3, 117 121.

Paik KH, Song SM, Ki CS, Yu HW, K, JS, Min KH, Chang SH, Yoo EJ, Lee IJ, Kwan EK, Han SJ, Jin D-K (2005). Identification of mutations in the GNPTA (MGC4170) gene coding for GlcNAc-phosphotransferase $\alpha / \beta$ subunits in Korean patients with mucolipidosis type II or type IIIA. Hum Mutat. 26, 308-314.

Pardo LM, MacKay I, Oosta B, Van Duijn CM, Aulchenko YS (2005). The effect of genetic drift in a young genetically isolated population. Ann Hum Genet 69(3), 288-295. 
Pinto R, Caseiro C, Lemos M, Lopes L, Fontes A, Ribeiro H, Pinto E, Silva E, Rocha S, Marcao A, Ribeiro I, Lacerda L, Ribeiro G, Amaral O, Sa Miranda MC (2004). Prevalence of lysosomal storage disease in Portugal. Eur J Hum Genet. 12, 87-92.

Poenaru L, Castelnau L, Dumez Y, Thepot F (1984). First-semester prenatal diagnosis of múcolipidosis II (I-cell disease) by chorionic biopsy. Am J Hum Genet. 36, 1379-1385.

Poorthuis BJ, Wevers RA, Kleijer WJ, Groener JEM, De Jong JGN, Van Weely S, NiezenKoning K, Van Diggelen OP (1999). The frequency of lysosomal storage diseases in The Netherlands. Hum Genet. 105, 151-156.

Pouyez C, Lavoie Y (1983). Les Saguenayens : Introduction à l'histoire des populations du Saguenay XVIe-Xxe siècles. Sillery, Canada, Presses de l'Université du Québec, 386p.

Prévost C (2006). CSSSC (Conseil génétique), communication personnelle.

Raas-Rothschild A, Cormier-Daire V, Bao M, Genin E, Salomon R, Brewer K, Zeigler M, Mandel H, Toth S, Roe B, Munnich A, Canfield WM (2000). Molecular basis of variant speudo-Hurler polydystrophy (mucolipidosis IIIC). J Clin Invest. 105, 673-681.

Rapola J, Aula P (1977). Morphology of the placenta in fetal I-cell disease. Clin Genet. 11(2), 107-13.

Reitman ML, Varki A, Kornfeld S (1981). Fibroblasts from patient with I-cell disease and pseudo-Hurler polydystrophy are deficient in uridine 5'-diphosphate-Nacetylglucosamine:glycoprotein $\mathrm{N}$-acetylglucosaminylphosphotransferase activity. $J$ Clin Invest. 67, 1574-1579.

Roy R, Bouchard G, Declos M (1988). La première génération de Saguenayens ; provenance, apparentement, enracinement. Cah Québ Démogr. 17(1),113-134.

Shanske S, Miranda AF, Penn AS, DiMauro S (1981). Mucolipidosis II (I-cell disease): studies of muscle biopsy and muscle cultures. Pediatr Res. 15(10), 1334-1339.

Sheffield VC, Stone EM, Carmi R (1998). Use of isolated inbred human population for identification of disease genes. Trends Genet. 14:391-396.

Sly, WS (2000). The missing link in lysosomal enzyme targeting. J Clin Invest. 105, 563564.

Spranger JW, Wiedemann HR (1970). The genetic mucolipidoses. Diagnosis and differential diagnosis. Humangenetik 9(2), 113-39.

Staba SL, Escolar ML, Poe M, Kim Y, Martin PL, Szabolcs D, Allison-Thacker J, Wood S, Wenger DA, Rubinstein P, Hopwood JJ, Krivit W, Kurtzberg J (2004). Cord-blood transplants from unrelated donors in patients with Hurler's syndrome. $N$ Engl J Med. 350(19), 1960-1969. 
Stanc LC, Evans JA, Hamerton JL (1997). Chorionic villus sampling and amniocentesis for prenatal diagnosis. Lancet. 349, 711-714.

Steet RA, Hullin R, Kudo M, Martinelli M, Bosshard NU, Schaffner T, Kornfeld S, Steinmann B (2005). A splicing mutation in the $\alpha / \beta$ GlcNAc-1-phosphotransferase gene results in a adult onset form of mucolipidosis III associated with sensory neuropathy and cardiomyopathy. Am J Med Genet. 132A, 369-375.

Tiede S, Sortch S, Lübke T, Henrissat B, Bargal R, Raas-Rothschild A, Braulke T (2005). Mucolipidosis II is caused by mutations in GNPTA encoding the $\alpha / \beta$ GlcNAc-1phosphotransferase. Nat Med. 11(10), 1109-1112.

Tiede S, Cantz M, Spranger J, Braulke T (2006). Missense mutation in the Nacetylglucosamine-1-phophostransferase gene (GNPTA) in a patient with mucolipidosis II induces changes in the size and cellular distribution of GNPTG. Hum mutat. 27(8), 830831.

Tipping AJ, PearsonT, Morgan NV, Gibson RA, Kuyt LP, Havenga C, Gluckmani E, Joenje H, de Ravel T, Jansen S, Mathew CG (2001). Molecular and genealogical evidence for a founder effect in Fanconi anemia families of the Afrikaner population of South Africa. Proc Natl Acad Sci U S A. 98(10), 5734-5739.

Tremblay AC (2004). Étude généalogique d'individus atteints de maladies inflammatoires chroniques non-spécifiques de l'intestin. Mémoire de maîtrise en médecine expérimentale (Université du Québec à Chicoutimi/Université Laval), Chicoutimi, Université du Québec à Chicoutimi, $133 \mathrm{p}$.

Unger S, Paul DA, Nino MC, McKay CP, Miller S, Sochett E, Braverman N, Clarke JTR, Cole DEC, Superti-Furga A (2005). Mucolipidosis II presenting as severe neonatal hyperparathyroidism. Eur J Pediatr. 164, 236-243.

Van Hoof F (1974). Mucopolysaccharidoses and mucolipidoses. J Clin Pathol Suppl ( $R$ Coll Pathol). 8, 64-93.

Van Hoof F (1972). Les mucopolysaccharidoses en tant que thesaurismoses lysosomiales. Thèse. Louvain, Vander, $285 \mathrm{p}$.

Varki A, Reitman ML, Vannier A, Kornfeld S, Grubb JH, Sly WS (1982). Demonstration of the heterozygous state for I-cell disease and pseudo-Hurler polydystrophy by assay of NAcetylglucosaminylphosphotransferase in white blood cells and fibroblasts. Am J Hum Genet. 34, 717-729.

Vellodi A (2004). Lysosomal storage disorders. Br J Haematol, 128, 413-431.

Vézina H, Durocher F, Dumont M, Houde L, Szabo C, Tranchant M, Chiquette J, Plante M, Laframboise R, Lépine J, Nevanlinna H, Stoppa-Lyonnet D, Goldgar D, Bridge P, Simard J 
(2005a). Molecular and genealogical characterization of the R1443X BRCA1 mutatio in high-risk French-Canadian breast/ovarian cancer families. Hum Genet. 117,119-132.

Vézina H, Tremblay M, Houde L (2005b). Mesures de l'apparentement biologique au Saguenay-Lac-St-Jean (Québec, Canada) à partir de reconstitutions généalogiques. Ann Dëmogr Hist, 2, 67-84.

Vidgoff J, Rowe S, Stafford R, Buist NRM, Lovrien EW (1982). Localization of the gene for I-cell disease (mucolipidosis II). Am J Hum Genet. 34, 64A.

Waheed A, Pohlmann R, Hasilik A, von Figura K, van Elsen A, Leroy JG (1982). Deficiency of UDP-N-acetylglucosamine:lysosomal enzyme N-acetylglucosamine-1phosphotransferase in organs of I-cell patients. Biochem Biophys Res Commun. 105(3), 1052-1058.

Walbaum R, P Dehaene, Scharfman W, Farriaux JP, Tondeur M, Vamos-Hurwitz E, Kint JA, Van Hoof F (1973). La mucolipidose de type II (I-cell disease). Arch Fr Pediatr. 30(6), 577-592.

Wasant P, Svasti J, Srisomsap C, Liammongkolkul S, Naylo EW, Matsumoto I (1999). Inherited metabolic disorders in Thailand - Siriraj experience. Southeast Asian J Trop Med Public Health. 30 Suppl 2, 124-137.

Wiesmann UN, Vassella F, Herschkowitz NN (1971). I-cell disease : leakage of lysosomal enzymes into extracellular fluids. $N$ Engl J Med. 285, 1090-1091.

Ylikangas PK, Mononen IT (1998). Glycosylasparaginase as a marker enzyme in the detection of I-cell disease. Clin Chem. 44(12), 2543-2544.

Yotova V, Labuda D, Zietkiewick E, Gehl D, Lovell A, Lefebvre JF, Bourgeois S, Lemieux-Blanchard É, Labuda M, Vézina H, Houde L, Tremblay M, Toupance B, Heyer E, Hudson TJ, Laberge C (2005). Anatomy of a founder effect : myotonic dystrophy in Northeastern Quebec. Hum Genet. 117:177-187.

\section{Site internet :}

Institut de la statistique du Québec: www.stat.gouv.qc.ca/region. Visité le 24 octobre 2006.

Online mendelian inheritance in man (OMIM) : www.ncbi.nlm.nih.gov

National centre for biotechnology information (NCBI) EntrezGene : www.ncbi.nlm.nih.gov 